\title{
Microchannel Heat Transfer
}

\author{
C. W. Liu' 1 , H. S. Ko ${ }^{2}$ and Chie Gau ${ }^{2}$ \\ ${ }^{1}$ Department of Mechanical Engineering, National Yunlin University of Science and \\ Technology, Yunlin 64002 \\ 2Institute of Aeronautics and Astronautics, National Cheng Kung University, Tainan \\ 70101, \\ Taiwan
}

\section{Introduction}

Microchannel Heat transfer has the very potential of wide applications in cooling high power density microchips in the CPU system, the micropower systems and even many other large scale thermal systems requiring effective cooling capacity. This is a result of the microsize of the cooling system which not only significantly reduces the weight load, but also enhances the capability to remove much greater amount of heat than any of large scale cooling systems. It has been recognized that for flow in a large scale channel, the heat transfer Nusselt number, which is defined as $\mathrm{hD} / \mathrm{k}$, is a constant in the thermally developed region where $h$ is the convective heat transfer coefficient, $k$ is thermal conductivity of the fluid and D is the diameter of the channel. One can expect that as the size of the channel decrease, the value of convective heat transfer coefficient, $h$, becomes increasing in order to maintain a constant value of the Nusselt number. As the size of the channel reduces to micron or nano size, the heat transfer coefficient can increase thousand or million times the original value. This can drastically increase the heat transfer and has generated much of the interest to study microchannel heat transfer both experimentally and theoretically.

On the other hand, the lab-on-chip system has seen the rapid development of new methods of fabrication, and of the components - the microchannels that serve as pipes, and other structures that form valves, mixers and pumps - that are essential elements of microchemical 'factories' on a chip. Therefore, many of the microchannels are used to transport fluids for chemical or biological processing. Specially designed channel is used for mixing of different fluids or separating different species. It appears that mass or momentum transport process inside the channel is very important. In fact, the transfer process of the mass is very similar to the transfer process of the heat due to similarity of the governing equations for the mass and the heat (Incropera et al., 2007). It can be readily derived that the Nusselt number divided by the Prandtl number to the nth power is equal to the Sherdwood number (defined as the convective mass transfer coefficient times the characteristic length and divided by the diffusivity of the mass) divided by the Schmidt number (defined as the kinematic viscosity divided by the diffusivity of the mass) to the nth power. Understanding of the heat transfer can help to understand the mass transfer or even the momentum transfer inside the microchannel (Incropera et al., 2007). 
However, the conventional theories, such as the constitutive equations describing the stress and the rate of deformation in the flow, or the Fourier conduction law, are all established based on the observation of macroscopic view of the flow and the heat transfer process, but do not consider many of the micro phenomena occurred in a micro-scale system, such as the rarefaction or the compressibility in the gas flow, and the electric double layer phenomenon in the liquid flow, which can significantly affect both the flow and the heat transfer in a microchannel. Therefore, both the flow and the heat transfer process in a microchannel are significantly different from that in a large scale channel. A thorough discussion and analysis for both the flow and the heat transfer process in the microchannels are required. In addition, experimental study to confirm and validate the analysis is essential. However, accurate measurements of flow and heat transfer information in a microchannel rely very much on the exquisite fabrication of both the microchannel and the microsensors by the MEMS techniques. Successful fabrication of these complicated microchannel system requires a good knowledge on the MEMS techniques. Especially, accurate measurement of the heat transfer inside a microchannel heavily relies on the successful fabrication of the microchannel integrated with arrays of miniaturized temperature and pressure sensors in addition to the fabrication of micro heaters to heat up the flow.

It appears that microfluidics has become an emerging science and technology of systems that process or manipulate small $\left(10^{-9}\right.$ to $10^{-18}$ liters) amounts of fluids, using channels with dimensions of tens to hundreds of micrometres (George, 2006; Vilkner et al., 2004; Craighead, 2006). Various long or short micro or nanochannels have used in the system to transport fluids for chemical or biological processing. The basic flow behavior in the microchannel has been studied in certain depth (Bayraktar \& Pidugu, 2006; Arkilic \& Schmidt., 1997; Takuto et al., 2000; Wu \& Cheng, 2003). The major problem in the past is the difficulty to install micro pressure sensors inside the channel to obtain accurate pressure information along the channel. Therefore, almost all of the pressure information is based on the pressures measured at the inlet and the outlet outside of the channel, which is used to reduce to the shear stress on the wall. The measurements have either neglected or subtracted an estimated entrance or exit pressure loss. These lead to serious measurement error and conflicting results between different groups (Koo \& Kleinstreuer, 2003). The friction factor or skin friction coefficient measured in microchannel may be either much greater, less than or equal to the one in large scale channel. Different conclusions have been drawn from their measurement results and discrepancies are attributed to such factors as, an early onset of laminar-to turbulent flow transition, surface roughness (Kleinstreuer \& Koo 2004; Guo \& Li 2003), electrokinetic forces, temperature effects and microcirculation near the wall, and overlooking the entrance effect. In addition, when the size or the height of the microchannel is much smaller than the mean free path of the molecules or the ratio of the mean free path of the molecules versus the height of the microchannel, i.e. Kn number, is greater than 0.01, one has to consider the slip flow condition on the wall (Zohar et al. 2002; Li et al. 2000; Lee et al., 2002). It appears that more accurate measurements on the pressure distribution inside the microchannel and more accurate control on the wall surface condition are necessary to clarify discrepancies amount different work.

The lack of technologies to integrate sensors into the microchannel also occurs for measurements of the heat transfer data. All the heat transfer data reported is based on an average of the heat transfer over the entire microchannel. That is, by measuring the bulk flow temperature at the inlet and the outlet of the channel, the average heat transfer for this channel can be obtained. No temperature sensors can be inserted into the channel to acquire 
the local heat transfer data. Therefore, detailed information on the local heat transfer distribution inside the channel is not reported. In addition, the entry length information and the heat transfer process in the thermal fully developed region is lacking. Besides, the wall roughness inside the channel could not be controlled or measured directly in the tube. Therefore, its effect on the heat transfer is not very clear. This was attributed to cause large deviation in heat transfer among different work (Morini 2004; Rostami et al., 2002; Guo \& Li, 2003; Obot, 2002). It appears that accurate measurements of the local heat transfer are required to clarify the discrepancies among different work.

Therefore, in this chapter, a comprehensive review of microchannel flow and heat transfer in the past and most recent results will be provided. A thorough discussion on how the surface forces mentioned above affect the microchannel flow and heat transfer will also be presented. A brief introduction on the MEMS fabrication techniques will be presented. We have developed MEMS techniques to fabricate a microchannel system that can integrate arrays of the miniaturized both pressure and temperature sensor. The miniaturized sensors developed will be tested to ensure the reliability, and calibrated for accurate measurements. In fact, fabrication of this microchannel system requires very complicated fabrication steps as mention by Chen et al. 2003a and 2003b. Successful fabrication of this channel which is suitable for measurements of both the local pressure drop and heat transfer data is a formidable task. However, fabrication of this complicated system can be greatly simplified by using polymer material (Ko et al., 2007). This requires fabrication of pressure sensor using polymer materials (Ko et al., 2008). The polymer materials that have a very low thermal conductivity can be fabricated as channel wall to provide very good thermal insulation for the channel and significantly reduce streamwise conduction of heat along the wall. This allows measurements of very accurate local heat transfer inside the channel. In addition, the height of the channel can be controlled at desired thickness by spin coating the polymer at desired thickness. The shape of the channel can be readily made by photolithography. All the design and fabrication techniques for both the channel and the sensor arrays will be discussed in this chapter. Measurements of both the local pressure drop and heat transfer inside the channel will be presented and analyzed. Therefore, the contents of the chapter are briefly described as follows:

1. Gas flow and the associated heat transfer characteristics in microchannels.

2. Liquid flow and heat transfer characteristics in microchannels including (a) the single phase and (b) the two phase flows.

3. MEMS fabrication techniques

4. Discussion on recent developments and challenges faced for MEMS fabrication of the microchannel system.

5. Working principle and fabrication of the miniaturized pressure and temperature sensors.

6. Fabrication of the complicated microchannel system integrated with arrays of either or both the miniaturized pressure and temperature sensors.

7. Local heat transfer and pressure drop inside the microchannels.

\section{Gas flow characteristics in microchannels}

Recent development of micromachining process which has been used to miniaturize the fluidic devices has become a focus of interest to industry, e.g. micro cooling devices, micro heat exchangers, micro valves and pumps, and lab-on-chips, more studies have been 
dedicated to this field. The fluid flows in micro scale capillary tube can be traced back to Knudsen at 1909. However, it has been very difficult to perform an experiment for micro scale flow and make detailed observation in a micro-channel due to the lack of techniques to fabricate a microchannel and make arrays of small sensors on the channel surface. Up to the present, most of the important information on micro scale thermal and flow characteristics inside the microchannel can not be obtained and measured. Instead, the flow and heat transfer experiments performed for micro scale flow in the past are mostly based on the measurements of pressures or temperatures at inlet and outlet of the channel and the mass flow rate, or the measurements on the surface of a relatively large scale channel. Therefore, some of peculiar transport processes which are not important in a large scale channel may play a dominant role to affect the flow and heat transfer process in the micro scale channel, e.g. the rarefaction effect of the gas flow. Therefore, the rarefaction of a gas flow in the microchannel should be taken into account in the analysis.

\subsection{Theoretical analysis}

In order to describe the rarefaction of gaseous flow, a ratio of the mean free path to the characteristic length of the flow called Knudsen number $(\mathrm{Kn})$ has been used as a dimensionless parameter. The Knudsen number is defined as $\lambda / D_{c}$, where " $\lambda$ " denotes the mean free path of gas molecules and " $D_{c}$ " denotes the characteristic dimension of the channel. For convenience, it has been suggested (Tsien, 1948) that the rarefaction in gases can be typically classified into three flow regions by the magnitude of the Knudsen number, which are "the continuum flow regime", "the free-molecular flow regime" and "the nearcontinuum flow regime", as described as follows.

1. Continuum flow regime: This regime is defined for flow with $\mathrm{Kn}<0.001$. In this regime, the theories of the gas flow and fluid properties completely conform to the continuum assumption, and the Knudsen numbers approach to zero. In addition, the modified classical theories of the liquid flow are also suitable in this regime.

2. Near-continuum flow regime: this flow regime is defined in the range with $0.001 \leq \mathrm{Kn}<10$. The Knudsen number in this flow regime is still large enough that the flow is subject to a slight effect of rarefaction. The flow can be considered as a continuum in the core region except in the region adjacent to the wall where a small departure from the continuum such as velocity-slip or temperature jump is assumed. For convenience, one can further subdivide the flow into two regimes, i.e. the slip-flow regime and the transition-flow regime. In the slip-flow regime, the macroscopic continuum theory, therefore, is still valid due to small departures from the continuum. However, in order to conform to the real-gas behavior, it is necessary to adopt some appropriate corrections for the slip of fluid at the boundary. The slip-flow regime is defined in the range of $0.001 \leq \mathrm{Kn}<0.1$ while the transition-flow regime is defined in the range of $0.1 \leq \mathrm{Kn}<10$. In the transition-flow regime, the intermolecular collisions and the collisions between the gaseous molecules and the wall are of more or less equal importance. The flow configuration can be regarded as neither a continuum, nor a freemolecular flow. There is no simplified approach to attack this problem. Some conventional methods, such as, directly solving the complete sets of Boltzmann equations or using the empirical correlations from the experimental data, have been adopted.

3. Free-molecular flow regime: This flow regime is defined in the region with $10 \leq \mathrm{Kn}$. The rarefaction effect dominates the entire flow field. The gas is so rarefied that 
intermolecular collisions can be negligible. Hence, the flow characteristic is described by the kinetic theory of gas. Only interaction between gas molecules and boundary surface is considered.

Meanwhile, it has also been suggested (Tsien, 1946) that one can employ the kinetics theory of gases or the conventional heat transfer theory to study the gas flow in the continuum flow regime. When the gaseous rarefaction is within the range of the free-molecular flow regime, the kinetics theory of gases is suitable for use. However, in the range of the near-continuum flow regime, there has been no well-established method. In the slip-flow regime the gas flow can be considered as continuum. Hence, we can employ the macroscopic continuum theory to study the heat transfer in gases by taking account the velocity-slip and temperature-jump conditions at the wall. In the transition-flow regime the transport mechanisms in the rarefied gas are between the continuum and the free molecule flow regime, it is incorrect to consider the gas as a continuum or free molecule medium. Therefore, the theoretical study in the transition regime is very difficult. Many of the works (Ko et al., 2008, 2009, 2010; Bird et al., 1976a; Eckert and Drake, 1972; Yen, 1971; Ziering, 1961; Takao, 1961; Kennard, 1938) intend to develop some convenient methods to solve this problem, such as enlarging the validation of macroscopic continuum theory by using some corrections in boundary conditions or developing mathematical schemes to directly solve the highly nonlinear Boltzmann equation. However, these approaches are still not successful.

For theoretical study of the rarefied-gas flow, Kundt and Warburg (1875) have been the first to propose an important inference by experimental observation. They found an interesting phenomenon that the gaseous flow exhibits a velocity-slip on solid wall when the pressure in the system is sufficiently low. This phenomenon later has been confirmed by the analytical results from kinetics theory of gas by Maxwell (1890). In addition, Maxwell also defined a parameter " $f_{S}$ " called tangential momentum accommodation coefficient to modify the departures from the theoretical assumptions and real-gas behavior in molecular collision processes. The value of $f_{S}$ will presumably depend upon the character of the interaction between the gaseous molecules and the wall, such as the surface roughness or the temperature etc. In the observations of wall slip, Timiriazeff (1913) made the first direct measurements of wall slip. However, the most accurate measurements of velocity slip are undoubtedly made by Stacy and Van Dyke, respectively. Hence, a sound theory used to describe the rarefied gas behaviors has been established successfully. In the heat transfer studies, Smoluchowski (1910) has performed the first experiments for a heated rarefied gas flow and found the temperature-jump occurring on the solid wall.

Kennard (1938) has suggested that it could be analogous to the phenomenon of velocity slip and thus developed an approximate expression to describe this temperature discontinuity. In a flow field with a temperature of the gas flow different from the neighboring solid wall, there exists a temperature difference in a small distance " $\mathrm{g}$ ", which is called temperature jump distance, between the gas and the solid wall. The jump distance " $\mathrm{g}$ " is inversely proportional to the pressure but directly proportional to the mean-free-path of the gas. Due to the very small jump distance, it looks as having a discontinuity in the temperature distribution between the gas flow and the neighboring solid wall. By using the thermal accommodation coefficient proposed by Knudsen (1934) and the concepts of heat transfer mechanism between gas molecules defined by Maxwell, a theory for the microscopic heat transfer occurred in the rarefied gas flows has been successfully established.

In addition, the gas flow in a micro-channel also involves other problems, such as compressibility and surface roughness effects. Therefore, other dimensionless parameters, 
such as the Mach number, Ma, and the Reynolds number, Re, should also be adopted. The relationship among these parameters has been derived and can be expressed as follows.

$$
\operatorname{Re}=\sqrt{\frac{k \pi}{2}} \frac{M a}{K n}
$$

where $\mathrm{k}$ is the specific heat ratio $\left(\mathrm{c}_{\mathrm{p}} / \mathrm{c}_{\mathrm{v}}\right)$ of the gas. Since both Ma and $\mathrm{Kn}$ vary with compressibility of gas in the channel, the value of Re should vary according to the above equation. The full set of governing equations for two dimensional, steady and compressible gas flows can be written as follows (Khantuleva et al., 1982):

$$
\begin{gathered}
\frac{\partial(\rho u)}{\partial x}+\frac{\partial(\rho v)}{\partial y}=0 \\
\rho u \frac{\partial u}{\partial x}+\rho v \frac{\partial u}{\partial y}=-\frac{\partial p}{\partial x}+\mu\left[\frac{\partial^{2} u}{\partial x^{2}}+\frac{\partial^{2} u}{\partial y^{2}}+\frac{1}{3}\left(\frac{\partial^{2} u}{\partial x^{2}}+\frac{\partial^{2} v}{\partial x \partial y}\right)\right] \\
\rho u \frac{\partial v}{\partial x}+\rho v \frac{\partial v}{\partial y}=-\frac{\partial p}{\partial y}+\mu\left[\frac{\partial^{2} v}{\partial x^{2}}+\frac{\partial^{2} v}{\partial y^{2}}+\frac{1}{3}\left(\frac{\partial^{2} v}{\partial x^{2}}+\frac{\partial^{2} u}{\partial x \partial y}\right)\right] \\
\rho u C_{p} \frac{\partial T}{\partial x}+\rho v C_{p} \frac{\partial T}{\partial y}=u \frac{\partial p}{\partial x}+v \frac{\partial p}{\partial y}+k\left(\frac{\partial^{2} T}{\partial x^{2}}+\frac{\partial^{2} T}{\partial y^{2}}\right)+\mu\left[2\left(\frac{\partial u}{\partial x}\right)^{2}+2\left(\frac{\partial v}{\partial y}\right)^{2}+\left(\frac{\partial v}{\partial x}+\frac{\partial u}{\partial y}\right)^{2}-\frac{2}{3}\left(\frac{\partial u}{\partial x}+\frac{\partial v}{\partial y}\right)^{2}\right] \\
p=\rho R T=n k T
\end{gathered}
$$

The boundary conditions for the velocity slip and temperature jump on the top and bottom walls are shown as follows (Wadsworth et al., 1993):

$$
\begin{gathered}
u-u_{w}=\frac{2-\sigma_{u}}{\sigma_{u}} \lambda\left(\frac{\partial u}{\partial y}\right)_{w}+\frac{3 \mu}{4 \rho T}\left(\frac{\partial T}{\partial x}\right)_{w} ; y= \pm h / 2 \\
T-T_{w}=\frac{2-\sigma_{T}}{\sigma_{T}} \frac{2 \gamma}{(\gamma+1)} \frac{\lambda}{\operatorname{Pr}}\left(\frac{\partial T}{\partial y}\right)_{w} ; y= \pm h / 2
\end{gathered}
$$

where $\sigma_{u}$ and $\sigma_{T}$ are the momentum and the energy accommodation coefficient, respectively. $\lambda, \gamma$ and $h$ are the mean free path, the specific heat ratio and the height of the microchannel, respectively. Review of the recent literature indicates that compressible gas flow problems have been studied from the slip to the continuum flow regimes, however, different results are obtained in the micro-channels as described in the following paragraphs.

To analyze the rarefied gas characteristics in the near-continuum flow regime, the methods used (Takao, 1961; Kennard, 1938) in the classical kinetics theory of gas include (1) the small-perturbation approach, (2) the moment methods and (3) the model equation. The mathematical procedures of the small-perturbation approach are to use the perturbation 
technique to linearize the Boltzmann equation. Since this method can be used in both the near-continuum regime and the near free-molecules regime, therefore, it is suitable for practical applications. The moment methods are first to make adequate assumptions in the velocity distribution $f$ such as to express $f$ in terms of a power series, i.e. $f=f_{\mathrm{o}}\left(1+\mathrm{a}_{1}(\mathrm{Kn})+\right.$ $\left.\mathrm{a}_{2}(\mathrm{Kn})^{2}+\ldots\right)$ as proposed by Chapman and Enskog. Then, substitute the assumed velocity distribution into the Boltzmann equation. The methods of the model equation are to construct a physics model, such as the B-G-K model proposed by Bhatnagar, Gross and Krook (1954), to simplify the expression of Boltzmann equation. Since the governing equation of the system is greatly simplified by the appropriate assumptions in the previous two methods, these approaches can be used for limited ranges of flows. In the numerical simulation (Bird, 1976a; Yen, 1971; Ziering, 1961), a very efficient computational scheme, i.e. DSMC (Direct Simulation Monte Carlo) method, has been developed. However, this method still suffers from the highly nonlinear behavior in the Boltzmann equation. Meanwhile, the use of different approach to solve even the same physical problem will encounter different difficulties due to the different advantages and limitations faced by each method. In addition, the predictions from the analysis should be confirmed by the experiments.

In the studies of numerical calculation, Beskok and Karniadkis (1994) have developed a scheme called "spectral element technique" to simulate the momentum and heat transfer processes of a rarefied gas subjected to either a channel-flow or an external-flow condition. The results have indicated that when the gas passes through a micro-channel at velocity-slip condition, it can cause a significant reduction in drag coefficient $C_{D}$ on the walls. This is mainly caused by the thermal-creep effect when the Knudsen number increases significantly. Meanwhile, they have also addressed that the thermal-creep effect of the gas flow in a uniformly heated micro-channel can increase the mass flow rate, and the increase can be greatly enhanced by raising the inlet velocity. In addition, other effects, i.e. the compressibility and the viscous heating effects that may be occurred in the rarefied gas flow should also be considered. Chu et al. (1994) has used numerical analysis to evaluate the efficiency of heat removal when gas flows through an array of micro-channel under continuum or the velocity-slip condition. This numerical simulation is intended to study the cooling performance inside a micro-channel array that fabricated in a silicon chip. The numerical approaches have adopted the finite-difference methods incorporated with SOR (Successive over-relaxation) techniques to solve the problem with Neumann boundary conditions. The assumptions used include fully developed hydrodynamic condition, fully developed thermal condition and uniform heating on the bottom wall with the top wall well insulated. From the numerical results they have found that even though the temperaturejump causes decrease in Nusselt number that is contrary to continuum flow, the entire heat transfer performance were still higher than the case of continuum flow; this peculiar phenomenon is mainly due to the velocity-slip effects that induce greater mass flow per unit time into the channel. Therefore, the design of gas flow through a micro-channel array at the slip-flow regime as cooling is suggested. Fan and Xue (1998) have used the numerical method of the "DSMC" to simulate the gas flow in micro-channels at the slip-flow regime. They have assumed that the gas flow is simultaneously subjected to the effects of the velocity-slip and the compressibility. In addition, the effects of pressure ratio " $\mathrm{P}_{\mathrm{o}}$ " between two ends of the micro-channel on the flow are also studied. Simulation analysis was carried out under different ratios of $\mathrm{P}_{\mathrm{o}}$, and the results indicated that the velocity-profiles of the flow near both ends of the channel are deviated from the parabolic profile. The mean flow velocity near the channel outlet increases greatly by increasing the ratio of $P_{o}$. The deviation 
from the parabolic profile is caused mainly by both the entrance and the exit effect of the microchannel, only the flow field far from the end of the micro-channel can conform to the fully developed flow conditions. The second account of flow acceleration is not only significantly affected by the velocity-slip, but also induced by the compressibility of gas. Since the compressibility effect causes decrease in both the density and the pressure near the exit of channel, and the greater decrease in the exit pressure can accelerate the flow again to make up the density drop. Therefore, acceleration of the flow in a microchannel can be increased by increasing the pressure ratio $P_{\mathrm{o}}$. Meanwhile the slip flow characteristics in the channel can be observed from the simulation results for the shear stress and velocity distributions near the wall region. The results further exhibit that the compressibility induced by the increase of $P_{o}$ can greatly affect the gas flow behavior when the flow in the microchannel is at the slip-flow regime.

\subsection{Experimental measurements}

For experiments of gas flow in micro-channels, $\mathrm{Wu}$ and Little (1983) have measured the friction factors for both laminar and turbulent gas flows in trapezoidal channels. The widths of the channels are from 130 to $200 \mu \mathrm{m}$ and the depths are from 30 to $60 \mu \mathrm{m}$, respectively. The working fluids used include nitrogen, helium and argon gases. The friction factors, $\mathrm{f}$, obtained in his experiment are larger than the theoretical prediction for the critical Reynolds number less than 400 . The deviations of the data form the prediction are attributed to the very high degree of surface roughness and measurement uncertainty. For a nitrogen gas flow in micro-tubes, the effects of wall surface roughness on the pressure drop or the friction factors are studied by Choi et al. (1991) for both laminar and turbulent flow. The micro-tube diameters are from 3 to $81 \mu \mathrm{m}$ and the wall roughness is from 0.00017 to 0.0116 . It is found that the Poiseuille number, Po, which is defined as $\mathrm{f} \times \mathrm{Re}$, is 53 in the laminar region when the diameter of the tube is less than $10 \mu \mathrm{m}$. The Po of 53 in his experiment is lower than the theoretical value of 64 for fully developed laminar flow in the large scale tube, where the Po is kept as a constant. In the experiments of turbulent flow region, the results indicate that the Colburn analogy is not valid when the diameter of micro-tubes is less than $80 \mu \mathrm{m}$.

Some of pressure drop measurements have a good agreement with the predictions of the conventional theory. Acosta et al. (1985) has measured the friction factors in rectangular micro-channels, and the results are very close to the friction factor predicted by the conventional theory in small aspect ratios channels. Lalonde et al. (2001) has studied the friction factor of air flow in a micro-tube with a diameter of $52.8 \mu \mathrm{m}$. The experimental data has a good agreement with the predictions from the conventional theory. Turner et al. (2001) has performed an experiment to measure the friction factor with different working fluids, such as nitrogen, helium and air in microchannels with hydraulic diameters varying from 4 to $100 \mu \mathrm{m}$. The walls of the rectangular channels consider both the rough and the smooth wall conditions. The results indicate that the friction factors in laminar region for both the rough and the smooth wall conditions have good agreement with the conventional theory. In contrast to the results that agree with the conventional theory, Pfahler et al. (1990a, 1990b) and Pfahler et al. (1991) have performed experiments to obtain the friction factor for working fluids of helium and nitrogen in micro-channels with the heights varying from 0.5 to $40 \mu \mathrm{m}$. The results indicate a significant reduction of $\mathrm{C}_{\mathrm{f}}\left(\mathrm{Po}_{\mathrm{exp}} / \mathrm{Po}\right.$ theo $)$ which is a function of channel depth. The $C_{f}$ decreases with decreasing Re in the smallest channel. Yu et al. (1995) has performed the experiments of gas flow in a micro-channel with either a trapezoidal or a rectangular cross section. The hydraulic diameter varies between 1.01 and 
$35.91 \mu \mathrm{m}$. They have observed a friction factor smaller than the prediction of the conventional theory, and conclude that the deviation may be caused by both effects of compressibility and rarefaction of the gas. Harley et al. (1995) has performed the experiments for subsonic, compressible flow in a long micro-channel. The working fluids used are nitrogen, helium and argon gases. The channels are fabricated by silicon wafer, and the dimensions of the channels are $100 \mu \mathrm{m}$ wide, $10 \mathrm{~mm}$ long with depths varied from 0.5 to $20 \mu \mathrm{m}$. The experimental data have been presented in terms of the Po with hydraulic diameter from 1 to $36 \mu \mathrm{m}$. The measured friction factors agree with the theoretical prediction, but become smaller when the depth of channel decreases to $0.5 \mu \mathrm{m}$. The reduction in the friction factor is attributed to the occurrence of slip flow. The compressibility effects are also found by Li et al. (2000) who have performed an experiment of nitrogen gas flow in five different micro-tubes with diameters from 80 to $166 \mu \mathrm{m}$. The pressure drop along the tube became nonlinear when the Much number is higher than 0.3.

In order to understand more detailed pressure information inside a micro-channel, arrays of the pressure sensors should be integrated in the micro-channel for measurement of pressure distribution. Pong et al. (1994) are the first to present that a rectangular micro-channel can be fabricated with integrated arrays of pressure sensors for pressure distribution measurements. Both the helium and the nitrogen gas are used as the working fluid in his study. The channels are from 5 to $40 \mu \mathrm{m}$ wide, $1.2 \mu \mathrm{m}$ deep and $3000 \mu \mathrm{m}$ long. The experimental results indicate that the pressure distribution is not linear and is lower than the prediction based on the continuum flow analysis in the micro-channel. The non-linear effects are caused by both effects of rarefaction and compressibility of the gas due to the high pressure loss. Liu et al. (1995) have used the similar channel as in Pong et al. (1994) but having different shapes to perform the experiments. The channel has a uniform cross section and has the dimensions of $40 \mu \mathrm{m}$ wide, $1.2 \mu \mathrm{m}$ deep and $4.5 \mathrm{~mm}$ long. The pressure drop distribution found is also nonlinear. For the channel with non-uniform cross section, sudden pressure changes are found at locations where variations of the cross section occur. In the mean time, analysis of the channel flow has also been performed with the assumptions of a steady, isothermal, and continuum flow with wall slip condition. However, the analysis can not explain the small pressure gradients measured near the inlet and the outlet of the channel.

Shih et al. (1996) has repeated the experiments of Pong by using a similar micro-channel with dimensions of $40 \mu \mathrm{m}$ wide, $1.2 \mu \mathrm{m}$ deep and $4000 \mu \mathrm{m}$ long to measure the pressure distribution and mass flow rate for helium or nitrogen gas flow. The results of helium have a good agreement with the analysis based on the Navier-Stokes equations with slip boundary condition. The boundary condition of a slip flow on the wall is given by

$$
u_{w}=\psi K n(\partial u / \partial y)
$$

where $\psi$ is momentum accommodation coefficient. In general, $\psi=1$ has been used for engineering calculation. All the experimental data indicate a non-linear dependence of the pressure drop with the mass flow rate. Li et al. (2000) and Lee et al. (2002) have performed experiments for channels with orifice and venture elements. The dimensions of channels are $40 \mu \mathrm{m}$ wide, $1 \mu \mathrm{m}$ deep and $4000 \mu \mathrm{m}$ long. The working fluid used is nitrogen which has an inlet pressure up to 50 Psig. The mass flow rates are measured as a function of the pressure drop. The results indicate that the pressure distribution is non-linear and the pressure drop is a function of mass flow rate. The experimental data are used to compare with the 
prediction from the Navier-Sotkes equation with a slip boundary condition. The friction factors for both channels with either the orifice or the venture are all lower than theoretical prediction.

It appears that contradictory results have been found in the previous studies. More accurate measurements of the pressure drop and heat transfer inside a microchannel are required. This requires fabrication of a micro-channel system, integrated with arrays of micro pressure sensors or temperature sensors, fabricated by surface micromachining process. However, the microchannel fabricated previously with arrays of pressure sensor is limited to a channel height of $1.2 \mu \mathrm{m}$ due to the use of oxide sacrificial layer which is deposited by chemical vapor deposition (CVD) process. Much thicker deposition of the oxide layer is not possible with the current technology. In addition, the channel structure is very weak due to fabrication of the channel wall with a very thin film, only gas flow is allowed for the experiment. Therefore, in order to provide a channel which has a much greater height and is suitable for liquid flow conditions with a strong wall, an entirely new fabrication process for the channel should be considered and designed.

\section{Liquid flow characteristics in microchannels}

The liquid flow can be regarded as a continuum even in a very small channel. However, liquid flow can become boiling when the wall temperature is higher than the vaporization temperature of the liquid. Therefore, the liquid flow regimes can be divided into the single phase flow and the two phase flow regime. The real behaviors of heat transfer in the laminar or the transition flow (before turbulent) regime are deviated significantly from the prediction using the continuum theory due to the nonlinear terms of the surface forces in the Navier-Stokes equations. The surface forces play a major role in the micro-scale liquid flow, which can be significantly affected by the geometry, the electro-kinetic transport process, the hydrophilic or hydrophobic of the surface condition etc. inside the microchannel.

\subsection{Experimental results}

Single-phase liquid flow is considered incompressible in a micro-channel. However, the geometric configurations, such as the aspect ratio, the geometric cross-section of the channel or the surface roughness etc., can significantly affect the characteristics of the flow and the heat transfer process in a microchannel. Harms et al. $(1997,1999)$ have observed a friction factor well predicted by the conventional theory in the laminar region. Webb et al. (1998) have observed that the conventional theory is able to predict the single phase heat transfer and the friction factor for a rectangular channel. Pfund et al. (1998) have studied the water flow in rectangular micro-channels at Reynolds numbers between 40 and 4000 . The friction factor has a good agreement with the conventional theory in the laminar flow region, but increase by the surface roughness in the turbulence region. Xu et al. $(1999,2000)$ have fabricated the rectangular micro-channels by bonding an aluminum plate or a silicon wafer with a Plexi glass. The channels were etched on a silicon or aluminum substrate. The hydraulic diameters of the aluminum channels are from 46.8 to $344.3 \mu \mathrm{m}$ and for silicon channels are from 29.59 to $79.08 \mu \mathrm{m}$, respectively. The experimental results for liquid flow in micro-channels have very good agreement with the prediction from the Navier-Stokes equation for a Newtonian flow in laminar region. Qu et al. $(2000,2002)$ has performed experiments for water in silicon micro-channels with trapezoidal cross section having hydraulic diameter from 51 to $169 \mu \mathrm{m}$. The pressure drop measured has a good agreement 
with the prediction based on conventional theory. More experiments have indicated that the deviation from the prediction is attributed to the roughness of the channel wall and viscosity of the fluid. The friction factors obtained from these experiments are higher than the predictions from the conventional theory. Li et al. $(2000,2003)$ have fabricated different micro-tubes made by glass, silicon or stainless steel with diameters ranging from 79.9 to $166.3 \mu \mathrm{m}, 100.25$ to $205.3 \mu \mathrm{m}$ and from 128.6 to $179.8 \mu \mathrm{m}$, respectively. The results of the friction factor measured for DI water, in glass and silicon micro-tubes where tube wall can be considered smooth, has good agreement with the conventional theory. The deviation of the data in the stainless steel tube is attributed to the surface roughness. They have concluded that the relative roughness of the wall can not be neglected for micro-tube in the laminar flow region. Sharp et al. (2000) have considered laminar flow of water in microtubes with hydraulic diameters ranging from 75 to $242 \mu \mathrm{m}$. Their data agree with the conventional theory. Wu et al. (2003) have provided the experimental data of friction factor for DI water in smooth silicon micro-channels with trapezoidal cross section having hydraulic diameter from $25.9 \mu \mathrm{m}$ to $291 \mu \mathrm{m}$. The results of their data have a good agreement with the prediction from the conventional theory. They conclude that the Navier-Stokes equations are still valid for laminar flow of DI water in microchannel with smooth wall and hydraulic diameters as small as $26 \mu \mathrm{m}$.

Some work reported the friction factors that are very different from the theoretical prediction. Yu et al. (1995) has performed experiments of water flow in silica micro-tubes with diameters ranging from 19 to $102 \mu \mathrm{m}$ and the Reynolds numbers between 250 and 20000. The friction factors are lower than the theoretical predictions. Jiang et al. $(1995,1997)$ have studied water flow through rectangular or trapezoidal channels. The dimensions of the channels are 35 to $120 \mu \mathrm{m}$ wide and 13.4 to $46 \mu \mathrm{m}$ deep. The friction factor data are greater than the theoretical prediction, but become lower when the Reynolds numbers are between 1 and 30. It appears that the deviations of the friction factor measured from the prediction may be attributed to the surface behaviors of the liquid flow, especially the surface roughness of the channel wall, the surface potential and the electro-kinetic effect induced by the electrical double layer (EDL) etc. as discussed in the following section.

\subsection{Analysis of electric double layer effect}

If the liquid contains a very few amount of ions (ex. impurities), the electrostatic charges on the non-conducting solid surface will attract the counter-ions in the liquid flow. The rearrangement of the charges on the solid surface and the balancing charges in the liquid is called the electrical double layer. The thickness of the EDL is significantly affected by the ion concentration, the liquid flow polarity, the surface roughness and the surface potential. A thicker EDL possibly induced by a lower ion concentration, a polar liquid, a poor surface roughness or a higher surface potential could cause a larger friction factor and pressure gradient. This can significantly reduce the flow velocity, and the heat transfer of a liquid flow in the microchannel. This is true for infinitely diluted solution such as the millipore water, the thickness of the EDL is considerably large (about $1 \mu \mathrm{m}$ ). However, for solution with high ionic concentration, the thickness of the EDL becomes very small, normally a few nanometer. In this case, therefore, the EDL effects on the flow in microchannels can be negligible.

To account for the EDL effect for polar liquid flow in the microchannel, most of the work performed in the past is the theoretical simulation where the physical models can be formulated based on (1) the Poisson-Boltzmann equations for the EDL potential, (2) the 
Laplace equations with the applied electrostatic field, and (3) the Navier-Stokes equations modified to include effects of the body force due to the interaction between electrical and zeta potential. However, the numerical results are always lower than the empirical data due to the unusual and complex surface behaviors described above. In addition, the aspect ratio and the geometric cross-section of the channels can also affect the thickness of the EDL. In general, the friction factor increases with decreasing the aspect ratio of the channels. A microchannel with a cross section of circular shape usually has the lowest friction factor. The friction factor in a silicon channel is larger than in a glass channel due to the different surface potential of the channel walls with millipore water.

The Poisson-Boltzmann equations for the EDL potential in a rectangular microchannel are described as follows (Beskok \& Karniadakis, 1994):

$$
\begin{gathered}
\frac{\partial^{2} \psi}{\partial y^{2}}+\frac{\partial^{2} \psi}{\partial z^{2}}=-\frac{\rho_{e}}{\varepsilon_{o} \varepsilon}=\frac{2 n_{\infty} z e}{\varepsilon_{o} \varepsilon} \sinh \left(\frac{z e \psi}{k_{b} T}\right) \\
n_{i}=n_{i \infty} \exp \left(-\frac{z_{i} e \psi}{k_{b} T}\right) \\
\rho_{e}=z e\left(n_{+}-n_{-}\right)=-2 z e n_{\infty} \sinh \left(\frac{z e \psi}{k_{b} T}\right)
\end{gathered}
$$

where $\psi$ and $\rho_{e}$ are the electrical potential and the net charge density per unit volume. $\varepsilon$ is the dielectric constant of the solution. $\varepsilon_{o}$ is the permittivity in vacuum. $n_{i \infty}$ and $z_{i}$ are the bulk ionic concentration and the valence of type $i$ ions, respectively; $e$ is the charge of the proton; $k_{b}$ is the Boltzmann constant; $T$ is the absolute temperature.

To account for the electric field effect, the Navier-Stokes equation describing the flow motion can be rewritten as following:

$$
\frac{\partial^{2} u}{\partial y^{2}}+\frac{\partial^{2} u}{\partial z^{2}}=\frac{1 d p}{\mu d x}-\frac{1}{\mu} E_{x} \rho_{e}
$$

where $E_{x}$ is an induced electric field (or called electrokinetic potential) and $p$ is the hydraulic pressure in the rectangular microchannel.

At a steady state, the net electrical current is zero, which means:

$$
\begin{gathered}
I=I_{s}+I_{c}=0 \\
I_{s}=4 \int_{h-1 / k}^{h} \int_{w-1 / k}^{w} u(y, z) \rho_{e}(y, z) d y d z
\end{gathered}
$$

where $I_{S}$ and $I_{c}$ are the streaming and the conduction currents, respectively. In addition, the net charge density is non-zero essentially only in the EDL region whose characteristic thickness is given by $1 / k$ ( $k$ is the Debye-Huckel parameter).

The conduction current, that is the transport of the excess charge in the EDL region of a rectangular microchannel, driven by the electrokinetic potential is given by: 


$$
\begin{gathered}
I_{c}=4 \lambda_{o} E_{x}(h+w) \frac{1}{k} \\
k=\left[2 z^{2} e^{2} n_{\infty} /\left(\varepsilon \varepsilon_{o} k_{b} T\right)\right]^{1 / 2}
\end{gathered}
$$

where $\lambda_{0}$ is the bulk electrical conductivity $(1 / \Omega \mathrm{m}) . h$ and $w$ are the height and the width of the microchannel, respectively. Substituting Eq.(3-6) and Eq.(3-7) into Eq.(3-5), the electrokinetic potential $\left(E_{x}\right)$ can be written as follows:

$$
E_{x}=-\frac{\int_{h-1 / k}^{h} \int_{w-1 / k}^{w} u(y, z) \rho_{e}(y, z) d y d z}{\lambda_{o}(w+h)(1 / k)}
$$

Both the Poisson-Boltzmann equation, Eq.(3-1) and Navier-Stokes equation, Eq.(3-4), can be solved numerically in order that both the EDL and the velocity fields in the rectangular microchannel can be determined.

\subsection{Comparison with the data}

Despite the theoretical prediction, some work presents occurrence of the electrical double layer of water flow in a micro-channel. Ren et al. (2001) have performed experiments to measure the interfacial electrokinetic effects of a liquid flow through rectangular silicon micro-channels with diameters of 28.1, 56.1 and $80.3 \mu \mathrm{m}$. Both the DI water and the $\mathrm{KCl}$ solutions with two different concentrations of 10-4 and 10-2 $\mathrm{M}$ are used as working fluid. The measured pressure drops for the pure DI water and the lower $\mathrm{KCl}$ concentration solution are significantly higher than that for higher concentration solution and the theoretical prediction. The authors have concluded that a significant increase in the friction factor is attributed to occurrence of the electrical double layer (EDL) which increases the pressure drop in the small micro-channels. Similar results have also been obtained by Li et al. (2001).

To compare with the experimental results, the analytical predictions for both the flow and the heat transfer developed from continuum assumption indicate large discrepancy when the characteristic length of the micro-channel becomes small enough. In the studies of liquid flow, many investigators (Ren et al., 2001; Fan et al., 1998; Chen, 1996; Chu et al., 1994; Choi et al., 1991; White et al., 1991; Pfahler et al., 1990, 1991) have concluded that even though the liquids can be regarded as a continuum in a very small system, the real behaviors of heat transfer at the laminar or the transition (before turbulent) condition are deviated from the predictions based on the conventional theory. Usually, for the data published, the uncertainties of flow rate measured and friction factor estimated are 2-5\% and 10-15\%, respectively. For most heat transfer studies, the uncertainties are under $\pm 20 \%$. In summary, the geometric effects, such as the aspect ratio, the cross-section shape or the surface roughness etc., can significantly affect the characteristics of both the flow and the heat transport in a microchannel. The onset of transition to turbulent flow in smooth microchannels does not occur if the Reynolds number is less than 1000. For a laminar flow, the Nusselt number varies as the square root of the Reynolds number. In turbulent flow, however, the numerical studies are not applicable and thus many empirical correlations have been proposed, but were not verified. However, satisfactory estimates of the heat 
transfer coefficients can be obtained with sufficient accuracy by using either experimental results in smooth channels with large hydraulic diameter or conventional correlations.

Tso and Mahulikar (1998) have obtained the heat transfer for laminar liquid flow through a microchannel in both the thermal-developing region and the thermal-developed region. It is found that the Nusselt number decreases with increasing the Reynolds number not only in the thermal-developed region, but also in the thermal entry region. The results also indicate that the pressure distribution along the microchannel exhibits a non-linear profile. Despite much of the studies has addressed that the liquid flow appears a greatly complicated relation between Nusselt number and Reynolds number, however, all the results are very based on the assumption of continuum flow. Therefore, more detailed analysis combined with experiments is still required to clarify the role of the EDL and different results among different works.

\subsection{Two-phase flow phenomenon in the microchannel}

The two-phase flow or flow-boiling phenomenon in the microchannel exhibits some unusual characteristics. It is found that the bubbles are not rapidly generated even at a very high heat flux from the heated microchannel (Qu et al., 2000). Therefore, further experimental investigations on the flow boiling in microchannels were made by others (Ren et al., 2001; Peng \& Wang, 1993; Lin and Pisano, 1991, 1994). In addition, the effect of microchannel scale, geometric configuration, liquid velocity, liquid sub-cooling and liquid concentration on the flow boiling were investigated. It is found that the heat transfer enhanced by a large more volatile component concentration is greater than the pure more volatile liquid. The heat transfer coefficient at the onset of flow boiling and in the partial nucleate boiling region was greatly influenced by the liquid concentration, the geometric configuration, the size of microchannel, and the flow velocity and sub-cooling, but not in the fully nucleate boiling region. Peng and Wang (2001), and $\mathrm{Hu}$ (1998) found the so-called "bubble extinction" behavior due to an induced vigorous nucleate boiling mode on a normal-sized heater or abnormal-sized channels. The normal bubbles could not successfully grow and form, if the channel height is less than a critical liquid space required. In order to interpret the unusual behavior observed in microchannel boiling, Peng and Wang (1994) proposed the concepts of "evaporating space" and "fictitious boiling". In fact, the small bubbles that can form initially in microchannel will eventually collapse since the size of the bubble could not grow up exceed the critical radius of bubble $\left(r_{c}\right)$ formulated by conventional nucleation theory. The fictitious boiling occurred was attributed to the crowded tiny bubbles that grow and then collapse rapidly in a cyclic manner, and thereby mimicking a boiling state that can transfer large amount of heat. The observations suggest that close to bubble nucleation temperature the liquid will vigorously oscillate in the microchannel due to the emergence of tiny bubble embryos. More detailed explanations are given in (Jiang et al., 2001; Peng et al., 1998).

The experiments by Peng and Wang (1993) for flow boiling of water have been carried out in a stainless steel microchannel with rectangular cross-section of $600 \mu \mathrm{m} \times 700 \mu \mathrm{m}$. In a much smaller channel array, with hydrodynamic diameter of 40 and $80 \mu \mathrm{m}$, made on a silicon substrate by wet etch, three stable phase-change modes, i.e. local nucleation boiling, large bubble formation and annular flow, were observed depending on the input power level $(\mathrm{Qu}$ \& Mudawar, 2003). However, bubbly flow, commonly observed in macrochannels, could not be developed in the microchannels. A stable annual flow was also observed in a micro- 
channel heat sink contained 21 parallel channels having a $231 \mu \mathrm{m} \times 713 \mu \mathrm{m}$ cross-section (Lee et al., 2003).

Lee et al. (2003) proposed that a nearly rectangular microchannel heat sink with $14 \mu \mathrm{m}$ in depth integrated with a local heater and array of temperature sensors on silicon substrate was made to investigate the size and shape effects on the two-phase patterns in microchannel forced convection boiling. It is found that when the heat input power increases, the downstream movement of the transition region increases the void fraction and causes a lower devices temperature. However, at the high flow rate, the transition region almost occupies the entire channel, the increase in the heat input power results in a higher devices temperature. An annular pattern induced by flow boiling appears stably in triangular microchannels, but not in rectangular microchannels. Two-phase boiling or superheated flow has numerous promising applications such as in cooling of electronic components. The principle advantage of two-phase flow lies in the utilization of latent heat absorbed by the working fluid due to phase change from liquid to vapor without increasing the flow fluid temperature. In fact, two-phase flow heat transfer in microcahnnel is a very important and interesting problem indeed.

However, much of the attention at later time has been given to the study of dynamic flow boiling instability in microchannels (Cheng et al., 2009; Wang et al., 2008; Wang et al., 2007; Kandlikar, 2006; Wu \& Cheng, 2003, 2004; Brutin et al., 2003; Hetsroni et al., 2002; Hetsroni et al., 2001). A periodic annular flow and the periodic dry steam flow were observed for boiling of water in 21 silicon triangular microchannels having a diameter of $129 \mu \mathrm{m}$ in (Hetsroni et al., 2001, 2002). However, two types of two-phase hydrodynamic instabilities, i.e. severe pressure drop oscillation and mild parallel channel instability were identified $(\mathrm{Qu}$ \& Mudarwar, 2003) in the similar microchannels as in other work (Hetsroni et al., 2001). A simultaneous flow visualization and measurement was made on flow boiling of water in two parallel silicon microchannels of trapezoidal cross-section having hydraulic diameters of $158.8 \mu \mathrm{m}$ and $82.8 \mu \mathrm{m}$, respectively (Wu \& Cheng, 2003). The results shows that twophase flow and single-phase liquid flow appear alternatively in microchannels, which leads to large amplitude/long-period fluctuations with time in temperatures, pressures and mass flux. The flow pattern map in terms of heat flux versus mass flux showing stable and unstable flow boiling regimes in a single microchannel has been identified ( $\mathrm{Wu} \&$ Cheng, 2004). It is found that stable and unstable flow-boiling modes existed in microchannels, depending on four parameters, namely, heat/mass flux ratio, inlet water subcooling, channel geometry, and physical properties of the working medium (Wang et al., 2007). In addition, the magnitudes of temperature and pressure fluctuations in the unstable flowboiling mode depend greatly on the configurations of the inlet/outlet connections with the microchannels (Wang et al., 2008). By fabricating an inlet restriction on each microchannel or the installation of a throttling valve upstream of the test section, reversed flow of vapor bubbles can be suppressed resulting in a stable flow-boiling mode. Based on the exit quality of the flow from a microchannel, more detailed flow regimes are identified (Cheng et al., 2009).

In the past, however, a very important issue, i.e. the surface wettability effect, has been overlooked in the study of boiling flow heat transfer in a microchannel. The boiling flow phenomenon found in the microchannel is only for certain surface wettability. By changing the material of the microchannel or surface wetting property, the boiling flow phenomenon may be completely different. This may cause discrepancy of flow patterns observed in different channels made by different materials. Phan et al. (2009) have found that the 
wettability of a surface has a profound effect on the nucleation, growth and detachment of bubbles from the bottom wall in a tank. For hydrophilic (wetted) surfaces, it has been found that a greater surface wettability increases the vapor bubble departure radius and reduces the bubble emission frequency. Moreover, lower superheat is required for the initial growth of bubbles on hydrophobic (un-wetted) surfaces. However, the bubble in contact with the hydrophobic surface cannot detach from the wall and have a curvature radius increasing with time. At higher heat flux, the bubble spreads over the surface and coalesces with bubbles formed at other sites, causing a large area of the surface to become vapour blanketed.

The wettability of channel surface has been studied by Liu et al. (2011) who have fabricated three different microchannels with identical sizes at $105 \times 1000 \times 30000 \mu \mathrm{m}$ but at different wettability. The microchannels were made by plasma etching a trench on a silicon wafer. The surface made by the plasma etch process is hydrophilic and has a contact angle of $36^{\circ}$ when measured by dipping a water droplet on the surface. The surface can be made hydrophobic by coating a thin layer of low surface energy material and has a contact angle of $103^{\circ}$ after the coating. In addition, a vapor-liquid-solid growth process was adopted to grow nanowire arrays on the wafer so that the surface becomes super-hydrophilic with a contact angle close to $0^{\circ}$. Different boiling flow patterns on a surface with different wettability were found, which leads to large difference in temperature oscillations. Periodic oscillation in temperatures was not found in both the hydrophobic and the superhydrophilic surface. During the experiments, the heat flux imposed on the wall varies from 230 to $354.9 \mathrm{~kW} / \mathrm{m}^{2}$ and the flow of mass flux into the channel from 50 to $583 \mathrm{~kg} / \mathrm{m}^{2} \mathrm{~s}$. Detailed flow regimes in terms of heat flux versus mass flux are also obtained.

\section{Basic MEMS fabrication techniques}

\subsection{Chemical vapor deposition}

Chemical vapor deposition (CVD) is a typical technique to fabricate a thin film on a substrate. In a CVD process, gaseous reactants are introduced into a heated reaction chamber. The chemical reactive gases diffuse onto and absorbed by the substrate. Then thermal dissolution reaction of the reactive gases occurs which lead to deposition of a thin solid film on the heated substrate surfaces. Depending upon the relative pressure and the temperature used the CVD processes are categorized as: (1) the atmospheric pressure chemical vapor deposition (APCVD), (2) the low pressure chemical vapor deposition (LPCVD), and (3) the plasma-enhanced chemical vapor deposition (PECVD). The process temperatures of APCVD and LPCVD are ranged from $500^{\circ} \mathrm{C}$ to $850^{\circ} \mathrm{C}$. In PECVD processes, a part of thermal energy is shared from the plasma source. Therefore, the process temperatures of the PECVD are lower on the order of $100^{\circ} \mathrm{C}$ to $350^{\circ} \mathrm{C}$. The silicon based thin films such as poly-silicon, amorphous silicon, silicon dioxide, tetraethoxysilane (TEOS, $\left.\mathrm{Si}\left(\mathrm{C}_{2} \mathrm{H}_{5} \mathrm{O}\right)_{4}\right)$ or silicon nitride film can be fabricated by using the CVD process. The chemicals used and the reaction occurred in the CVD process for different kinds of films are listed in Table 1. The poly-silicon film can be used for fabrication of pressure or temperature sensors or micro-heaters. The TEOS oxide layer is fabricated as insulator between each sensor layer. In addition, deposition of the silicon nitride film can be used to prevent penetration of moisture into the sensors during liquid flow experiments which may cause damage of the micro-sensors or micro electronics integrated in the micro-channel. 


\begin{tabular}{|l|l|}
\hline Films & Chemical reactions \\
\hline Poly-silicon & $\mathrm{SiH}_{4} \rightarrow \mathrm{Si}+2 \mathrm{H}_{2}$ \\
\hline Silicon dioxide & $\begin{array}{l}\mathrm{SiH}_{4}+\mathrm{O}_{2} \rightarrow \mathrm{SiO}_{2}+2 \mathrm{H}_{2} \\
\mathrm{SiCl}_{2} \mathrm{H}_{2}+2 \mathrm{~N}_{2} \mathrm{O} \rightarrow \mathrm{SiO}_{2}+2 \mathrm{~N}_{2}+2 \mathrm{HCl}\end{array}$ \\
\hline TEOS (tetraethoxysilane) & $\mathrm{Si}\left(\mathrm{OC}_{2} \mathrm{H}_{5}\right)_{4} \rightarrow \mathrm{SiO}_{2}+$ by-products \\
\hline Silicon nitride & $3 \mathrm{SiH}_{4}+4 \mathrm{NH}_{3} \rightarrow \mathrm{Si}_{3} \mathrm{~N}_{4}+12 \mathrm{H}_{2}$ \\
$3 \mathrm{SiCl}_{2} \mathrm{H}_{2}+4 \mathrm{NH}_{3} \rightarrow \mathrm{Si}_{3} \mathrm{~N}_{4}+6 \mathrm{HCl}+6 \mathrm{H}_{2}$ \\
\hline
\end{tabular}

Table 1. Chemical reactions used in the CVD process for different kinds of films.

\subsection{Evaporation and sputtering deposition}

Both evaporation and sputtering deposition are classified as physical vapor deposition (PVD) process which can form different kinds of films on a substrate directly from a source material. PVD is typically used for deposition of electrically conducting layers such a metal or silicide. Evaporation deposition of a thin film on a substrate is done by sublimation of a heated source material in a vacuum chamber. The vapor flux from the source can be condensed and coated on the substrate surface. The evaporation methods can be further categorized as the vacuum thermal evaporation (VTA), the electron beam evaporation (EBE), and the molecular beam epitaxy (MBE).

The simplest evaporator consists of a vacuum chamber with a crucible which can be heated to a high temperature, as shown in Figure 1(a) and 1(b) by a filament. The filament is used as a heater, which is made of Tungsten (W), a refractory (high temperature) metal. Evaporation is accomplished by gradually increasing the temperature of the filament until the source material melts. Filament temperature is then further raised to evaporate the source material from the crucible. The substrates are mounted on top of the crucible and are deposited with a thin film of evaporated material.

In the electron beam (E-beam) evaporation system, the high-temperature filament is replaced with an electron beam, as shown in Figure 1(c). A high-intensity beam of electrons, with energy up to $15 \mathrm{keV}$, is focused on the source material to be evaporated in a crucible. The energy from the electron beam only melts a portion of the source material, which eventually evaporates and condenses on the substrate to form a thin layer.

Sputtering deposition requires generation of plasma gas between high voltage electrodes, as shown in Figure 2, where positively ions can be accelerated and bombards on a target material (a cathode) so that flux of atoms can be sputtered and collected on the substrate. Usually, a physically inert gas, such as argon gas, is made into plasma by knocking out electrons of the molecules with high speed electrons emitted from the cathode. The sputtering deposition has the advantages of depositing various materials include not only for pure materials or metals, but also for compounds, alloys, refractory materials, or piezoelectric ceramics. In addition, puttering deposition has no shadowing effect as that occurred in evaporation deposition, which causes non-uniform deposition of a film. Therefore, sputtering deposition has been widely used for deposition of different kinds of films. 


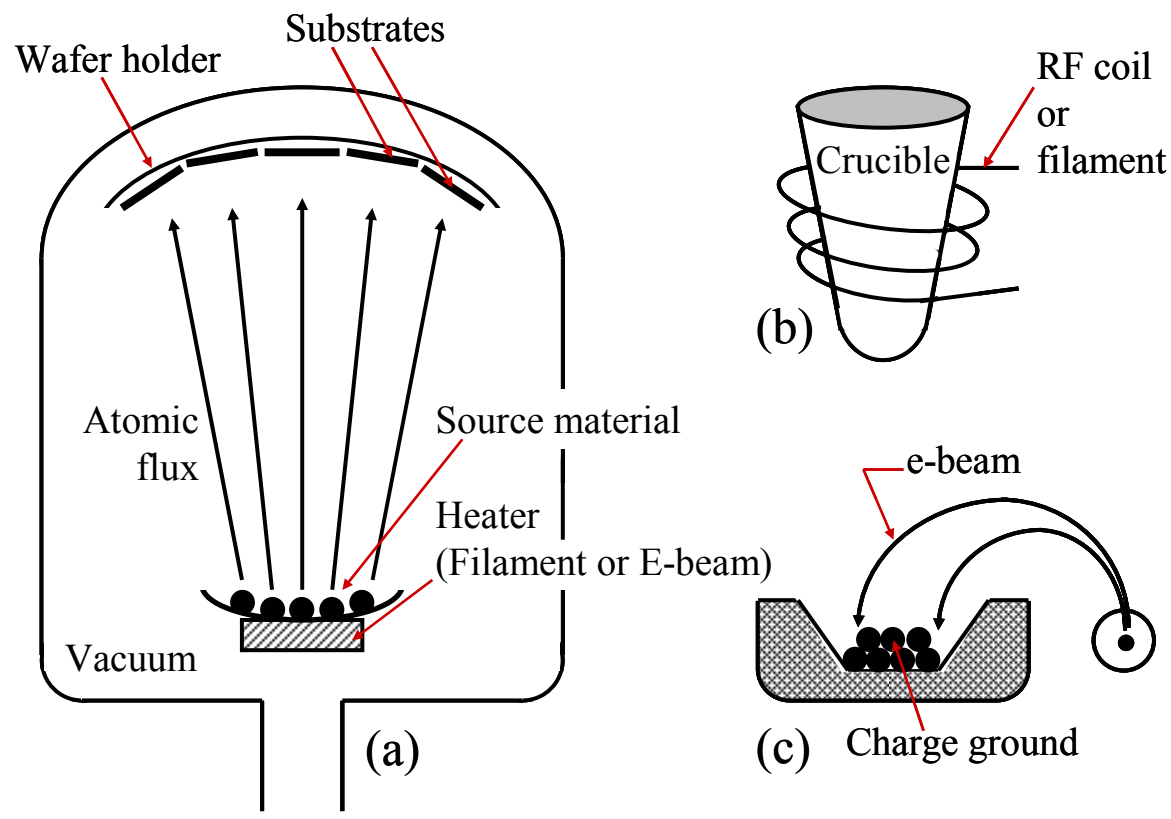

Fig. 1. (a) Schematic of the thermal evaporation system, (b) the use of filament or RF coil as heating source and (c) the use of electron beam as the heating source.

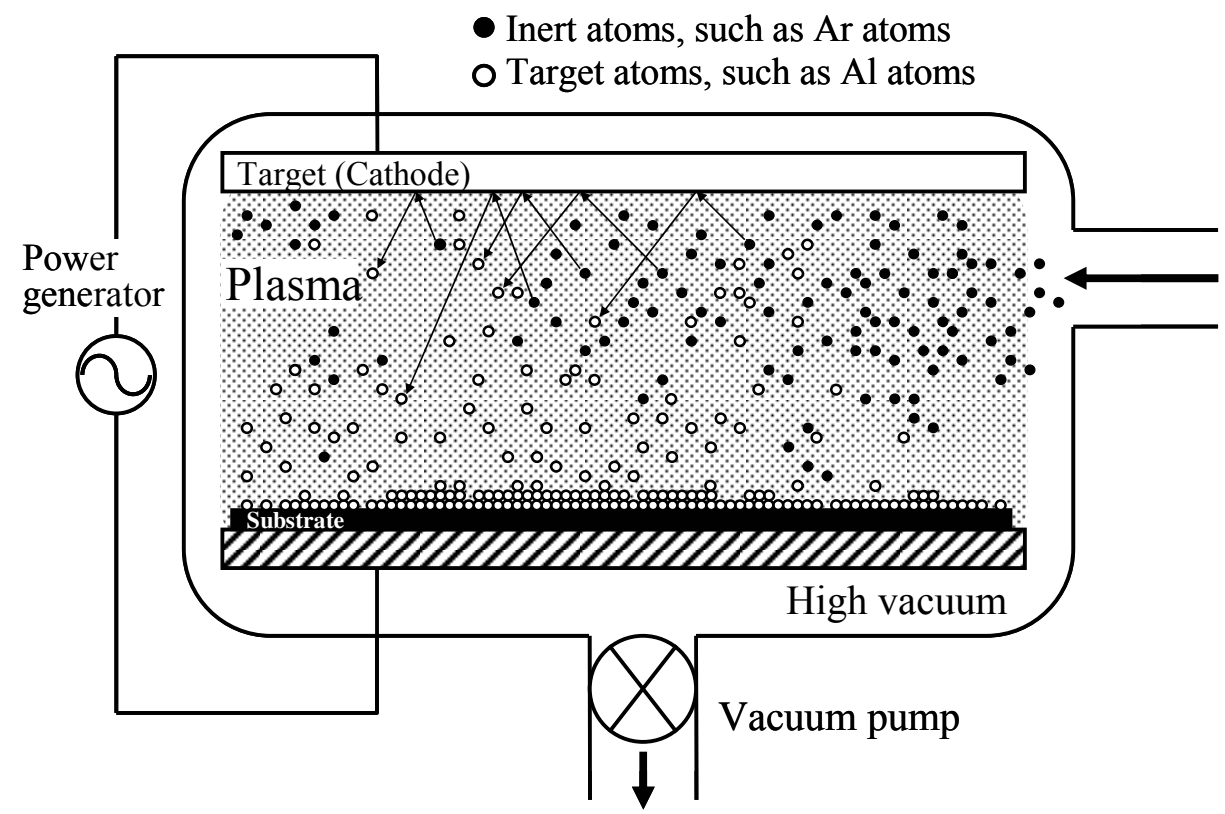

Fig. 2. Schematic of a sputtering system. 


\subsection{Photolithography}

Lithography is the most important technique for transferring micro-patterns onto substrate. Depending upon resolution required, the light sources used for lithography process can be a mercury lamp, a laser light, an electron beam, X-ray or an ion beam. However, photolithography using mercury lamp or laser light is the most popular method for low-cost and fast prototyping of micro-fluidic fabrications. This technique uses a photosensitive polymer layer, the so called photo-resist (PR), to transfer a desired pattern from a photomask to the substrate. The mask is a transparent glass plate or a plastic sheet with metal (chromium, Cr) or ink patterns. The photolithography process is shown in Figure 3. First, the photo-resist is spin coated onto the substrate. After light exposure and a developing process of the PR a desired pattern can be transferred from the photomask to the $\mathrm{PR}$, and then transferred to the underneath layer by a wet or a dry etch process. The resolution of a proximity photolithography $(\mathrm{R})$ process which depends on the wavelength $(\lambda)$ of the light source can be written as follows:

$$
R=K_{1} \frac{\lambda}{N A}
$$

where $\mathrm{K}_{1}$ is the optical system constant and NA is the numerical aperture of image lens system. The reduction of the resolution can be made by reducing the wavelength or increasing the NA. However, increasing the NA can lead to large reduction in the depth of the focus, which is very detrimental to the images. It appears that the resolution of photolithography is primarily determined by the wavelength of the light source.

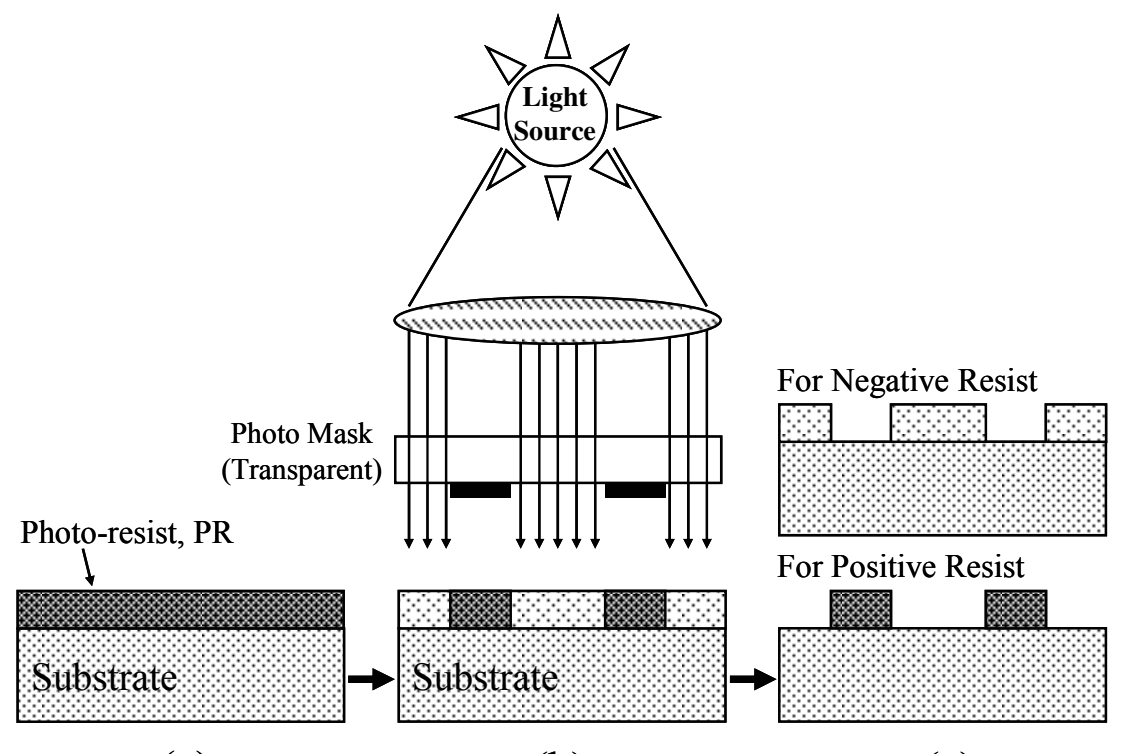

(a)

(b)

(c)

Fig. 3. Process of photolithography: (a) spin coat the PR, (b) light exposure and (c) developing the PR. 


\subsection{Anisotropic wet etching}

Single crystal silicon can be anisotropically etched. In general, the etching rate is highly dependent on the crystal's orientation in the single-crystal silicon as shown in Figure 4. Most of the chemical solutions have a distinct slow etching rate on the crystal face of (111), which practically causes a etch stop on this surface. This allows formation of microstructures with sharp edges and corners that can be defined in a single crystal substrate. For the different orientation silicon substrates, the angle between other crystal faces with respect to the (111) crystal face are shown in Figure 5. Different etchants, such as $\mathrm{KOH}, \mathrm{NaOH}, \mathrm{TMAH}$ (Tetramethyl ammonium hydroxide) and EDP (Ethylenediamine pyrochatechol), may be used for anisotropic wet etch for the silicon. The angles between different facets are $54.7 \mathrm{o}$ and $90^{\circ}$ for $\{100\}$ to $\{111\}$ and $\{110\}$ to $\{111\}$, respectively. However, using $\mathrm{KOH}$ solution the etching selectivities for different facets are around 400 and 600 for $\{100\} /\{111\}$ and $\{110\} /\{111\}$, respectively. Therefore, V-shaped or rectangular cavities can be readily fabricated and obtained by this method.

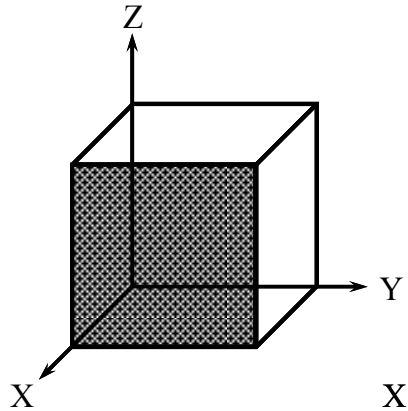

(100) cystal face

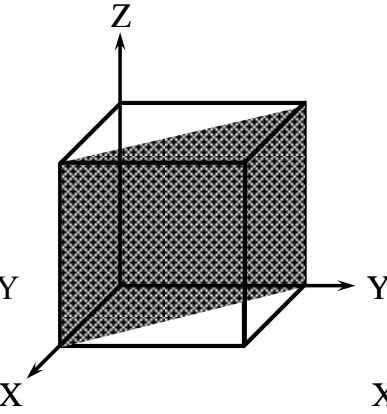

(110) cystal face

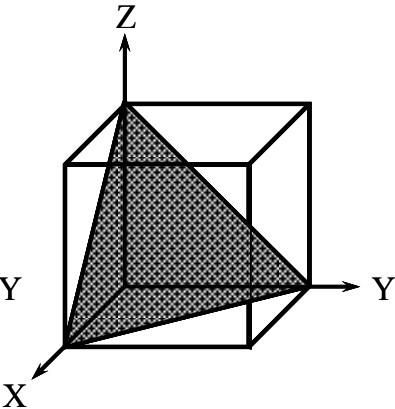

(111) cystal face

Fig. 4. The crystal planes in silicon lattice structure.

\section{Anisotropic etching solution}

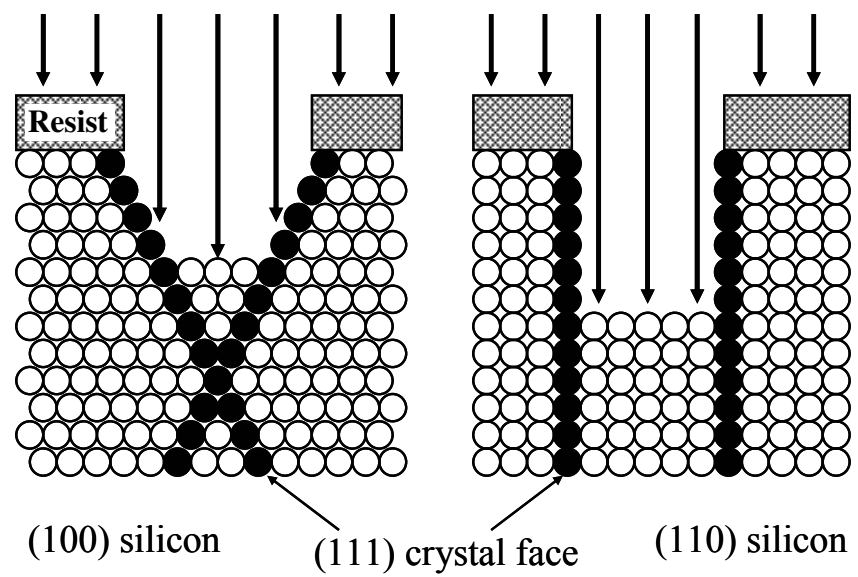

Fig. 5. Anisotropic etching in the single crystal silicon. [Madou, 2002] 


\subsection{Deep reactive ion etching}

The process which can remove the materials from the surface of a substrate or a bulk substrate is called "ETCHING". Anisotropic dry etching process does not depend on crystal orientation of silicon wafer. This micromachining process involves the exposure of the substrate to an ionized gas. Etching occurs through chemical or physical interaction between the ions in the gas and the atoms of substrate. The most often applied techniques can be divided into three groups: (1) physical sputter etching or ion beam etching, (2) chemical plasma etching and (3) combined physical/chemical etching. The physical method as so called "sputtering etching or ion beam etching" can achieve an anisotropic profile structure. As opposed to sputtering etching, chemical plasma etching is completely isotropic etching profile and has excellent selective properties. The etching rate of plasma etching is much faster than sputtering etching and is uncontrollable. However, the reactive ion etching (RIE) method combines the physical and chemical etchings to achieve excellent high selectivity and anisotropy for micromachining of silicon substrate. The etching rate ranges from 20 to $200 \mathrm{~nm} / \mathrm{min}$. However, this low etching rate can not satisfy the micromachining of microchannel with a high aspect ratio structure.

The problems of reactive ion etching (RIE) used in the micromachining process are that the sidewalls of the trenches are not vertical and the etching speeds are too slow. Therefore, two modified RIE techniques, i.e. the Bosch process and the cryogenic process, are developed to solve this problem. In the first approach, the Bosch process consists of cyclic etching and deposition process, as shown in Figure 6. In the etching step, silicon is etched by $\mathrm{SF}_{6}$ plasma. In the deposition step, the supply gas is switched to $\mathrm{C}_{4} \mathrm{~F}_{8}$ so that a fluorocarbon polymer thin film with a thickness of $10 \mathrm{~nm}$ can be deposited on the side wall of the trench. In the next cycle, the polymer film at the bottom surface of the trench is removed by Ar ion bombardment, while the film at the sidewalls is intact, which can protect the sidewalls from the attack of the $\mathrm{SF}_{6}$. Usually, the etching rate of Bosch process ranges from 1 to $12 \mu \mathrm{m} / \mathrm{min}$. In the second approach, i.e. the cryogenic process, the substrate is cooled down to -110 to $195{ }^{\circ} \mathrm{C}$ with liquid Helium. The cryogenic temperatures allow reactant gas such as $\mathrm{SF}_{6}$ or $\mathrm{O}_{2}$ to condense on the trench surface. The condensed film can protect the side-wall, while the condensed film on the bottom can be removed by the ion bombardment. The exposed bottom wall can be further etched into the substrate, as shown in Figure 7.
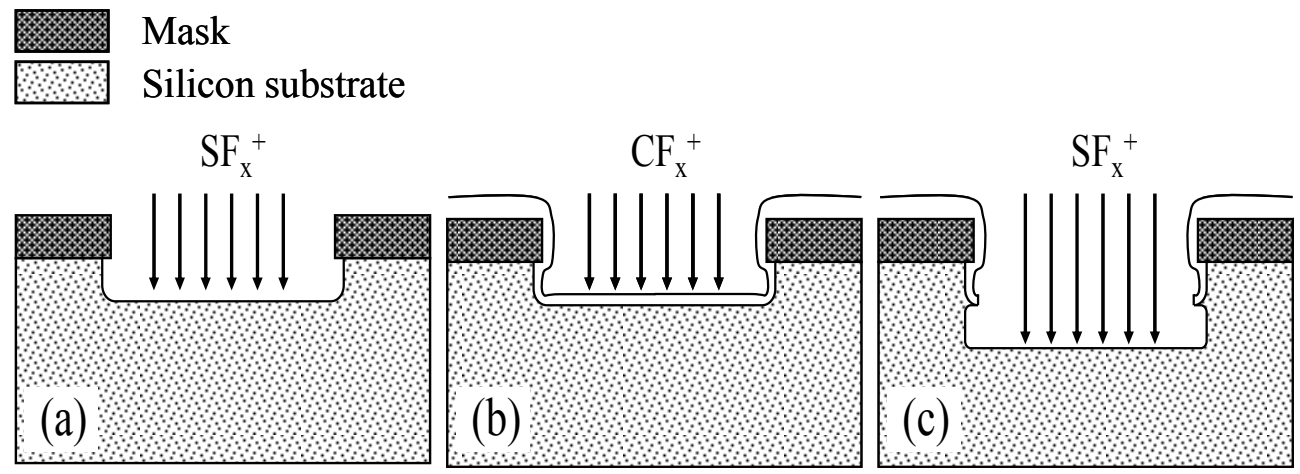

Fig. 6. Anisotropic dry etching: Bosch process. (a) $\mathrm{SF}_{\mathrm{x}}{ }^{+}$etching, (b) $\mathrm{CF}_{\mathrm{x}}{ }^{+}$deposition and (c) $\mathrm{SF}_{\mathrm{x}}{ }^{+}$etching. 
Mask
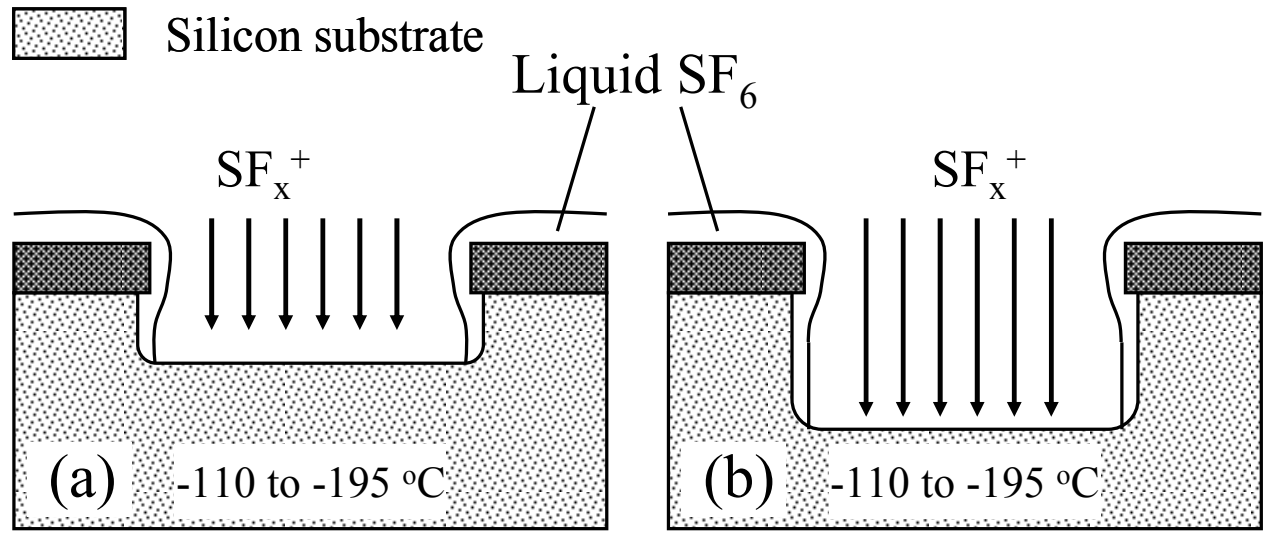

Fig. 7. Anisotropic dry etching: cryogenic process.

\subsection{Doping}

Doping is probably the best known semiconductor technique. Here, doping atoms are introduced into a silicon substrate in a defined way so that either n-type or p-type semiconductor layer can be formed. The techniques play an important role in fabrication of semiconductor devices. In addition to varying the electrical properties, doping can also improve wear and corrosion of a semiconductor material. The doping atoms, like boron or phosphorous, can create an etching stop layer in a silicon substrate, allowing fabrication of a thin film or microstructure at desired locations by wet etch when doping atoms can be placed in the desired location.

\subsubsection{Ion implantation}

Ion implantation is one of the most expensive technology processes, after photolithography, due to the complex systems involved. Ion implantation involves shooting charged ions, which are externally accelerated in a vacuum, into the silicon wafer. The ions can penetrate up to a few micrometers below the surface. The silicon disc is irradiated uniformly with scanning focused ion beam. By measuring the beam current, the amount of dopant implanted can be precisely controlled. In addition, the doping concentration obtained has improved homogeneity, the doping parameters can be easily adjusted, and the doping profile under the wafer's surface can be accurately controlled.

An ion implantation process usually includes the initial ion implantation and the following thermal annealing process. For example, after dopants are implanted into the central portion of a LPCVD polysilicon layer, the implanted layer requires annealing at $950{ }^{\circ} \mathrm{C}$ for 30 minutes in a standard anneal furnace to re-crystallize the polysilicon layer and to diffuse the dopants uniformly across the layer (Ko et al., 2007; Liu, 2004; Qu et al., 2003). After annealing process, the doped polysilicon layer can be patterned. The variation of the resistivity of the doped LPCVD polysilicon with the boron concentration is shown in Figure 8. This empirical data can be used to design arrays of polysilicon sensors or heaters integrated with the microchannel system. 


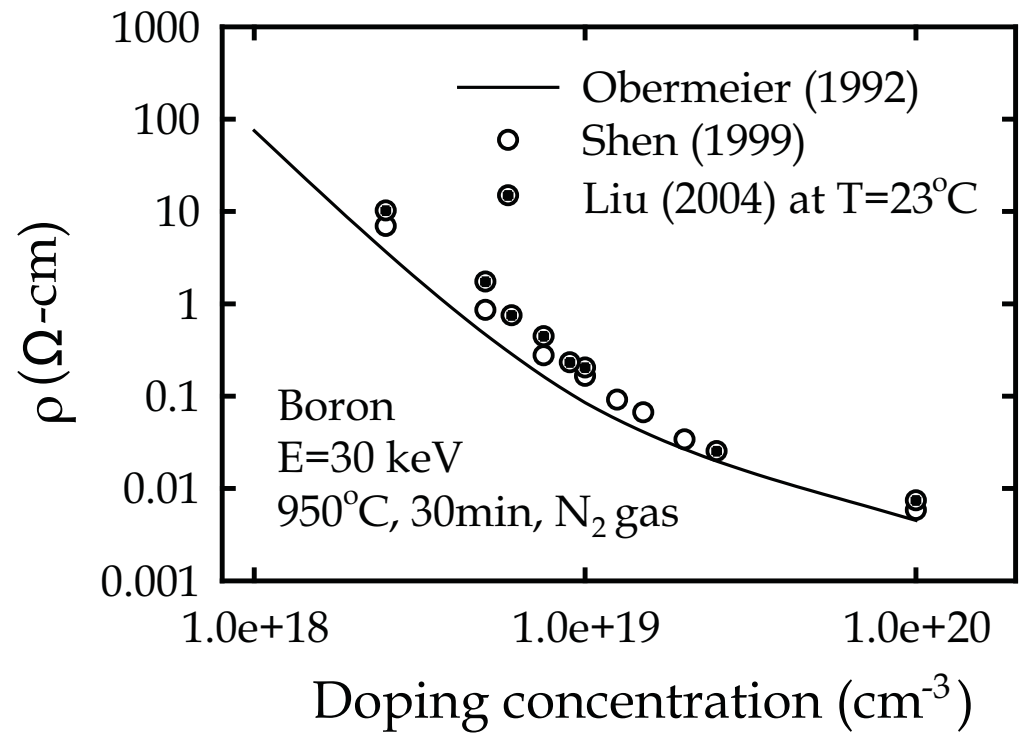

Fig. 8. The resistivity of boron-doped LPCVD polysilicon at different boron concentrations.

\subsubsection{Dopant diffusion}

In the diffusion method, silicon wafers are put into a furnace under a high temperature range from 850 to $1050{ }^{\circ} \mathrm{C}$, where dopant can be thermally diffused into the substrate. The sources of dopants can be either gases, liquids or solids. The solid dopant source can be BN, As2O3, $\mathrm{P} 2 \mathrm{O} 5$, the liquid dopant source can $\mathrm{BBr} 3, \mathrm{AsCl} 3, \mathrm{POCl} 3$ while the gas dopant source can be $\mathrm{B} 2 \mathrm{H} 6, \mathrm{AsH} 3, \mathrm{PH} 3$. However, the liquid dopant sources are the most frequently used. More detailed description can be found in the ref. (Sze, 2002). However, either of them has to be vaporized first and then the vapor can diffuse into the silicon substrate and form covalent bonding with the silicon lattice atoms. The main difficulty is the determination of the amount of dopant diffused into the substrate and the concentration of the doping atoms bonded in the silicon. Despite of the low cost, the method can only make a doping profile on the surface of a wafer, which restrains the wide applicability of this technique.

\section{Fabrication of microchannel by MEMS techniques}

\subsection{Silicon based microchannel fabrication \\ 5.1.1 Bulk micromachining process}

Either isotropic or anisotropic etch process can be used to fabricate microchannels in a bulk material, such as a silicon or a glass substrate. A channel with a variety of cross-sectional shapes can be made by different etch processes, as shown in Figure 9. Different microchannels can be formed by either anisotropic etch of the $\{100\}$ or $\{110\}$ silicon wafers or by isotropic etch of silicon or glass substrate, respectively. Finally, either anodic or fusion bonding can be employed to bond and enclose the channels with a glass plate or a silicon wafer. 
(a)

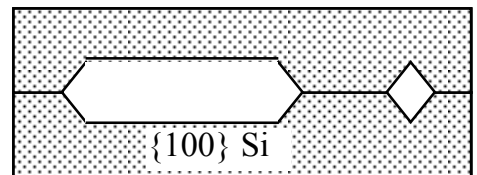

(b)

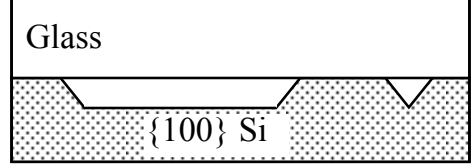

(c)

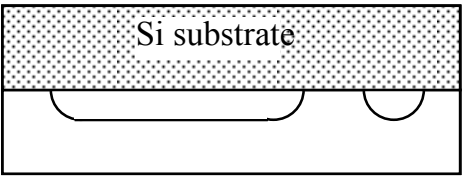

(d)

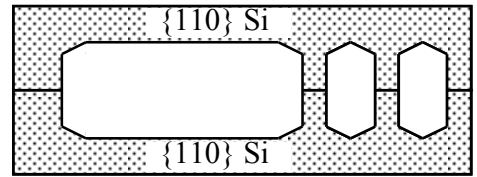

(e)

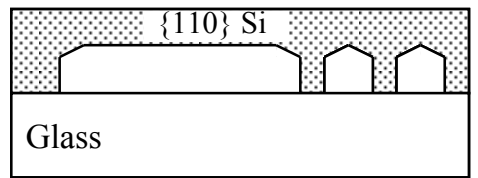

(f)

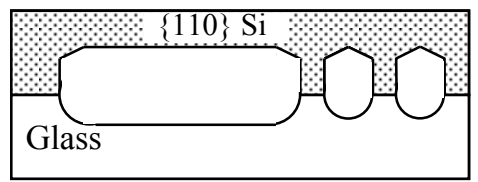

$(\mathrm{g})$

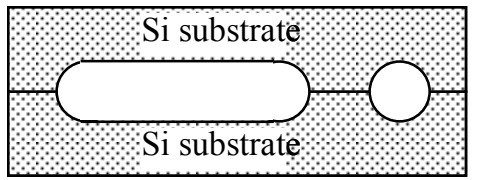

(h)

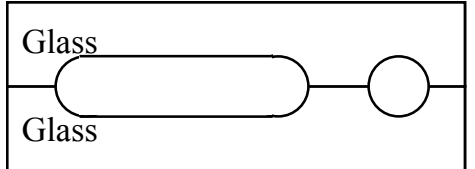

Fig. 9. Different microchannels made by bonding of bulk micromachined substrates in: (a) silicon-silicon, (b) glass-silicon, (c) silicon-glass, (d) silicon-silicon, (e) silicon-glass, (f) silicon-glass, (g) silicon-silicon, and (h) glass-glass.

\subsubsection{Surface micromachining process}

The surface micromachining is originated for deposition and patterning of thin layers into different structures, which may possibly use sacrificial layers to form microstructures. In this section, surface micromachining processes combined with deposition and etch of a polysilicon layer and the use of a sacrificial layer can be used to fabricate a microchannel. The fabrication process is described as follows:

1. Deposit and pattern the sacrificial layer, as shown in Figure 10(a).

2. Deposit and pattern the polysilicon layer as a microstructure, as shown in Figure 10(b).

3. Remove the sacrificial layer, followed by rinsing and drying the microstructure, as shown in Figure 10(c).

4. Seal the microstructure, as shown in Figure 10(d).

However, by using the surface micromachining the maximum height of the channel allowed for fabrication is only within a few micrometers ( 1 to $2 \mu \mathrm{m})$ due to the limitation of CVD deposition for the sacrificial layer. In comparison with the bulk micromachining process, the channel fabricated by the bulk micromachining process can be as large as a few hundred micrometers in height.

\subsection{Polymer based microchannel fabrication}

\subsubsection{SU-8 resist}

Photolithography of a thick resist is very beneficial for fabrication of a complicated microchannel system. Microchannel system can employ thick resists directly as a channel 


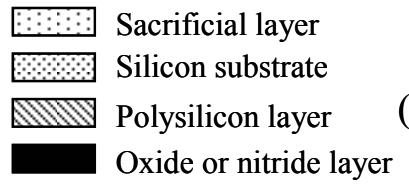

(a)

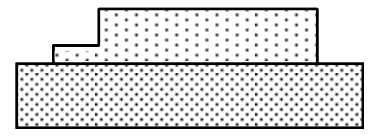

(b)

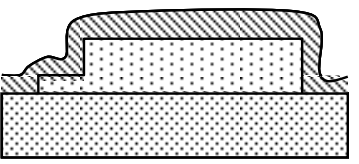

(c)

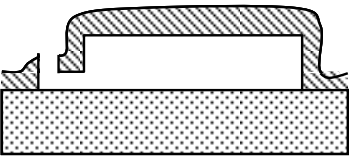

(d)

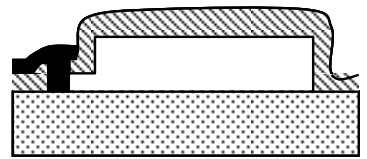

Fig. 10. The use of surface micromachining process to fabricate a channel with the use of a sacrificial layer.

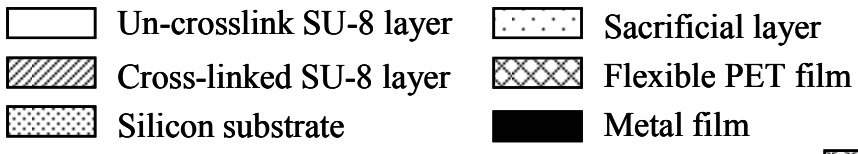

(1)

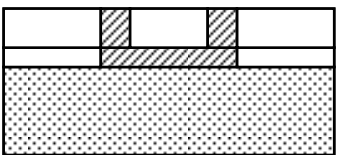

(1)

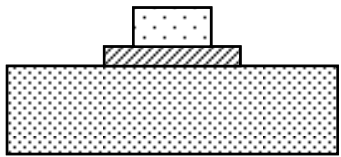

(2)

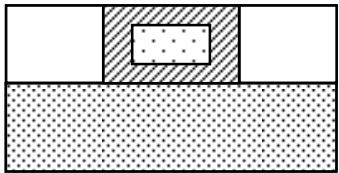

(3)

(b)
(2)

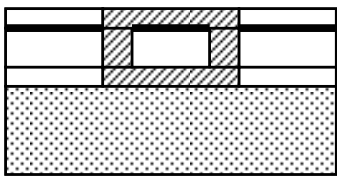

(3)

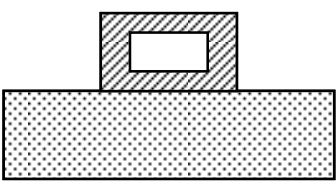

(a)

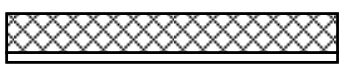

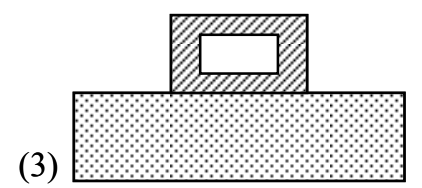

(3)

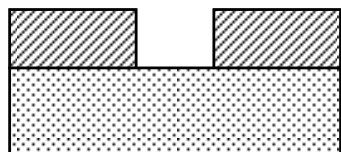

(2)
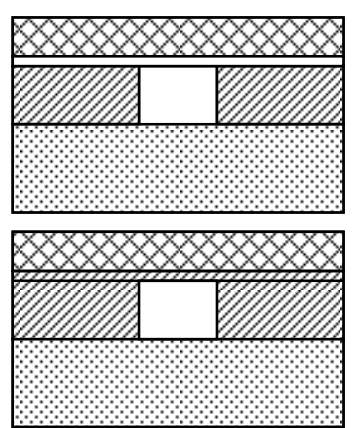

(c)

Fig. 11. Fabrication of SU-8 based microchannels with: (a) embedded metal mask, (b) removal of sacrificial layer and (c) direct use of the fusion bonding by SU-8. 
structure or a template for channel molding or electroplating of metal to form a channel with high aspect ratios. The most popular thick photoresist used is EPON SU-8 epoxy resin which is a negative and transparent PR and can form a layer with a thickness from less than $1 \mu \mathrm{m}$ to few $\mathrm{mm}$. The SU-8 appears to be the most suitable one since it can be readily spin coated on the substrate at desired thickness, and patterned into required shape of channel by photolithography. Therefore, different sizes and shapes of channel can be readily made. However, the use of SU-8 layer as part of the substrate has precluded any high temperature fabrication process since the material cannot withstand processing temperature higher than 200 oC. The formation of a SU-8 channel structure should be at a low temperature process. In many microfluidics applications, a single SU-8 layer can be used to form desired number of microchannels that may be integrated with arrays of microfluidic components or sensors. The top and bottom of the channels can be sealed with a SU-8 coated glass or plastic plate, using subsequent blanket exposure as shown in Figure 11.

\subsubsection{PDMS molding}

Poly-dimethylsiloxane (PDMS) is an excellent bio-compatible and an elastomeric polymer material, which is frequently used for applications in $\mu$ TAS (micro total analysis system) or lab-on-a-chip systems. This is attributed to a number of useful properties of this material, such as low cost, low toxic, transparent from visible into near ultraviolet in wavelengths and chemical inertness.

- PDMS $\square$ Glass

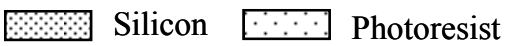

(1)

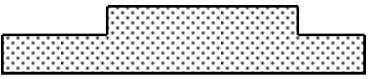

(2)

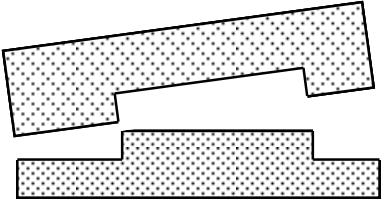

(3)

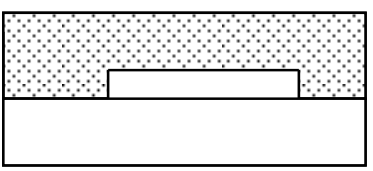

(a)
(1)

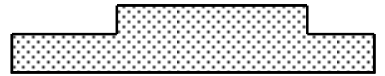

(2)

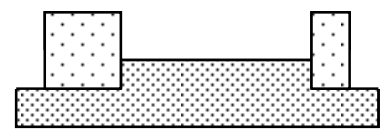

(3)

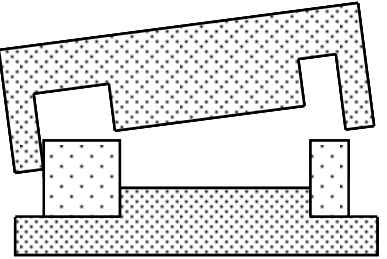

(4)

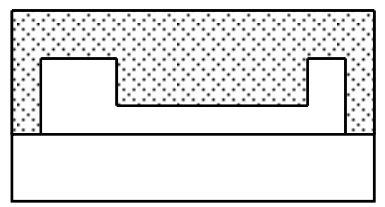

(b)

Fig. 12. Fabrication process for a (a) one-staged or (b) two-staged PDMS microchannels. 
PDMS is made by mixing different prepolymers. The weight ratio of the base and the curing agent can be 10:1 or 5:1. Then, the PDMS mixture is poured into a master and stays for a few minutes to self-level. The whole set is then cured at a low temperature in the range from 60 to $80{ }^{\circ} \mathrm{C}$ for several hours. After peeling off, the structured PDMS membrane is bonded with the other substrates such as silicon, glass, plastic plate or PDMS plate etc. to complete the channels. Due to its simplicity in fabrication and rapid prototyping, PDMS molding is also called microcasting, which is a direct transfer of patterns. In many applications, the elastomeric PDMS can be used directly as a microfluidic device with microchannel connecting different components. Fabrication of PDMS into a microcannel is described as follows:

1. Etch the silicon or glass master, as shown in Figure 12(a-1).

2. Molding the PDMS microstructures, as shown in Figure 12(a-2).

3. Seal and laminate the PDMS microstructures, as shown in Figure 12(a-3).

\subsubsection{Parylene}

Parylene is a polymer that can be deposited by a CVD process at a low or room temperature. The CVD process allows coating a conformal film with a thickness ranging from several

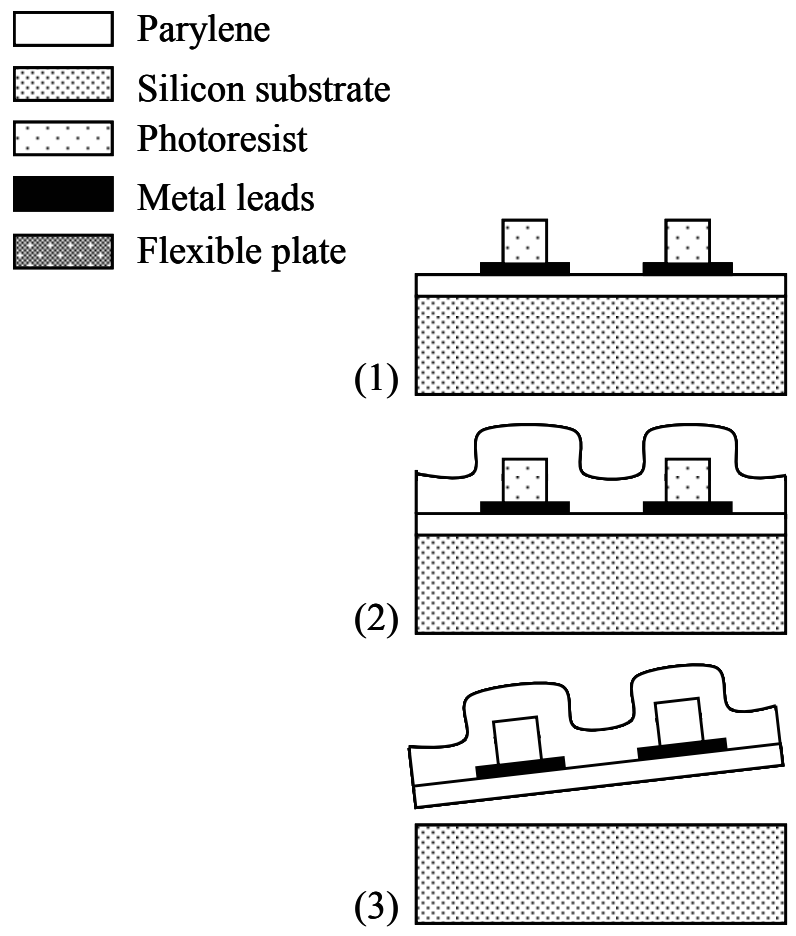

(a)
(1)

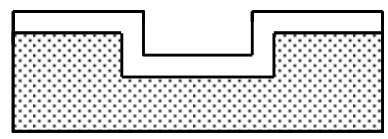

(2)

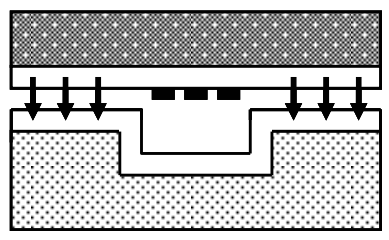

(3)

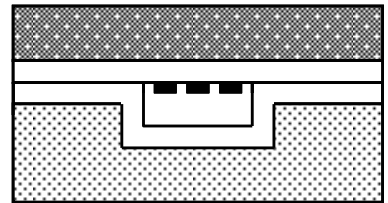

(4)

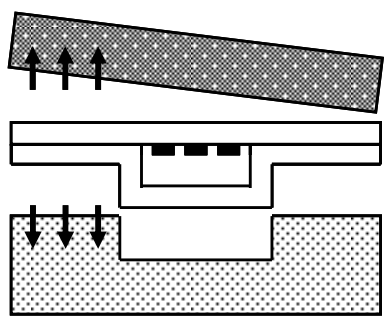

(b)

Fig. 13. Fabrication of Parylene based microchannels with: (a) removal of the sacrificial layer and (b) direct fusion bonding using Parylene. 
micros to several millimeters. The basic types of Parylenes are Parylene N, C and D, all of which have good dielectric, electrical, physical and hydrophobic properties. However, Parylene D is modified from the same monomer by the substitution of the chlorine atom with two of the aromatic hydrogens. Parylene D is similar in properties to Parylens C, but with an additional property to withstand higher temperature. Deposition rates are fast, especially for Parylene $C$, which is normally deposited at a rate of about $10 \mu \mathrm{m} / \mathrm{min}$. The deposition rates of Parylene $\mathrm{N}$ and Parylene D are slower. Parylene can be used in microfluidic devices as a structural material, which has a very low Young's modulus. Fabrication of microchannel using Parylene is described as follows:

1. Deposit a Parylene base on a provisional substrate, as shown in Figure 13(a-1).

2. Deposit and pattern a sacrificial layer on the Parylene base, as shown in Figure 13(a-2).

3. After Secondary deposition of a Parylene film on the top, then remove the sacrificial layer, as shown in Figure 13(a-3).

\section{Microsensors for pressure and temperature measurements}

\subsection{Miniaturized temperature sensors and heaters 6.1.1 Working principles}

When the polysilicon is doped heavily with boron, a relatively low resistivity that is independent of temperature can be obtained. This heavily doped polysilicon layer can be used as a heater. However, when the polysilicon is doped with a less amount of boron, a linear relationship between the resistivity and the temperature of the layer can be obtained and this doped polysilicon layer can be used as a temperature sensor. The temperature variation of the resistivity for the doped polysilicon layer at different concentrations has been demonstrated (Ko et al., 2007; Liu, 2004; Qu et al., 2003). Shen proposed that the resistance change with temperature is slightly nonlinear at low boron concentration. The temperature coefficient of the resistance (TCR) of the doped polysilicon layer is negative over the range covered and the temperature dependence increases with decreasing doping concentration, as shown in Figure 14 made by Shen (2003). It appears that for the boron concentration of $10^{20}$ atoms $/ \mathrm{cm}^{3}$, the resistivity of the doped polysilicon layer is almost independent of temperature with a near zero TCR. The polysilicon doped at this concentration can be used as a heater which can provide a constant heating power for a long period of operation. Otherwise, for the boron concentration at $10^{19}$ atoms $/ \mathrm{cm}^{3}$, the resistivity of the doped polysilicon layer has a linear relationship with temperatures. Therefore, the polysilicon doped at this concentration can be used as a temperature sensor. All the temperature sensors and heaters required and made in a microchannel system should be based on different doping conditions of the concentrations described above.

\subsubsection{Design consideration}

The total resistance of a device is proportional not only to the resistivity $(\rho)$ and thickness $(t)$ of the doped polysilicon layer, but also to the ratio of $l_{R} / w_{R}$, i.e. shape effect. The definition of resistance is written as follows:

$$
R=(\rho / t) \cdot\left(l_{R} / w_{R}\right)=R_{S} \cdot\left(l_{R} / w_{R}\right)
$$

where $R_{S}=(\rho / t)$ is called the sheet resistance of the material. $l_{R}$ and $w_{R}$ are the length and the width of the resistor, respectively. 


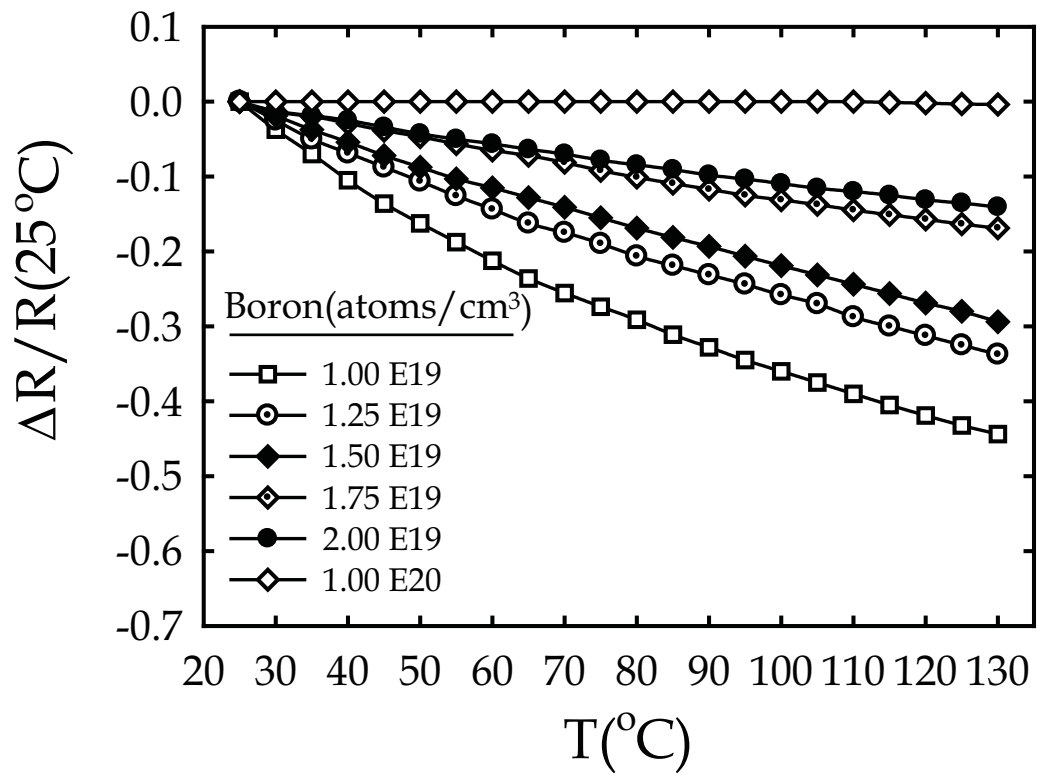

Fig. 14. The relative resistance variation with temperature at different concentrations of boron doped in polysilicon (Shen, 2003).

The TCR, $a$, is defined as follows:

$$
\begin{gathered}
\alpha=\left(\Delta R / R_{o}\right) / \Delta T=\Delta R /\left(R_{o} \cdot \Delta T\right) \\
\Delta R=R-R_{o} \\
\Delta T=T-T_{o}
\end{gathered}
$$

where $R_{o}$ is the resistance of the material at a reference temperature. $R$ is the resistance of the material measured at certain temperature. The zero TCR means that the $\Delta R$ is near zero and the resistance of the material is constant within the range of the temperatures measured.

The resolution $\left(\mathrm{R}_{\text {esoul. }}\right.$ ) of temperature sensor is defined as follows:

$$
R_{\text {esoul. }}=\Delta R /\left(R_{o} \cdot \Delta T\right) \times R
$$

For example, the size of temperature sensor designed is $80 \mu \mathrm{m} \times 20 \mu \mathrm{m} \times 0.4 \mu \mathrm{m}$ in length, width and thickness, respectively. The material used as the sensor is polysilicon. The concentration of boron used for doping is $10^{19}$ atoms $/ \mathrm{cm}^{3}$. The $\rho$ is found to be $0.2034 \Omega-\mathrm{cm}$, as shown in Figure 8. After a calculation, the sheet resistance $\left(R_{S}\right)$, total resistance $(R)$ and TCR of temperature sensor are $5.085 \times 10^{3} \Omega$ /squ., $20.34 \mathrm{k} \Omega$ at $23 \mathrm{oC}$ and $-4.286 \times 10^{-3}$ /oC. Therefore, the resolution of the polysilicon sensor can be calculated and is found to be -87.18 $\Omega /$ oC. It appears that the resolution of the temperature sensor made by the doped polysilicon is much better than any types of the thermocouples. 


\subsubsection{Fabrication processes (Ko et al., 2007, 2009; Liu,2004)}

1. A $0.3 \mu \mathrm{m}$ thick LPCVD tetraethoxysilane (TEOS) oxide is deposited on the (100) wafer as a insulation layer between sensors to silicon substrate.

2. Then, a $0.3 \mu \mathrm{m}$ thick LPCVD polysilicon film is deposited and then implanted heavily with boron with a dose of $3 \times 10^{15}$ atoms $/ \mathrm{cm}^{2}$. This amount of dosage corresponds to a concentration of $10^{20}$ atoms $/ \mathrm{cm}^{3}$ in the layer. After annealing at $950 \circ \mathrm{C}$ for 30 minutes, the doped polysilicon is patterned as the heaters. In this doping concentration, the TCR of resistors are near zero, as shown in Figure 15(a).

3. Next, after a deposition of a $0.3 \mu \mathrm{m}$ thick LPCVD TEOS layer as insulation, the temperature sensors were made by depositing a $0.3 \mu \mathrm{m}$ thick LPCVD polysilicon layer and then implanting with boron ions with a dose of $3 \times 10^{14}$ atoms $/ \mathrm{cm}^{2}$. This amount of dosage corresponds to a concentration of $10^{19}$ atoms $/ \mathrm{cm}^{3}$ in the layer. After annealing at $950{ }^{\circ} \mathrm{C}$ for 30 minutes to re-crystallize the polysilicon layer and to uniformly diffuse the dopant ions across the layer, the doped polysilicon was patterned. The concentration of $10^{19}$ atoms $/ \mathrm{cm}^{2}$ will give a linear relationship between the resistance and the temperature of the doped polysicon layer. Thus, after proper calibration, the doped polysilicon layer can be used as temperature sensors, as shown in Figure 15(b).

4. Before metallization, a $0.3 \mu \mathrm{m}$ thick LPCVD TEOS oxide is deposited as insulation. Then, contact holes were opened in this layer for metallization. The metallization was made by sputtering standard IC four layers of metals, i.e. Ti/TiN/Al-Si-Cu/TiN with a thickness of $0.04 \mu \mathrm{m} / 0.1 \mu \mathrm{m} / 0.9 \mu \mathrm{m} / 0.04 \mu \mathrm{m}$, respectively, onto the substrate surface. The metal layers were then patterned into circuits, as shown in Figure 15(c).

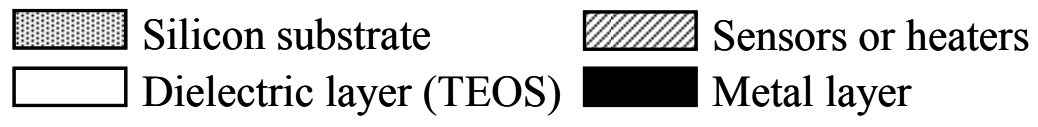

(a)

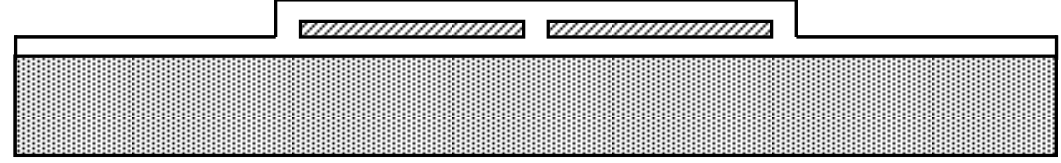

(b)

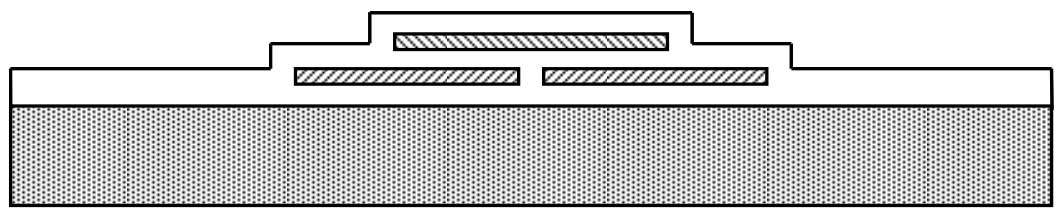

(c)

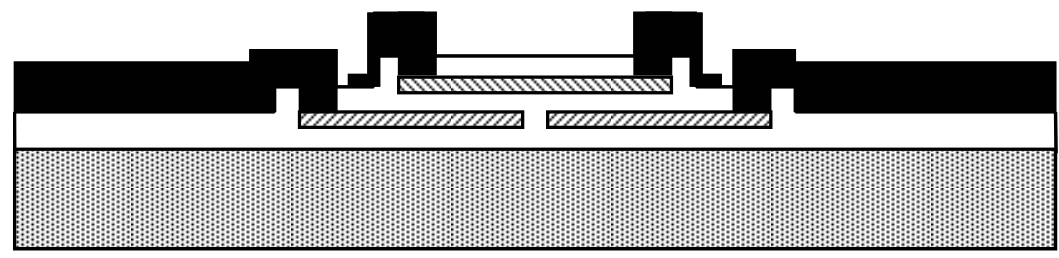

Fig. 15. Fabrication process of temperature sensor and heater (Ko et al., 2007; Liu, 2004). 


\subsubsection{Characteristics of temperature sensors and heaters}

All the temperature sensors and the heater fabricated on the silicon substrate have to be calibrated in a constant temperature oven to ensure a measurement accuracy of $\pm 0.1^{\circ} \mathrm{C}$. In fact, all the temperature sensors and the heaters can be moved onto a glass substrate for other purpose. The procedure to move all the sensors and heaters onto a glass substrate will be described in section 6.2 or 7.2. In that case, the substrate now is a very low thermal conductivity material, it is difficult for the heat in the oven to conduct into the substrate, especially in the region for the channel formation, and to provide a uniform and constant temperature condition required for the calibration. Therefore, the calibration procedure will take a much longer time than the case with silicon substrate. The electric resistance measured in the doped polysilicon layer at various boron concentrations and temperatures is compared with the published data (Ko et al., 2007; Liu, 2004), as shown in Figure 16. It is found that the resistance in the current work for the concentration at $10^{20}$ atoms $/ \mathrm{cm}^{3}$ agrees well with the published results. However, the data for the current case with the concentration at $10^{19}$ atoms $/ \mathrm{cm}^{3}$ is slightly different from other work, as indicated by the red circle as shown in Figure 16. This difference is attributed to the use of different implantation equipments from different companies, and the batch deposition of LPCVD polysilicon layer with a 5-10\% uniformity can occur in a single wafer or from wafer to wafer. The characteristic curves of the polysilicon temperature sensor and the heater used in the present channel system are also shown in Figure 17 (Liu, 2004). It is found that the output signal of the temperature sensor has a linear relation with the temperatures and a high resolution of $1.26 \mathrm{~K} \Omega /{ }^{\circ} \mathrm{C}$. Therefore, this can provide a very accurate measurement in the temperature. In addition, the resistance of the heater does not vary with the temperature. This can readily provide a uniform and constant heating power required in the experiments.

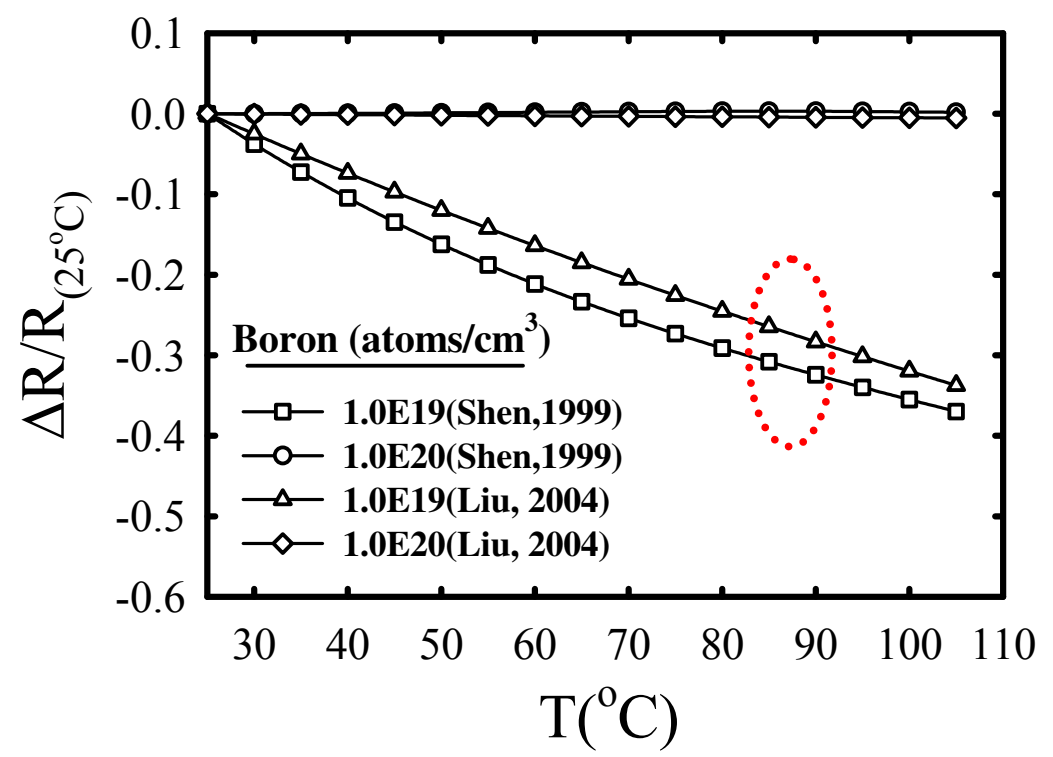

Fig. 16. Comparison of the resistance variation with temperatures between works for the polysilicon doped at different concentrations (Ko et al., 2007; Liu, 2004). 


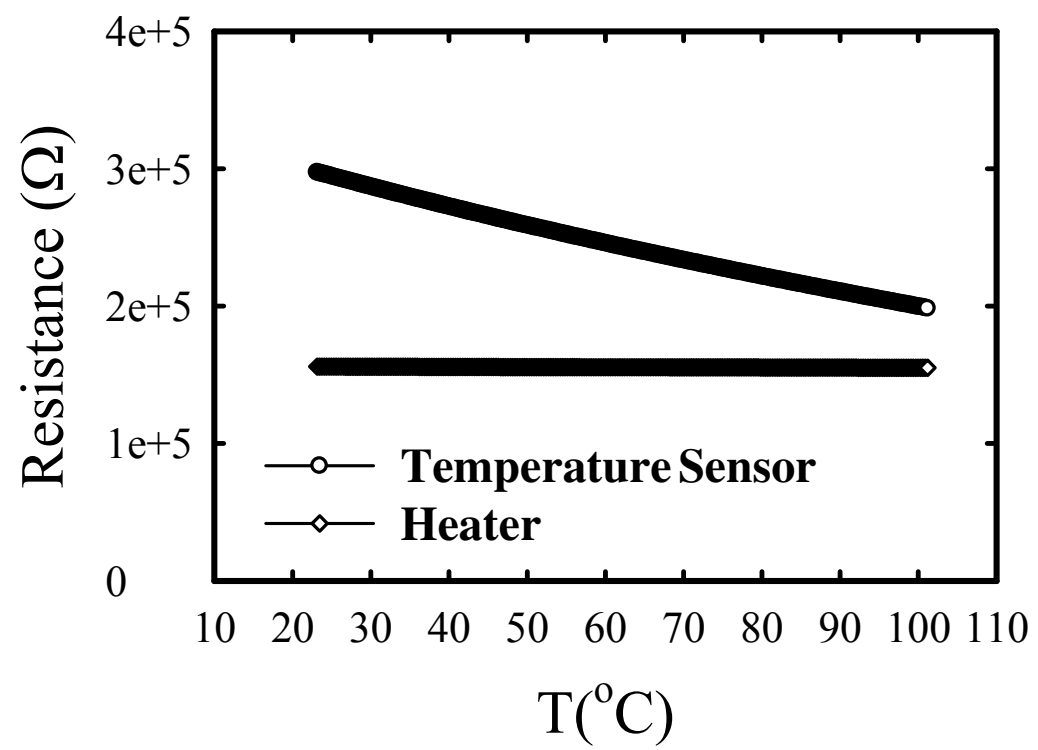

Fig. 17. Characteristic curves of the polysilicon temperature sensor and the heater that can be used in the present channel system (Liu, 2004).

\subsection{Miniaturized pressure sensors \\ 6.2.1 Working principles}

Fabrication process of the micro pressure sensor has attracted much attention due to its wide industrial applications in various areas (Sze, 1994). In general, fabrication of pressure sensor adopts inorganic materials, e.g. piezoresistive sensor which is fabricated on a silicon substrate. Fabrication of these kinds of piezoresistive pressure sensors can be classified into bulk (Sze, 1994; Peake et al., 1969; Tufte et al., 1962) and surface (Guckel, 1991; Sugiyama et al., 1991; Clark et al., 1979) micromachining process. In the conventional designs of pressure sensor, both the bulk and the surface micromachining can be used. For the bulk micromachining technique, $\mathrm{KOH}$ solution is usually used to etch into the silicon substrate to form cavities, allowing for diaphragm deformation, in trapezoid shape with a 54.70 inclined wall. Since the silicon substrate is relatively thick and the bottom region consumed is much larger than the top region where pressure diaphragm defines. The number of sensors per wafer fabricated with bulk micromachining is much less than that fabricated with surface micromachining. Fortunately, this sensor is readily made and the yield of sensor is very high.

For the surface micromachining process, however, the number of sensors per wafer fabricated is much higher due to the fact that much smaller size of cavities for the pressure sensors can be made. However, the height of the cavities which allows deformation of diaphragm is made much smaller due to the use of sacrificial layer for later formation of the diaphragm. The sacrificial layer is deposited by chemical vapor deposition (CVD) process, which is relatively thin and is usually less than $2-3 \mu \mathrm{m}$. This has limited the height of the cavity defined by the sacrificial layer. Therefore, the pressure measurement range for the sensor made by the surface micromachining is much narrow. In addition, stiction of 
diaphragm can readily occur in the drying of DI water rinse process after removal of the sacrificial tetraethyl orthosilicate (TEOS) or phosphorus silicate glass (PSG) oxide. Special attention should be made to avoid the problem of stiction (Kim et al., 1998; Komvopoulos, 1996; Core et al., 1993; Legtenberg et al., 1993). In addition, the height of the cavity cannot be made large enough which will not give enough space for diaphragm deformation and allow the pressure measurement in a wider range. This is attributed to the use of sacrificial material, such as silicon oxide, that cannot be deposited thick enough by the CVD process.

In view of the disadvantages of the inorganic pressure sensor fabricated by bulk or surface micromachining of silicon material, the current work proposes fabrication of pressure sensor with polymer material, such as SU-8. In a review of literature, there are few other polymer materials that were found for fabrication of sensor system (Madou, 2002; Martin et al., 1998; Shirinov et al., 1996). A schematic diagram for a cross-section view of the sensor is shown in Figure 18 where the cavity can be filled with pressurized gas that causes deflection of the diaphragm on the top. All the wall material used, including the diaphragm for the sensor, is SU-8 except for the sensing material and circuit system on the top. The fabrication process presented in this paper can make arrays of pressure sensors and has the advantages of both the bulk and the surface micromachining process. The process can fabricate a greater number of sensors per wafer, and the sensors fabricated allow wider measurement range of pressure. The substrate can be any material. Here we select Pyrex glass. The fabrication process is very simple and the sensor can be readily made by spin coat SU-8 layer and patterning with lithography. In addition, the height of the cavity which allows deformation of diaphragm can be varied readily by spin coat different thickness of the SU-8 layer. Especially, the SU-8 diaphragm is formed without use of sacrificial layer and subsequent DI water rinse processes after removal. Therefore, fabrication process has completely absence of diaphragm stiction and has a much higher yield.

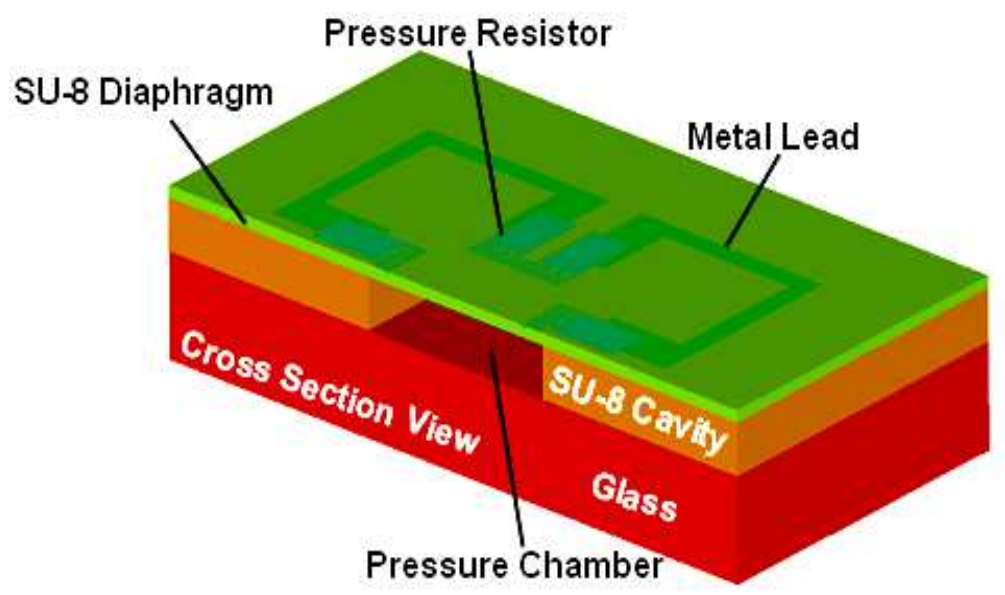

Fig. 18. A schematic diagram for a cross-section view of the pressure sensor designed.

The SU-8 material has been widely used for formation of microfluidic system (Arshak et al., 2006; Ribeiro et al., 2005; Lee et al., 2003), and relatively few in sensor system (Giordani et al., 2007). Therefore, current pressure sensor can also be readily applied and integrated into a microfluidic system or lab-on-chip (Pelletier et al., 2007; Trung et al., 2005; Vilkner et al., 
2004) where pressure information is required. Arrays of current pressure sensors can be readily fabricated along the channel or in a micromixer for more detailed flow information. They can also be fabricated at inlet, outlet or inside of a micropump for evaluation of its performance.

Theoretical modeling for the stress and deformation of the diaphragm is derived. Numerical calculation is provided for diaphragm design consideration. Finally, the current pressure sensors made can provide a much better thermal insulation than the ones made by the previous surface micromachining process of silicon because of the use of the extremely low thermal conductivity materials, such as the SU-8 and the Pyrex glass. The SU-8 material has a thermal conductivity of $0.2 \mathrm{~W} / \mathrm{mK}$ (Monat et al., 2007) where the Pyrex glass has a value of $1.4 \mathrm{~W} / \mathrm{mK}$. This is highly important in the fabrication of a micro thermal system where thermal insulation should be seriously considered. More detailed fabrication techniques and performance evaluation of this sensor are also provided and discussed.

\subsubsection{Design consideration}

Before fabrication process, the size of the SU-8 diaphragm used in the pressure sensor should be determined from a proper analysis and design. The size of the SU-8 diaphragm is actually determined by the pressure range to be measured, the maximum strain that the diaphragm can sustain and the sensitivity required. The deformation of SU-8 diaphragm can be modeled as a square shell or plate with four edge clamped under a uniform normal pressure force as shown in Figure 19.

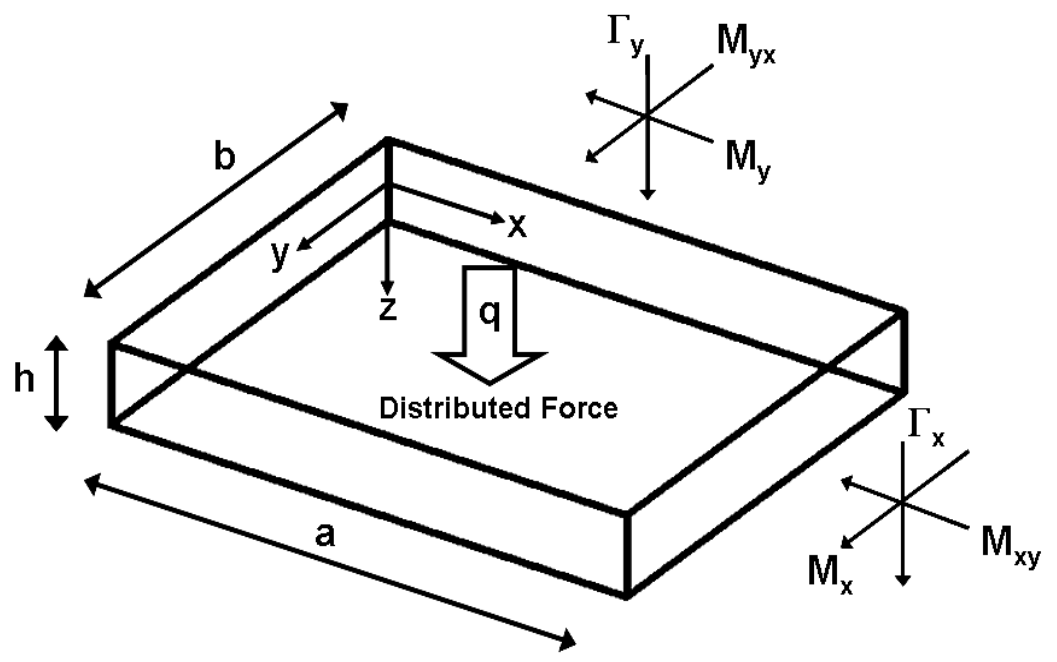

Fig. 19. Schematic diagram for the square plate deformed under pressure force.

From the solving of the governing equation for the deflection of the plate, the deflection of plate can obtain:

$$
u=\frac{q_{n}}{D}\left(\frac{b}{\pi n}\right)^{4} \sum_{n=1,3,5, \ldots}^{\infty} X_{n}(x) \sin \frac{n \pi y}{b}
$$


By letting $n=1,3$ and 5 only, the maximum deflection can be found as follows:

$$
u_{\max }=C\left(1-v^{2}\right) \frac{p b^{4}}{E h^{3}}
$$

where $\mathrm{C}$ is $\frac{0.032}{1+\alpha^{4}}$, with the assumption that all edges of the plate are clamped, and $\alpha$ is ratio of the width to the length of the plate. However, C obtained by Guckel (1990) is 0.0152 . The comparison is shown in Figure 20, which shows that for the diaphragm size of $200 \mu \mathrm{m}$ by $200 \mu \mathrm{m}$ and the thickness of the diaphragm varying from three to thirteen micron, the numerical result from ANSYS calculation agrees very well with the approximate solutions of Westergaard and Guckel, respectively. Therefore, the ANSYS is adopted for calculation in the design for proper size of diaphragm.

For a pressure range from 1 to 4 atms, the prediction for the maximum strain occurred in the plate versus the applied pressure force is presented in Figure 21 for different thickness of diaphragm. The maximum strain the SU-8 layer can sustain is found 0.77\% (Guckel, 1991). Therefore, the rectangle presented in Figure 21 represents the safety region where the maximum strain is less than $0.77 \%$ for the diaphragm size designed. For a better sensitivity, i.e. more deflection, the size of $150 \mu \mathrm{m} \times 150 \mu \mathrm{m}$ wide at a thickness of approximately $9 \mu \mathrm{m}$ is selected.

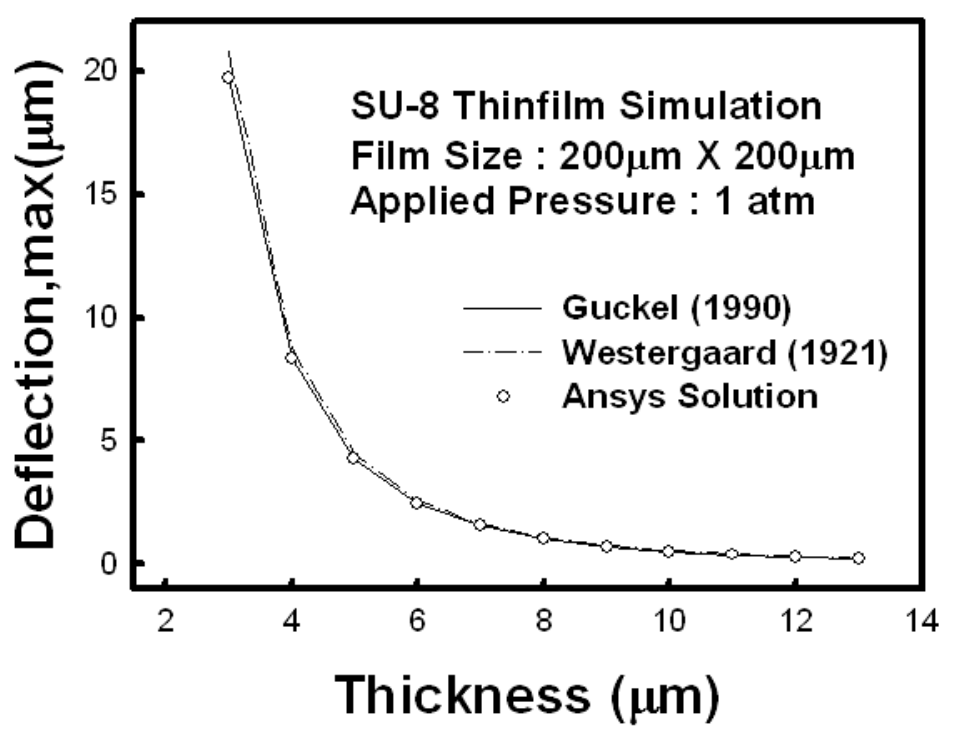

Fig. 20. Comparison of the numerical result from the ANSYS with the analytical results and other published data.

Polymer pressure sensor does not have the problems of narrow depth of cavity and stiction of diaphragm made by surface micromachining method. The most promising candidate for pressure sensor fabrication is the use of the photoresists, i.e. SU-8. The SU-8 can be readily 
spin coated on the substrate from a few microns to a hundred microns thick. This can give us a much deeper cavity depth if diaphragm layer can be properly deposited on the top to enclose the cavity, as shown in Figure 18. The diaphragm designed uses the same material as the cavity side wall in order to reduce difference of the thermal expansion coefficient for the cavity wall and the diaphragm which may cause deflection of diaphragm and significantly affect measurement accuracy. In this way, one would face another problem of selecting suitable sacrificial material to fill into the cavity to create a flat surface in order to spin coat the SU-8 diaphragm on the above. In addition, the sensor material currently available, which is to be deposited on the top of diaphragm, is piezoresistive film that is a doped polysilicon layer deposited by LPCVD at a high temperature process. The use of high temperature process of doped polysilicon for sensor formation has precluded the possible use of SU-8 as both diaphragm and side wall of cavity.
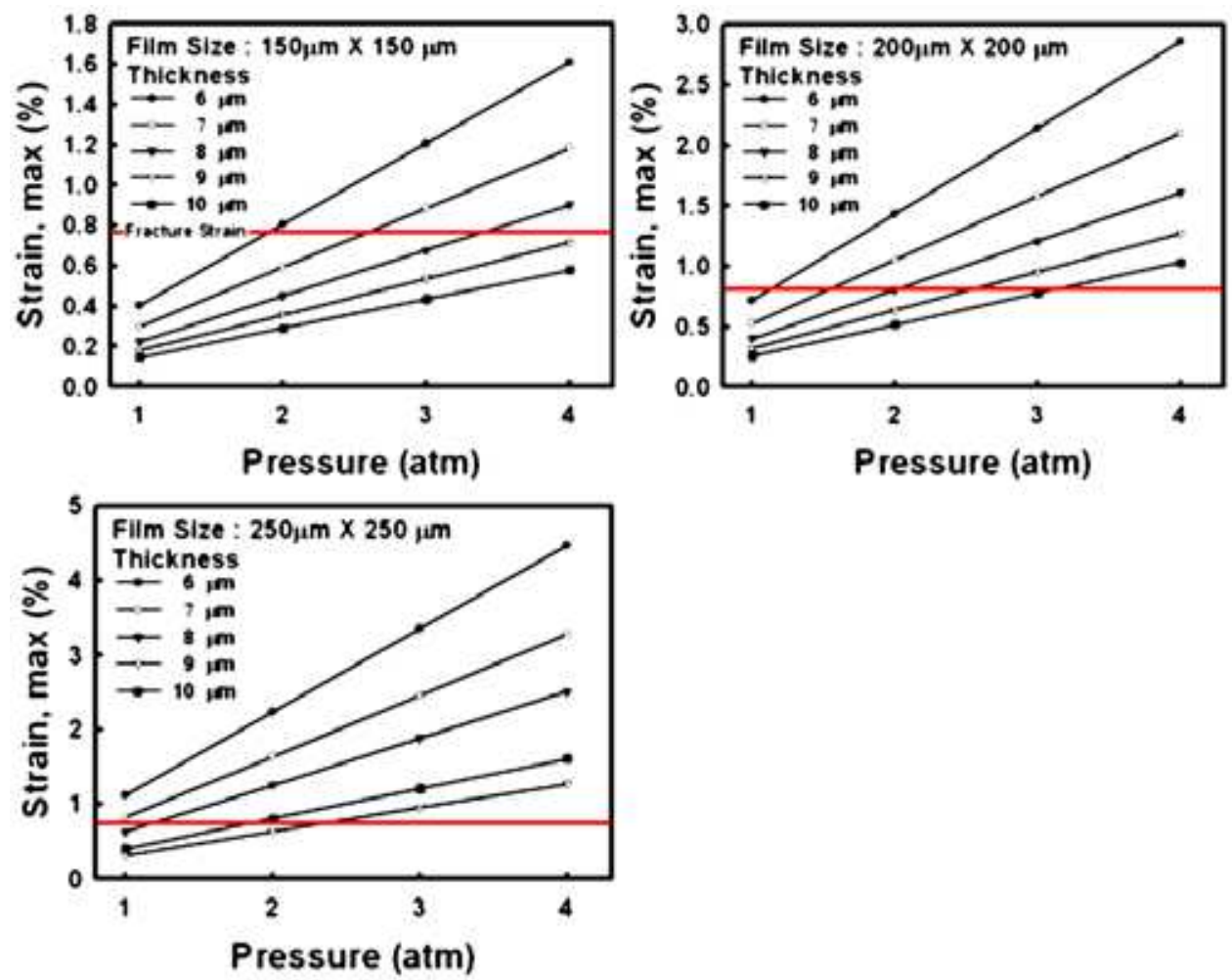

Fig. 21. The maximum strain variation with pressure for different sizes and thicknesses of SU-8 diaphragm.

However, this difficulty can be readily overcome by reversing the fabrication process of the pressure sensor. That is, one can first deposit the the piezoresistive layer and the metal lines on the silicon substrate which is a high temperature process, and then the diaphragm and the cavity wall which is a low temperature process. The piezoresistive layer can be made with the polysilicon layer implanted with very high concentration of boron or phosphorous. 
In the current process, one selects very high concentration of boron such that the resistivity variation with the temperature in the polysilicon layer can be minimized. From the experimental data plotted in (Shen, 2004; Kanda, 1982; Mason, 1969), for boron concentration greater than $10^{20}$ atms $/ \mathrm{cm}^{3}$ the resistivity variation with temperature can be negligible small. Thus, this concentration of boron is adopted in the implantation process for the polysilicon layer. After implantation, the polysilicon is annealed for 30 mins at $950{ }^{\circ} \mathrm{C}$. The next step is to spin coat SU-8 diaphragm, which has the flexibility to readily control the thickness. It is then followed by spin coat another layer of SU-8 for cavity wall at desired thickness. Thus, the formation of SU-8 layer will not go through a high temperature process. Finally, a Pyrex glass can be bonded with the patterned SU-8 layer on the top to enclose the cavities. Once the silicon substrate is completely removed by wet etch, a successful pressure sensors can be readily achieved.

\subsubsection{Fabrication processes (Ko, 2009)}

1. A $0.3 \mu \mathrm{m}$ thick LPCVD TEOS oxide is deposited on the (100) wafer and used as protection mask for the upper layer devices during the later long period of TMAH wet etch to completely remove the $\mathrm{Si}$ wafer.

2. Next, a $0.3 \mu \mathrm{m}$ thick LPCVD polysilicon film is deposited and then implanted heavily with boron with a dose of $3 \times 10^{15}$ atoms $/ \mathrm{cm}^{2}$. This amount of dosage corresponds to a concentration of $10^{20}$ atoms $/ \mathrm{cm}^{3}$ in the layer. After annealing at $950{ }^{\circ} \mathrm{C}$ for 30 minutes, the doped polysilicon is patterned as the pressure sensors.

3. Before metallization, a $0.3 \mu \mathrm{m}$ thick LPCVD TEOS oxide is deposited as insulation. Then, contact holes were opened in this layer for metallization. The metallization was made by sputtering standard IC four layers of metals, i.e. Ti/TiN/Al-Si-Cu/TiN with a thickness of $0.04 \mu \mathrm{m} / 0.1 \mu \mathrm{m} / 0.9 \mu \mathrm{m} / 0.04 \mu \mathrm{m}$, respectively, onto the substrate surface. The metal layers were then patterned into circuits, as shown in Figure 22(a).

4. A $9 \mu \mathrm{m}$ thick SU-8 layer is spin coated on the substrate as the pressure sensing diaphragm. Then, a $50 \mu \mathrm{m}$ thick SU-8 layer is spin coated again on the substrate and patterned into the active cavity to allow for movement of the pressure diaphragm. It is noted that there is a soft bake before layer exposure to evaporate the solvent and a post exposure bake to make the edge between the exposed and unexposed region more sharp and clear. Finally, instead of using the hard bake, a high intensity of light is used to illuminate to complete the cross-linking of the resin since the hard bake will need a temperature at $200 \circ \mathrm{C}$ that will damage the underneath thick epoxy layer. For the soft bake, the SU-8 layer is first maintained at $65{ }^{\circ} \mathrm{C}$ for 7 minutes with a $5{ }^{\circ} \mathrm{C} /$ minute ramping rate starting from room temperature, and then baked at $95{ }^{\circ} \mathrm{C}$ for 15 minutes with a $5 \circ \mathrm{C} /$ minute ramping rate starting from $65{ }^{\circ} \mathrm{C}$ to release the internal residual stress of SU-8 thick layer. In fact, the success of the SU-8 channel strongly depends on the baking process after light exposure.

5. It is now ready to move the devices made on the $\mathrm{Si}$ wafer onto a low thermal conductivity Pyrex glass. This is done first by bonding the silicon wafer with the Pyrex glass, as shown in Figure 22(b).

6. After the bonding process, the silicon substrate is ready for removal and cleared off. This is done by wet etch the silicon with TMAH solution at $90{ }^{\circ} \mathrm{C}$ for $5-6$ hours. Instead of using $\mathrm{KOH}$, the selection of TMAH is attributed to its relatively high selectivity for silicon versus oxide. This can avoid the sensors attacked by the etchant during the long period of wet etch process since the protection layer of the sensors are made of TEOS 
oxide. A successful movement of the pressure sensors onto the Pyrex glass substrate is shown in Figure 23(a). The cavities of the pressure sensors are successfully made, as shown in Figure 23(b). No distortion was found.

7. Next, a $80 \mu \mathrm{m}$ thick SU-8 layer is spin coated on the substrate and patterned by lithography to form a test section for the pressurized gas.

8. A PMMA plate is then bonded, using epoxy resin, to enclose the test section, as shown in Figure 22(c). The pressure sensor is completed.

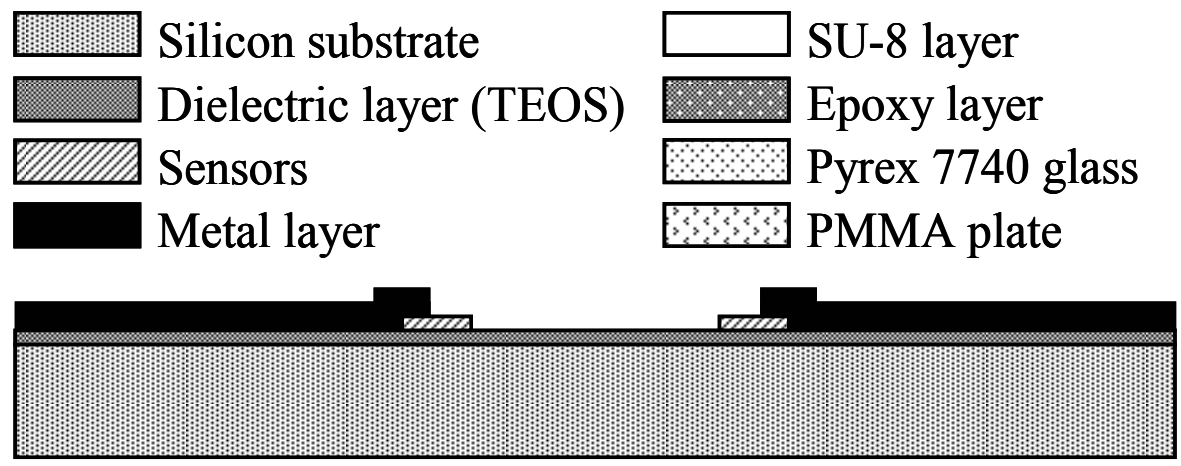

(a)

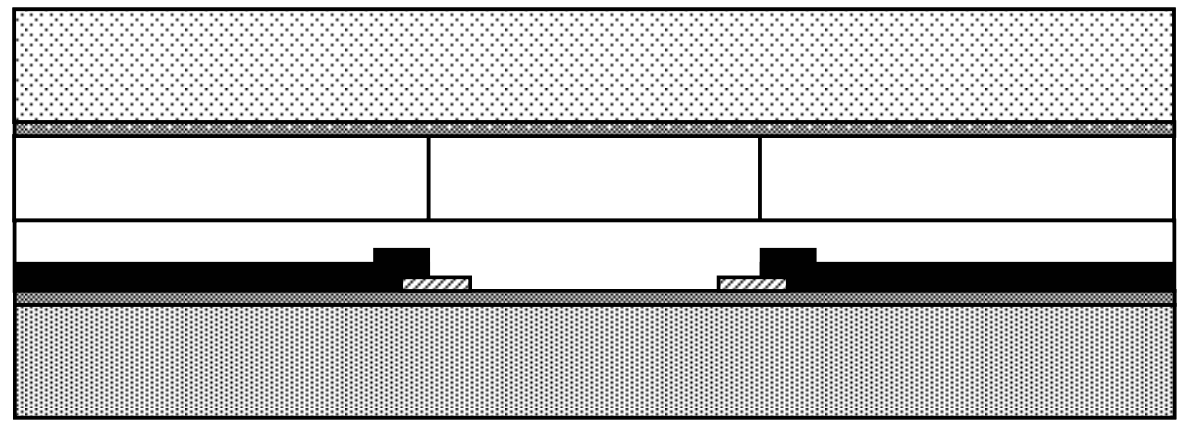

(b)

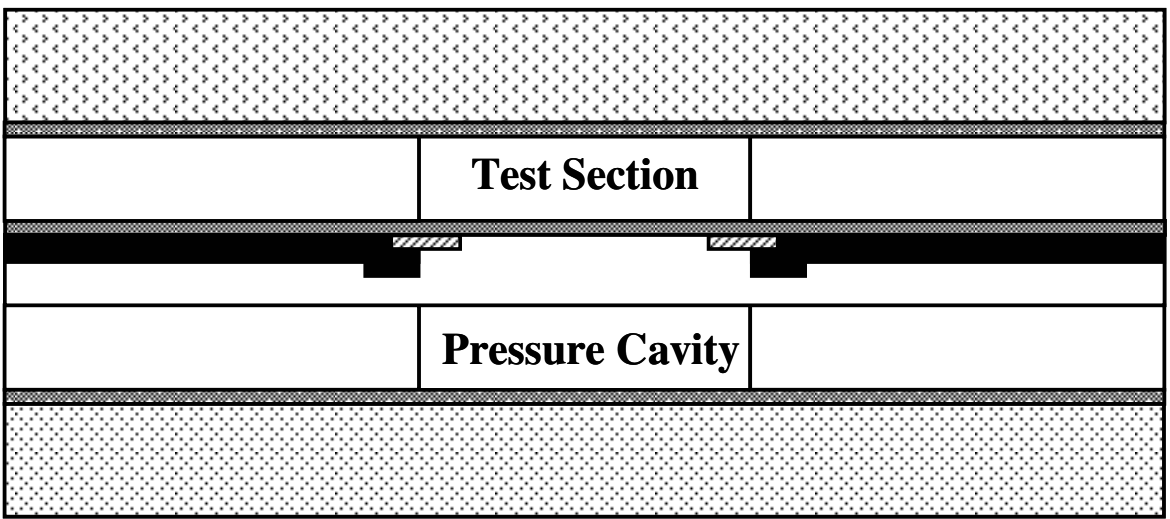

(c)

Fig. 22. Fabrication process of pressure sensor (Ko, 2009). 


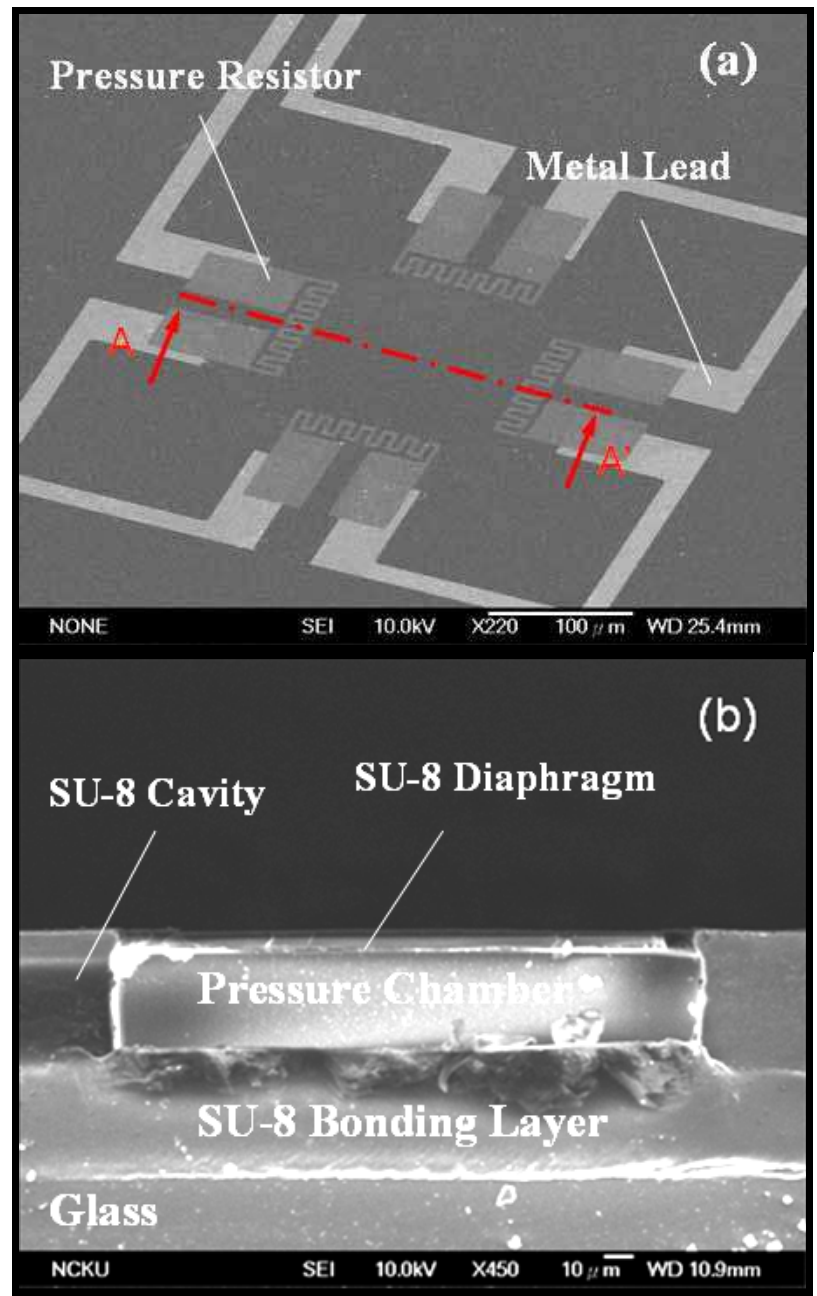

Fig. 23. Side view of SEM photographs. (a) Pressure sensor resistor embedded in SU-8 diaphragm and (b) pressure sensor diaphragm and cavity made by SU-8 lithography (Ko, 2009).

\subsubsection{Characteristics of pressure sensors (Ko, 2009)}

Since the arrays of pressure sensors were made of polysilicon layer doped with a designated concentration of $10^{20}$ atoms $/ \mathrm{cm}^{3}$ of boron, the temperature coefficient of resistance (TCR) of the sensors is almost zero which can eliminate the temperature effect for the sensors. In addition, the resistance of sensors designed is very large and is about 57-58 K $\Omega$. The pressure effect on the resistivity of the sensor is expected very large. Therefore, the sensors have a very high signal resolution. The complicated temperature compensation currents and the electrical signal amplifier are not required and used in this sensor system. The characteristic curves for the sensors were obtained, as shown in Figure 24. The results show 
a very linear variation between the pressure and the resistance of the sensors. Since the diaphragm is made of SU-8 materials, which has a smaller Young's modulus than the polysilicon film, this leads to a higher strain in the SU-8 film. Therefore, the resolution for the present SU-8 diaphragm sensors is much higher than the polysilicon diaphragm sensors and is found to be $20.88 \mathrm{ohm} / \mathrm{psig}$.

In order to test the reliability, i.e. the response, recovery and life time or fatigue of the current pressure sensors, a pressurized air is supplied to the sensor cavity for a period of 30 seconds and then released. The repeated sharp rise and descend of the pressure, as shown in Figure 25, suggests that the present SU-8 pressure sensor has very good reliability. Higher frequency of pressure oscillation still indicates that response and recovery test in the current sensor is still reliable except a slight drop of the oscillation signal is observed, as shown in Figure 26. This slight drop in oscillation signal is attributed to the frictional heating of the polymer diaphragm due to high frequency of vibrations. The frication heating increases the temperature and leads to reduction of the resistance of the polysilicon sensor. After cooling the sensor back to the ambient temperature, oscillation signal recovers back to the original value. The frictional heating may not be readily seen in polysilicon sensor due to the very high thermal conductivity of the material that can rapidly dissipate the frictional heating. The test for membrane under high frequency oscillation of pressure has proceeded for more than three thousand cycles which is more than 24 hours and does not indicates creeping or fatigue of the SU-8 membrane.

In addition, the sensor is put into oven at controlled temperatures for calibration at different temperatures. The results indicate that resistance variation at different temperatures is small and is less than $1 \%$ of the measured value. As one plots pressure variation versus temperature, as shown in Figure 27, the pressure variation is very small and less than 1 psig. The small pressure variation versus temperature may be attributed to the difference in the thermal expansion coefficient between the SU-8 and the Pyrex glass which causes small stress in the SU-8 side wall and the diaphragm. It is expected that replacing the Pyrex glass with other high temperature polymer plate, such as Poly(ether-ether-ketone) (PEEK), that can endure the high temperature annealing process of the SU-8 and have a closer thermal expansion coefficient to the SU-8, can further reduce the temperature effect on the pressure measurements.

Finally, in order to ensure that the SU-8 side wall or the diaphragm of the sensor is not permeable to the air, permeability test for the SU-8 to the air is performed. This is done by sending pressurized air into the test section (chamber), as shown in Figure 22(c), of the sensor at desired pressure level and closing both the inlet and outlet valves. The pressure variation in the test section is monitored by the sensor for more than 7 days, and the signals are sent into computer for plotting. It appears that the pressure inside the test section is almost kept constant except for a slight variation due to noise from the instrument. The variation of the pressure due to noise is less than $1.76 \%$ of the total pressure during a long period of 7 day observation. This result indicates that the pressurized air inside the test section will not leak slowly through the SU-8 diaphragm into the pressure chamber, nor the pressurized air (in either the test section or the pressure chamber) will leak slowly through the SU-8 side wall into the ambient. This permeability test also indicates that the SU-8 diaphragm will not creep under a constant pressure load of $350 \mathrm{kPa}$ for 7 days. Therefore, one may expect that the SU-8 diaphragm will not creep as long as the pressure load is within the elastic deformation of the material unless when the material becomes aged. 


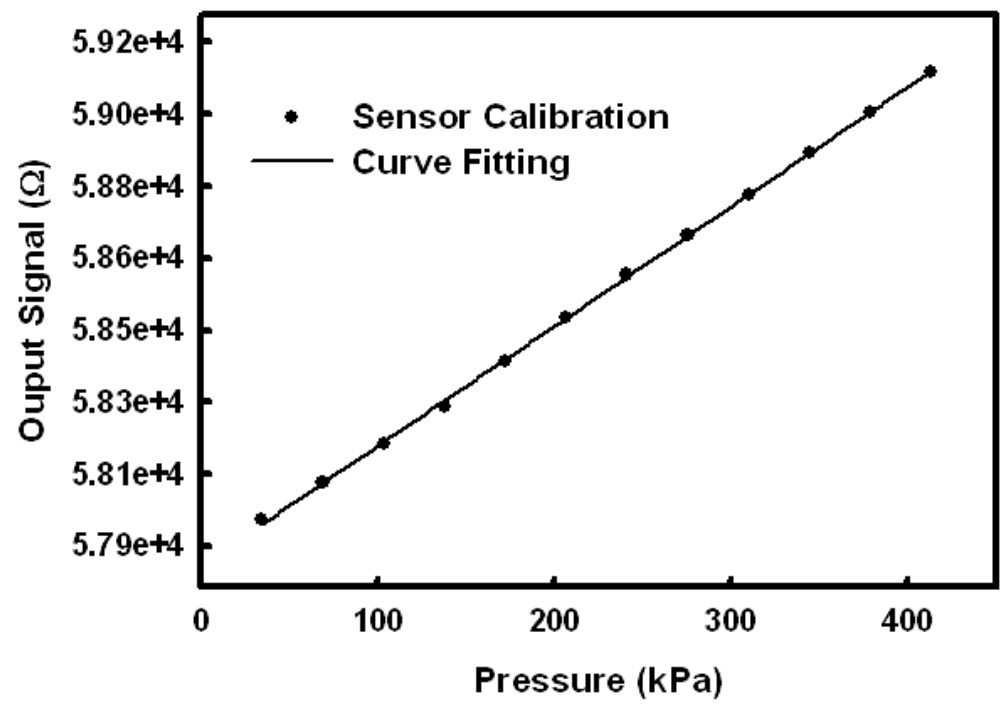

Fig. 24. A very linear variation between the pressure and the resistance of the sensors (Ko, 2009).

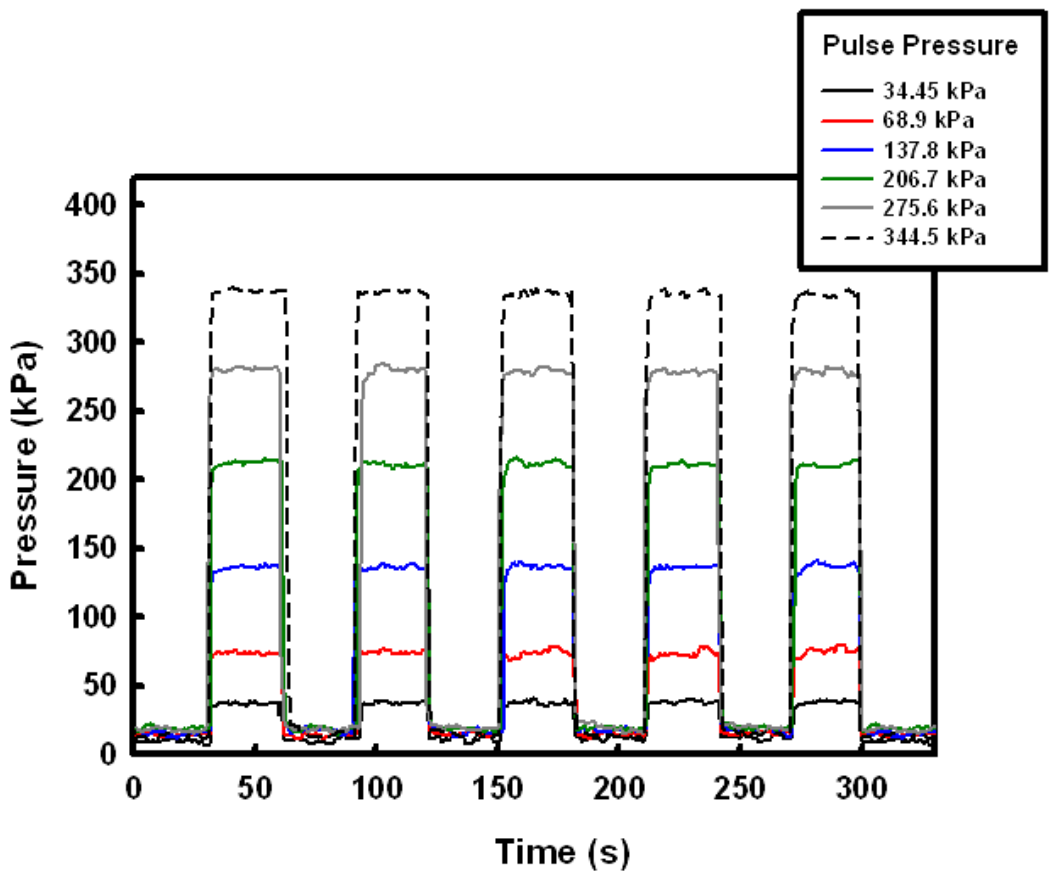

Fig. 25. Response and recovery test for pressure sensor at different pulsed pressures (Ko, 2009). 


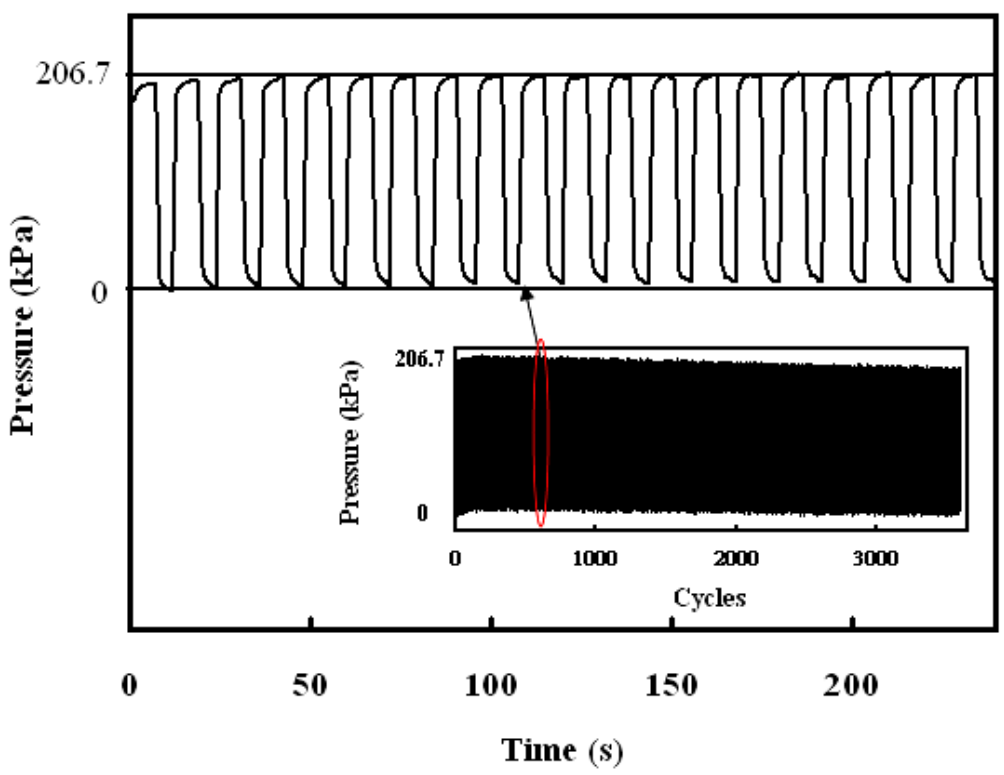

Fig. 26. Response and recovery test for pulsed pressure at high frequency (Ko, 2009).

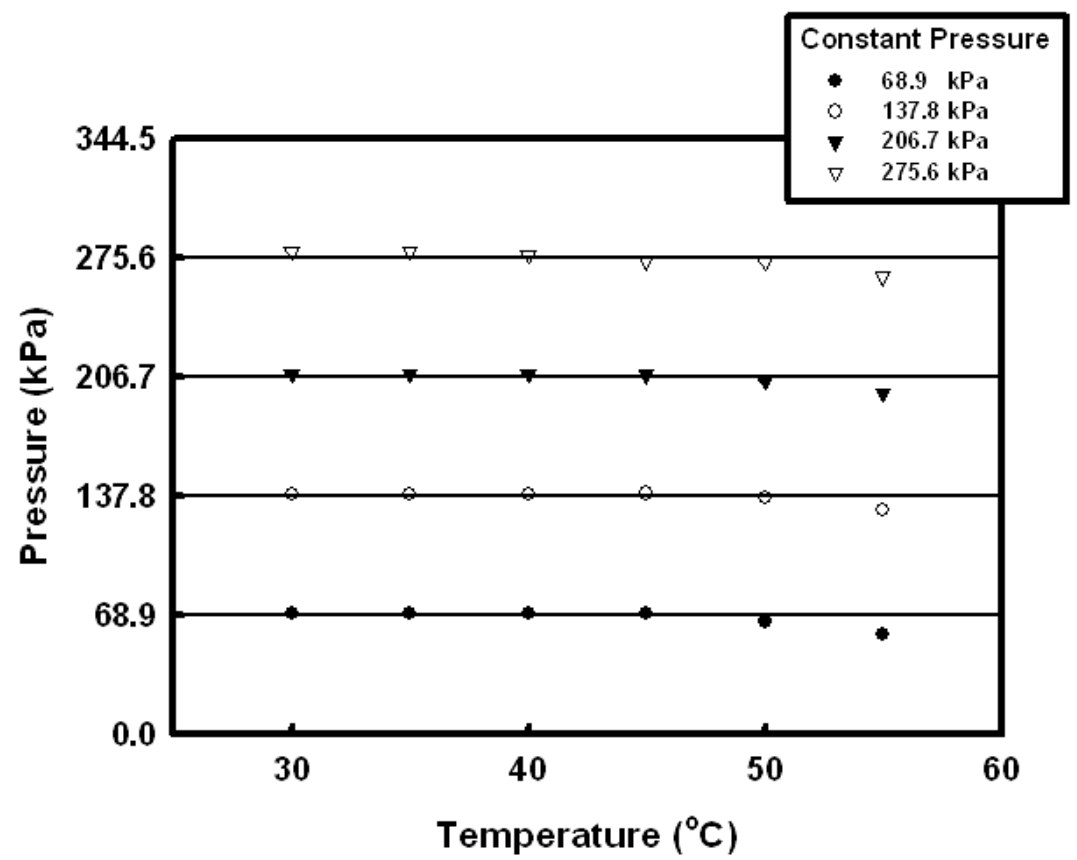

Fig. 27. Thermal stability test shows that the pressure signal is almost independent of temperature variation in the system (Ko, 2009). 


\section{Fabrication of microchannel integrated with arrays of miniaturized pressure sensors and temperature sensors}

The development and fabrication of a micro-flow heated channel for studies of local flow and heat transfer process is very important not only for the basic research but also for practical application in MEMS or NEMS thermal system. Unfortunately, most of the current micro-channel used (Choondal and Suresk, 2000; Yu et al., 1995) or fabricated (Jiang et al., 1999; Tao and Mahulikar, 1998; Chu et al., 1994) could not provide a local or detailed flow and heat transfer information, but a global information (only for flow information at inlet and outlet). How to prevent or control heat loss are the most important considerations for heat transfer study. Most of the MEMS or NEMS techniques developed up to the present are to use silicon wafer, a very good thermal conductor that has a very high thermal conductivity $(148 \mathrm{~W} / \mathrm{mK})$, as substrate to fabricate a microchannel (Pfahler et al., 1990; Pfahler et al., 1991; Arkilic and Breuer, 1994; Arkilic and Schmidt, 1997; Shih et al., 1996; Qu et al., 2000a and 2000b; Ren and Li, 2001; Ren et al., 2001a and 2001b). This will lead a large amount of heat loss from the inside channel to the outside ambient, a uniform heat flux boundary condition on the heated wall could not be maintained. Therefore, local heat transfer information in the channel cannot be obtained and understood.

The idea to fabricate a suspended channel over an air layer (Wu et al., 1998) to reduce the heat loss may be adopted to fabricate a heat transfer channel. However, this kind of channel that has a very thin wall can be readily deformed by the high-pressure flow. This deformation is expected to significantly affect the detailed flow and heat transfer process inside the channel. In addition, the techniques involved in the fabrication are suitable for fabrication with a very small height (in a few micrometers) channel.

The current work is to develop a novel fabrication procedure for a micro-channel system that can be used to study and obtain the flow and the local heat transfer coefficient inside the channel. One side of the channel wall can be heated uniformly and all the other sidewalls can be well insulated. In the meantime, the heated wall is integrated with an array of micro-temperature sensors and pressure sensors that can provide measurements of local temperature and local pressure of the heated wall and study the local flow and heat transfer process along the channel.

Initially, both the heater and the array of temperature sensors and pressure sensors that are made of polysilicon layer doped with different concentration of boron are deposited on a (100) silicon wafer by LPCVD. Then, an ultra thick SU-8 layer is spin coated on the substrate and patterned into the active cavity of the pressure diaphragm. After SU-8 lithography process, both the heater and the array of the sensor layers are moved to the surface of a low thermal conductivity Pyrex glass. This was made by bonding the deposited silicon wafer with the Pyrex glass to use a thick layer of epoxy resin. Then, the TMAH (25 wt \%) solution at $90{ }^{\circ} \mathrm{C}$ was used to etch and completely remove the silicon wafer. The next step is to spin a thick layer of SU-8 on the epoxy-glass substrate and form a micro-channel structure by lithography. The last step is to bond the epoxy-glass substrate with a thick PMMA plate to form a well-insulated and compact micro-channel. It is noted that both the SU-8 layer and PMMA plate are the very low thermal conductivity materials, as shown in Table 2. Design consideration and fabrication techniques involved in this processes will be discussed in the following sections. 


\subsection{Design consideration}

In the design of a micro-channel for the current flow and heat transfer study, the most important consideration is to reduce or control the amount of the heat loss from the channel to the ambient and to provide a uniform heat flux input on the wall that can be readily measured. To provide a uniform heat flux on the wall is not difficult. This can be achieved by selecting a resistor material that is independent of the temperature and distributing the resistor material uniformly on the channel wall. To pass a steady current through the resistor, a uniform heat generation along the wall can be obtained. However, the heater may have an uncontrollable heat loss at different locations such that the some of heat generated in the heater may lose to the substrate and the real heat input into the channel flow is not uniform. Thus, a uniform heat flux boundary condition on the wall cannot be obtained. In addition, the thermal energy inside the channel flow may lose to the wall and subsequently lose to the substrate if the wall is very conductive. Unfortunately, most of the MEMS techniques developed up to the present use silicon wafer, a very good thermal conductor that has a very high thermal conductivity, as a substrate to fabricate a micro-channel. These difficulties make the measurements and analysis of the heat transfer inside a formidable task. Chen et al. (2001) etched an air layer underneath the channel system to reduce the heat loss. This air layer is thick enough to effectively reduce the heat loss. However, it makes the heated wall very thin that the channel may distort itself during high-pressure gas or liquid flowing through the channel. In addition, the channel fabricated is very complicated. Although the design of using the air layer underneath the channel as insulation is a good idea, the fabrication process is very complicated and difficult, and the yield of the fabrication is very low.

\begin{tabular}{|l|l|l|}
\hline Material & $\begin{array}{l}\text { Thermal Conductivity } \\
(\mathrm{W} / \mathrm{mK}) \text { at 300K }\end{array}$ & $\begin{array}{l}\text { Thermal Expansion Coefficient } \\
(\mathrm{ppm} / \mathrm{K}) \text { at 300K }\end{array}$ \\
\hline Silicon & 148 & 2.6 \\
\hline Al-Cu-Si alloy & 161 & 19.2 \\
\hline Polysilicon & 34 & 2.4 \\
\hline Silicon nitride & 16 & 0.8 \\
\hline Silicon oxide & 1.38 & 10.3 \\
\hline Pyrex glass & 1.4 & 2.8 \\
\hline Epoxy resin & 0.15 & 62.5 \\
\hline PMMA plate & 0.16 & 62 \\
\hline SU-8 & $0.2^{*}$ & $52^{*}$ \\
\hline Air & 0.026 & \\
\hline
\end{tabular}

Data can be found in data sheet for NATOTM SU-8 negative tone photoresists, formulations 50 and 100, released by Micro Chem Corp.

Table 2. Thermal physical properties of the fabrication materials (Touloukian, 1970-1979).

In general, the heat input into the channel flow system can be moved away from the bottom heated wall of the channel by the convective flow, i.e. air or water flow through the channel. However, some portion of the heat input, i.e. the heat loss, can be moved away to the ambient by the conduction of the substrate or the channel structure. In fact, most of heat loss occurs by the substrate conduction, especially for a substrate with a higher thermal conductivity. Thus, in order to effectively reduce the heat loss and maintain a uniform heat 
flux boundary condition on the heated wall, several alternatives can be selected. One can use the thermal insulation materials on the back of the silicon substrate to reduce the heat loss. In addition, to reduce the spanwise heat conduction along the substrate, the thickness of the substrate can be reduced by mechanical polishing or particular wet etching techniques. In addition, instead of using the air layer underneath the channel, one was thinking of using other low thermal conductivity materials, such as Pyrex glass, as substrate. However, by a careful calculation even the Pyrex glass could not provide enough thermal insulation for both the channel and the heater. Other materials such as PMMA, polyimide or epoxy resin that have a much lower thermal conductivity, as shown in Table 2, can be used to avoid the heat loss from the heater to the ambient outside. An alternative insulation is to move the devices above the silicon wafer onto the Pyrex glass. This requires bonding the device with the Pyrex glass using epoxy resin, which is a low thermal conductivity material. Therefore, the epoxy resin can be served as both the bonding agent and a part of the substrate. This can significantly reduce both the normal and the spanwise conduction along the substrate. A schematic diagram designed for the microchannel integrated with arrays of micro pressure and temperature sensors is shown in Figure 29.

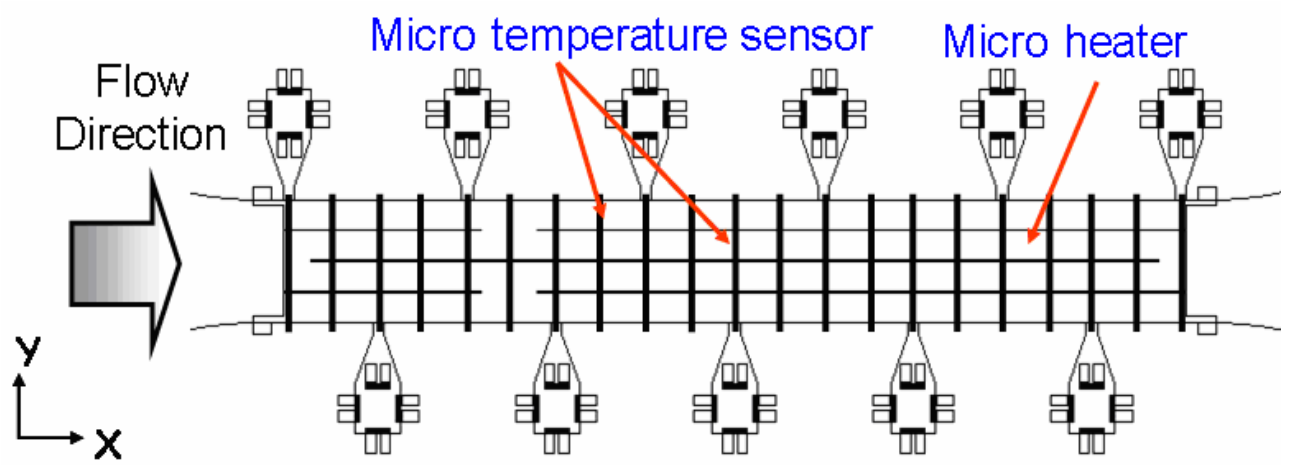

Fig. 28. Micro-channel system with arrangements of arrays of micro pressure sensors, micro temperature sensors and two sets of heaters used for study of micro scale heat transfer and pressure drop of the flow.

\subsection{Fabrication process flow}

The entire fabrication process, as shown in Figure 29, is described in the following:

1. A $0.3 \mu \mathrm{m}$ thick LPCVD tetraethoxysilane (TEOS) oxide is deposited on the (100) wafer and used as protection mask for the upper layer devices during the later long period of TMAH wet etch to completely remove the $\mathrm{Si}$ wafer.

2. The temperature sensors were made by depositing a $0.3 \mu \mathrm{m}$ thick LPCVD polysilicon layer and then implanting with boron with a dose of $3 \times 10^{14}$ atoms $/ \mathrm{cm}^{2}$. This amount of dosage corresponds to a concentration of $10^{19}$ atoms $/ \mathrm{cm}^{3}$ in the layer. After annealing at $950^{\circ} \mathrm{C}$ for 30 minutes to re-crystallize the polysilicon layer and to uniformly diffuse the dopant ions across the layer, the doped polysilicon was patterned. The concentration of $10^{19}$ atoms $/ \mathrm{cm}^{2}$ will give a linear relationship between the resistivity and the temperature of the doped polysicon layer. Thus, after proper calibration, the doped polysilicon layer can be used as temperature sensors. 
3. Next, after a deposition of a $0.3 \mu \mathrm{m}$ thick LPCVD TEOS layer as insulation, a $0.3 \mu \mathrm{m}$ thick LPCVD polysilicon film is deposited and then implanted heavily with boron with a dose of $3 \times 10^{15}$ atoms $/ \mathrm{cm}^{2}$. This amount of dosage corresponds to a concentration of $10^{20}$ atoms $/ \mathrm{cm}^{3}$ in the layer. After annealing at $950^{\circ} \mathrm{C}$ for 30 minutes, the doped polysilicon is patterned as the pressure sensors.

4. Before metallization, a $0.3 \mu \mathrm{m}$ thick LPCVD TEOS oxide is deposited as insulation. Then, contact holes were opened in this layer for metallization. The metallization was made by sputtering standard IC four layers of metals, i.e. Ti/TiN/Al-Si-Cu/TiN with a thickness of $0.04 \mu \mathrm{m} / 0.1 \mu \mathrm{m} / 0.9 \mu \mathrm{m} / 0.04 \mu \mathrm{m}$, respectively, onto the substrate surface. The metal layers were then patterned into circuits, as shown in Figure 29 (a).

5. A $9 \mu \mathrm{m}$ thick SU-8 layer is spin coated on the substrate as the pressure sensing diaphragm, as shown in Figure 29 (b). Then, a $50 \mu \mathrm{m}$ thick SU-8 layer is coated again on the substrate and patterned into the active cavity to allow for movement of the pressure diaphragm. It is noted that there is a soft bake before layer exposure to evaporate the solvent and a post exposure bake to make the edge between the exposed and unexposed region more sharp and clear. Finally, instead of using the hard bake, a high intensity of light is used to illuminate to complete the cross-linking of the resin since the hard bake will need a temperature at $200 \circ \mathrm{C}$ that will damage the underneath thick epoxy layer (refers to the epoxy layer mentioned in item 5 below). For the soft bake, the SU-8 layer is first maintained at $65{ }^{\circ} \mathrm{C}$ for 7 minutes with a $5{ }^{\circ} \mathrm{C} /$ minute ramping rate starting from room temperature, and then baked at $95{ }^{\circ} \mathrm{C}$ for 15 minutes with a 5 ${ }^{\circ} \mathrm{C} /$ minute ramping rate starting from $65{ }^{\circ} \mathrm{C}$ to release the internal residual stress of SU8 thick layer. In fact, the success of the SU-8 channel strongly depends on the baking process after light exposure.

6. It is now ready to move the devices made on the $\mathrm{Si}$ wafer onto a low thermal conductivity Pyrex glass. This is done first by bonding the silicon wafer with the Pyrex glass, as shown in Figure 29 (c), using epoxy resin as the bonding agent. Since the epoxy resin has a significantly lower thermal conductivity than the Pyrex glass, this can better reduce the heat loss from the channel to the ambient.

7. After the bonding process, the silicon substrate is ready for removal and cleared off. This is done by a wet etch process. The silicon is etched with TMAH solution at $90{ }^{\circ} \mathrm{C}$ for 5-6 hours. Instead of using $\mathrm{KOH}$, the selection of TMAH is attributed to its relatively high selectivity for silicon versus oxide. This can avoid the sensors attacked by the etchant during the long period of wet etch process since the protection layer of the sensors are made of TEOS oxide. After successful movement of the pressure sensors onto the Pyrex glass substrate, no distortion was found, as shown in Figure 29(d).

8. Next, another SU-8 layer is spin coated on the epoxy-glass substrate at desired thickness and patterned by lithography to form a rectangular microchannel and cavities of the pressure sensors that connect with channel through narrow size tunnels. The side walls of the channel, the narrow tunnels, or the cavities of the pressure sensors are successfully made, as shown in Figures 30 (a), (b) and (c). It is noted that a similar post exposure bake should be made in order to obtain a nice shape of channel and cavities of the pressure sensor.

9. A PMMA plate is then bonded, using epoxy resin, with the epoxy-glass substrate to enclose the channel and the cavities, as shown in Figure 29 (e).

A picture for the completed channel is shown in Figure 30 (d). 


\begin{tabular}{|ll}
\hline Silicon substrate & \\
Dielectric layer (TEOS) & SU-8 layer \\
ETIT Sensors & Epoxy layer \\
Metal layer & Pyrex 7740 glass \\
&
\end{tabular}

(a)

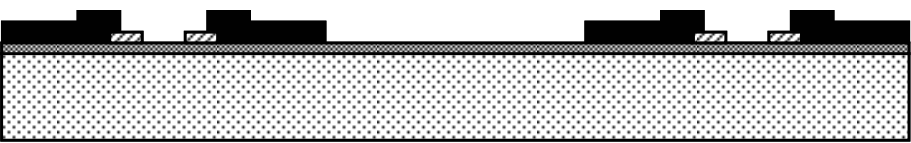

(b)

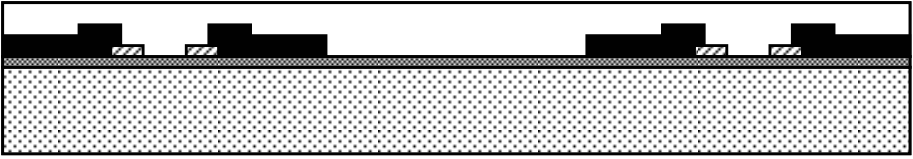

(c)

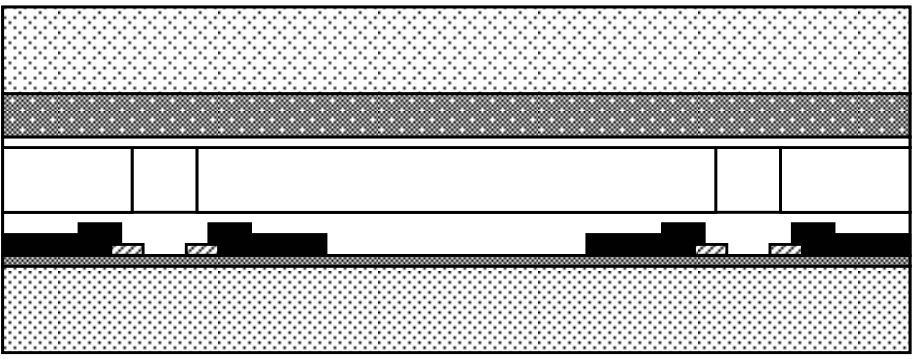

(d)

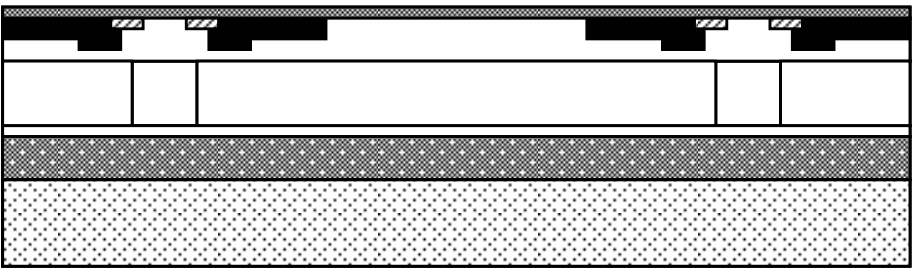

(e)

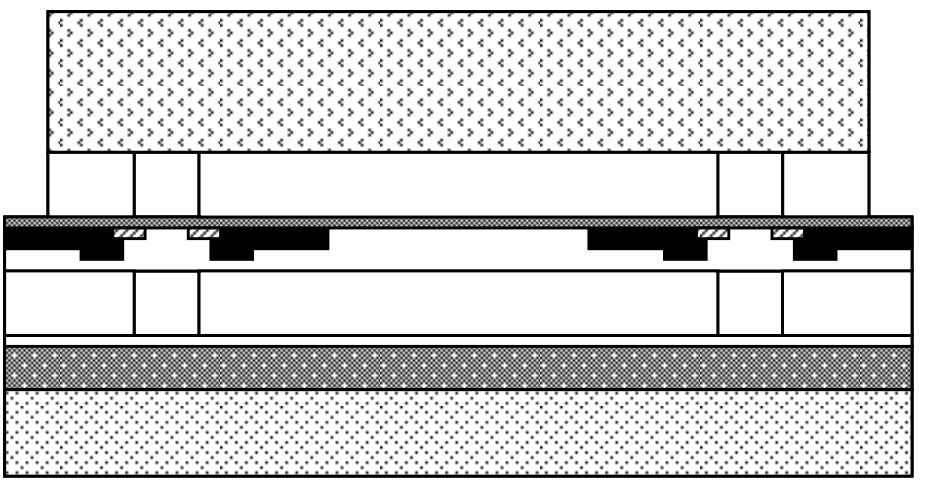

Fig. 29. Fabrication process for the entire microchannel system. 

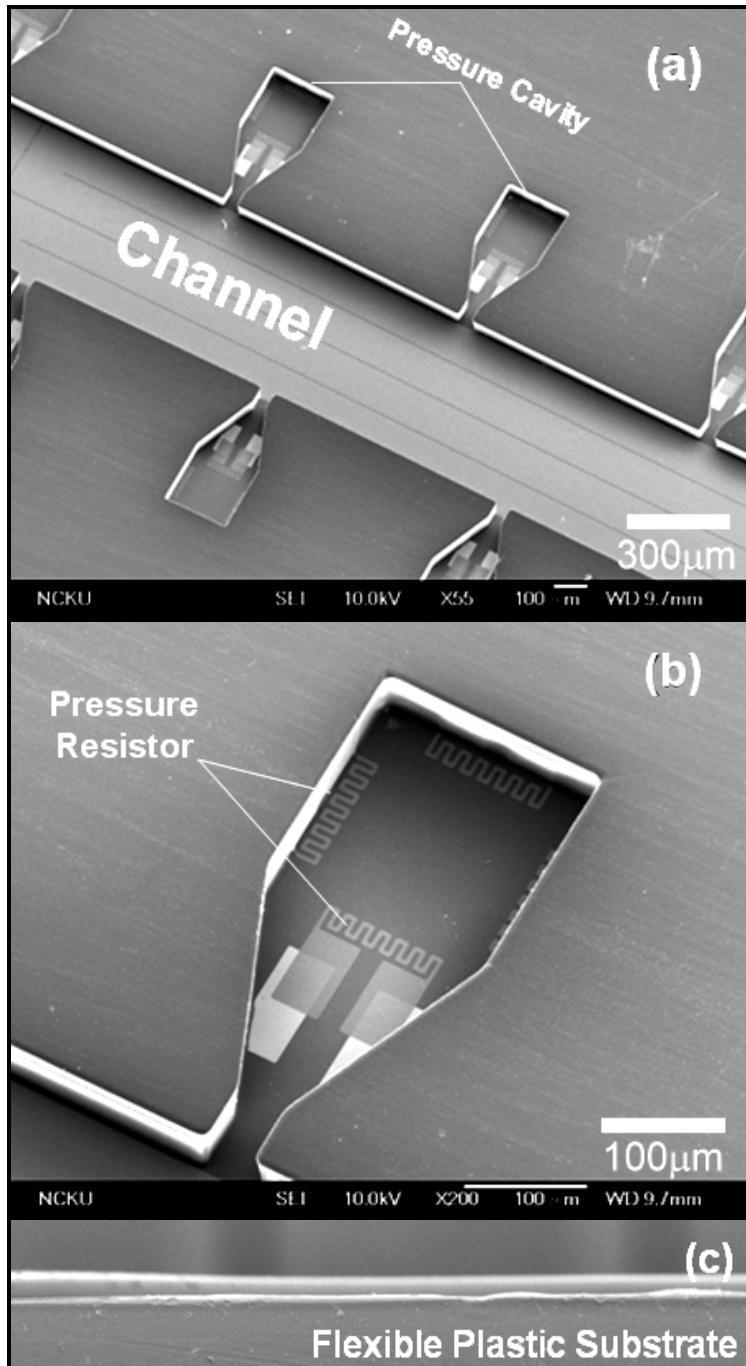

SU-8 Bonding Layer

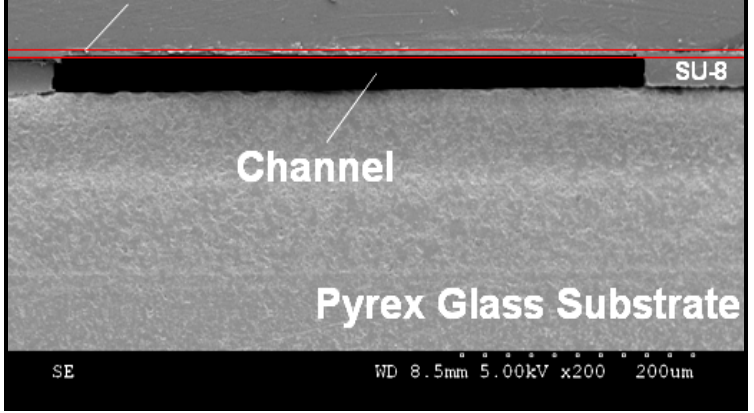




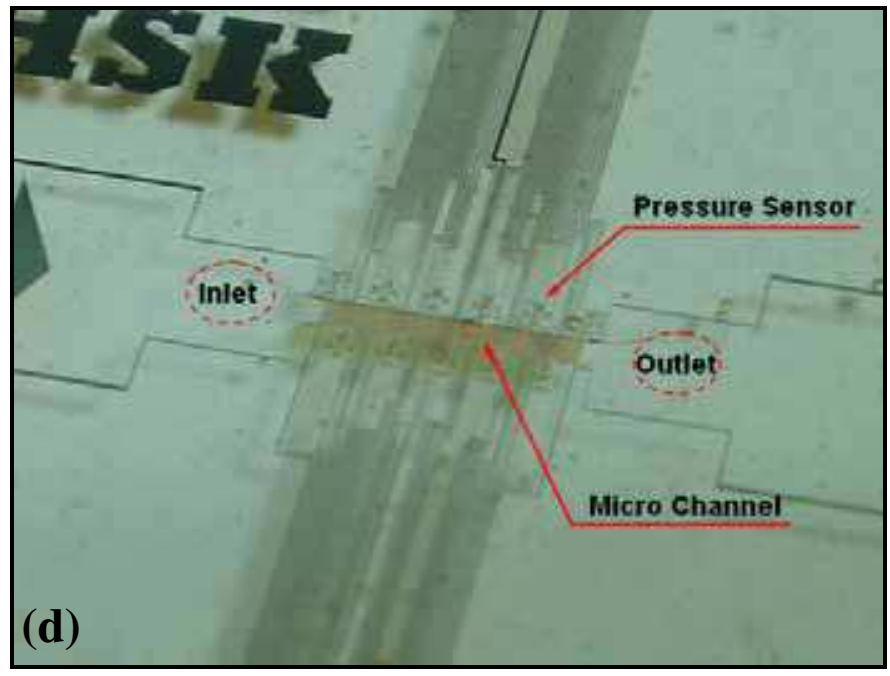

Fig. 30. SEM photographs of SU-8 channel integrated with arrays of micro pressure sensors: (a) global view, (b) close view and (c) cross section view and (d) the completed microchannel (Ko, 2009).

\section{Local pressure drop and heat transfer characteristic inside a microchannel}

\subsection{Liquid flow characteristics}

In order to compare with the experimental data, theoretical analysis of the flow characteristic inside the microchannel is performed. Since the microchannel has very wide in size as compared with the height, the microchannel flow can be assumed as parallel plate channel flow. Since the microchannel flow can rapidly become fully developed, as indicated in the later data measurement, the governing equation for fully developed flow in the microchannel can be greatly simplified. The solution can be readily found as follows (Incropera et al., 2007):

$$
u(y)=\frac{y^{2}}{2 \mu} \frac{d p}{d x}-\frac{H}{2 \mu} \frac{d p}{d x} y=\frac{1}{2 \mu} \frac{d p}{d x}\left(y^{2}-H y\right)
$$

To integrate the equation transversely, the mean velocity of the flow in the channel can be obtained as follows:

$$
U=-\frac{H^{2}}{12 \mu} \frac{d p}{d x}
$$

where $U$ is the mean velocity of the flow. From Eq. (6-2), the longitudinal pressure distribution can be found as follows:

$$
p_{x}=p_{i}-\frac{12 \mu U}{H^{2}} x
$$


or

$$
\Delta p=\frac{12 \mu U l}{H^{2}}
$$

The Reynolds number here is defined as the liquid density times the mean velocity of the flow and the hydraulic diameter $\left(\mathrm{D}_{\mathrm{h}}\right)$ of the rectangular channel divided by the dynamic viscosity of the liquid as follows:

$$
\operatorname{Re}=\frac{\rho U D_{h}}{\mu}
$$

where is $\rho$ the density of the water. The friction factor of flow can be calculated with a given pressure drop.

For the liquid flow, Qu et al. $(2000,2002)$ has found that the pressure drop in microchannel is significantly higher than the theoretical analysis due to the roughness effect. To eliminate the wall roughness effect, therefore, the roughness on the wall surface of the current microchannel is minimized, and is less than $\pm 5 \mathrm{~nm}$ to $15 \mathrm{~nm}$. This roughness is negligibly small in comparison with the height of the channel, which is either $68.2 \mu \mathrm{m}$ or $23.7 \mu \mathrm{m}$. During the experiment, the pressure distributions measured at different Reynolds numbers are compared with the analysis, as shown in Figure 31(a) for the channel height at $34.7 \mu \mathrm{m}$. The pressure drop of the water is found significantly higher than the prediction by Eq. (8-3). A similar result was also found by Mala and Li (1998) who showed that the pressure drop of water in micro-tubes is significantly higher than the analysis. Under the same flow rate and tube diameter, the pressure drop in metal tubes is lower than in silica glass tubes. This can be attributed to the electric surface potential in the channel which attracts counterions in the liquid and causes formation of electric double layer on the wall. The thickness of the EDL in the micro channel for these three different solutions can be estimated by the inverse of the square root of the Debye-Huckel parameter (Mala et al. 1997) as follows:

$$
\tau=\left(\frac{\varepsilon \varepsilon_{o} \kappa_{b} T}{2 z_{i}^{2} e^{2} n_{\infty}}\right)^{1 / 2}
$$

where $\varepsilon$ is the dielectric constant of the solution and $\varepsilon_{\mathrm{o}}$ is the permittivity of vacuum, $\mathrm{K}_{\mathrm{b}}$ is the Boltzmann constant, $\mathrm{T}$ is the absolute temperature, $\mathrm{n}_{\infty}$ and $\mathrm{z}_{\mathrm{i}}$ are the bulk concentration and the valence of type $\mathrm{i}$ ions. Therefore, the EDL thickness is approximately $1 \mu \mathrm{m}$ for water. In order to minimize the EDL effect, the working fluid used is changed to $\mathrm{KCl}$ solution at concentration of $10^{-4} \mathrm{M}$ or $10^{-2} \mathrm{M}$, which can effectively remove the surface charges by the metal ions in the solution and significantly reduce the thickness of EDL. The EDL thickness is approximately $100 \mathrm{~nm}$ for the $\mathrm{KCl}$ solution with concentration of $10^{-4} \mathrm{M}$ and $1 \mathrm{~nm}$ for the $\mathrm{KCl}$ solution with concentration of $10^{-2} \mathrm{M}$. The result indicates, as shown in Figure 31(a), that the pressure distribution for a higher $\mathrm{KCl}$ concentration $\left(10^{-2} \mathrm{M}\right)$ is significantly lower than for the pure DI water and is close to the analysis. It appears that the deviations for the experimental data of water from the prediction are attributed to surface charges and the EDL on the channel wall. The thicker the EDL, the greater is the deviation of the pressure drop from the analysis. The current finding for the reduction of EDL thickness which makes 
the pressure drop in the microchannel approach to the analysis agrees with the results in Ren et al. (2001). When the channel height increases to $68.2 \mu \mathrm{m}$, the pressure drops for the case of the pure water and the cases of different concentrations of $\mathrm{KCl}$ solutions collapse into a single line, as shown in Figure 31(b), and are closer but higher than the analysis. It appears that the EDL of different fluids does not have a significant effect on the pressure drop in a greater height of channel even though the EDL of different fluids on the wall has different thickness.

For a large scale channel, the entrance region can be clearly identified by the non-linear distribution of pressure distribution. However, in the entry region, no clear indication of non-linear distribution of pressure can be found, as shown in Figure 31(a) or 31(b). For large scale channel, the entry length can be estimated by the equation as follows Ren et al. (2001):

$$
\mathrm{L}_{\mathrm{in}}=0.02 \mathrm{D}_{\mathrm{h}} \operatorname{Re}
$$

For the channel height at $68.2 \mu \mathrm{m}$ and Reynolds number at 128, the hydrodynamic entry length calculated from Eq. (8-6) is approximately $300 \mu \mathrm{m}$. However, pressure drop within $300 \mu \mathrm{m}$ does not indicated greater or nonlinear variation, as shown in Figure 31(b). It shows that the hydrodynamic entry region in microchannel is very short and could not be identified from the current pressure distribution measurements. It appears that the boundary layer in the entrance region of a microchannel develops very fast and becomes fully developed very close to the entrance.

The same kinds of fluids are also performed in channels at the height of $23.7 \mu \mathrm{m}$. In the channel at the height of $23.7 \mu \mathrm{m}$, more deviations of the pressure drop data for different fluids occur, as shown in Figure 32(a) for pressure drop variation with the Reynolds numbers in the fully developed region. The pressure drop for water flow has the largest slop, and decreases when the concentration of $\mathrm{KCl}$ solution increases. These results clearly indicate the effect on the thickness of EDL relative to the height of channel. For water flow with a thicker EDL on the channel wall, the appearance of the EDL can increase the pressure drops by $13.4 \%$ in the smaller height of channel $(23.7 \mu \mathrm{m})$, but increase only $8.6 \%$ in the greater height of channel $(34.7 \mu \mathrm{m})$. For the channel height at $68.2 \mu \mathrm{m}$, all the pressure drop variations with the Reynolds number for different fluids collapse into a single line, as shown in Figure 32(b), and are closer but higher than the analysis. The higher pressure drop data for different fluids than the prediction by Eq. (8-3) can be attributed to the aspect ratio effect of the channel. The prediction by Eq. (8-3) is based on an analysis in a parallel plate channel, while the current channel with channel height of $68.2 \mu \mathrm{m}$ or $23.7 \mu \mathrm{m}$ has an aspect ratio of $1: 7.3$ or $1: 21$, respectively.

From the definition of the friction factor,

$$
f=\frac{\tau_{w}}{\frac{1}{2} \rho U^{2}}=\frac{D_{h}}{2 \rho U^{2}} \frac{d p}{d x}
$$

where $\mathrm{D}_{\mathrm{h}}$ is hydrodynamic diameter of the channel cross section and is equal to $2 \mathrm{Hw} /(\mathrm{H}+\mathrm{w})$.

The product of friction factor, $f$, and the Reynolds number is defined as the Poiseuille number (Po) (Baviere, 2004) and can be written as follows for parallel plate channel: 


$$
P o=f \operatorname{Re}=24
$$

The parallel plate channel has an infinite width in $z$ direction, the velocity is a two dimensional parabolic profile. However, when the channel width in the $\mathrm{z}$ direction is finite the velocity close to the side wall becomes three dimensional. The side wall effect can produce greater pressure drop. The smaller the channel width in the $\mathrm{z}$ direction, the greater the aspect ratio, the greater the pressure drop becomes. For large scale channel, the greater Po value for channel with greater aspect ratios has been calculated and correlated in terms of aspect ratio, a as follows Baviere et al. (2004):

$$
P o(a)=24\left(1-1.3553 a+1.9467 . a^{2}-1.7012 a^{3}+0.9564 a^{4}-0.2537 a^{5}\right)
$$

From Eqs. (8-7), (8-8) and (8-9) the pressure gradient can be re-calculated for the aspect ratio less than 1:21, as shown in Figure 33(a) and Figure 33(b) indicated by the red dash line. The pressure gradient predicted by Eq. (8-9) in the fully developed region agrees very well with the data for working fluid at the much higher concentration of $\mathrm{KCl}$ or when channel height is very large $(68.2 \mu \mathrm{m})$ and EDL effect is negligible small. For clarity, the Po number for both the data and the prediction by Eq. (8-8) has been plotted as shown in Figure 33. The agreement between data and the prediction at channel height of $68.2 \mu \mathrm{m}$ indicate that wall roughness in the current channel has a negligible effect on the pressure drop. Even at a smaller height of channel, $23.7 \mu \mathrm{m}$, the agreement between data at high concentration of $\mathrm{KCl}$ with negligible effect of EDL and the prediction further indicates the negligible effect of the wall roughness in the current channel.

In order to compare with the pressure drop data published in the literature, the normalized friction constant which is most frequently used is adopted and written as follows.

$$
C_{f}^{*}=\frac{P o_{\text {exp }}}{P o_{\text {theory }}}
$$

where the friction constant Poxp $_{\exp }$ is found from the product of Re with the measured friction factor and $\mathrm{Po}_{\text {theory }}$ is directly evaluated from Eq. (8-8). Large discrepancy among different works can be found as shown in Figure 34(a) and Figure 34(b). The data selected here for comparison are only limited to rectangular channels which have a channel height close to the current channel. More detailed sizes of the channels and the materials the channels used are also listed in the table underneath the figure. In general, the normalized friction constants for all the work in the past are not only much greater than unity which is a theoretical prediction for large scale channel, but also greater than the data of the current work. This is attributed to the use of the inlet and outlet pressure to calculate the pressure drop in the channel which is used to evaluate the friction constant. Most of the work in the past can not obtain the pressure inside the channel, but measure the pressure outside the channel at the inlet and outlet (Pfund et al., 2000; Xu et al., 2000; Papautsky et al.,1999; Peng et al., 1995). Since there is large pressure loss for flow entering or exiting the channel, the pressure drop measured outside the channel at the inlet and the outlet is much greater than the actual pressure drop in the channel. Therefore, much greater friction constants obtained from others are expected. 

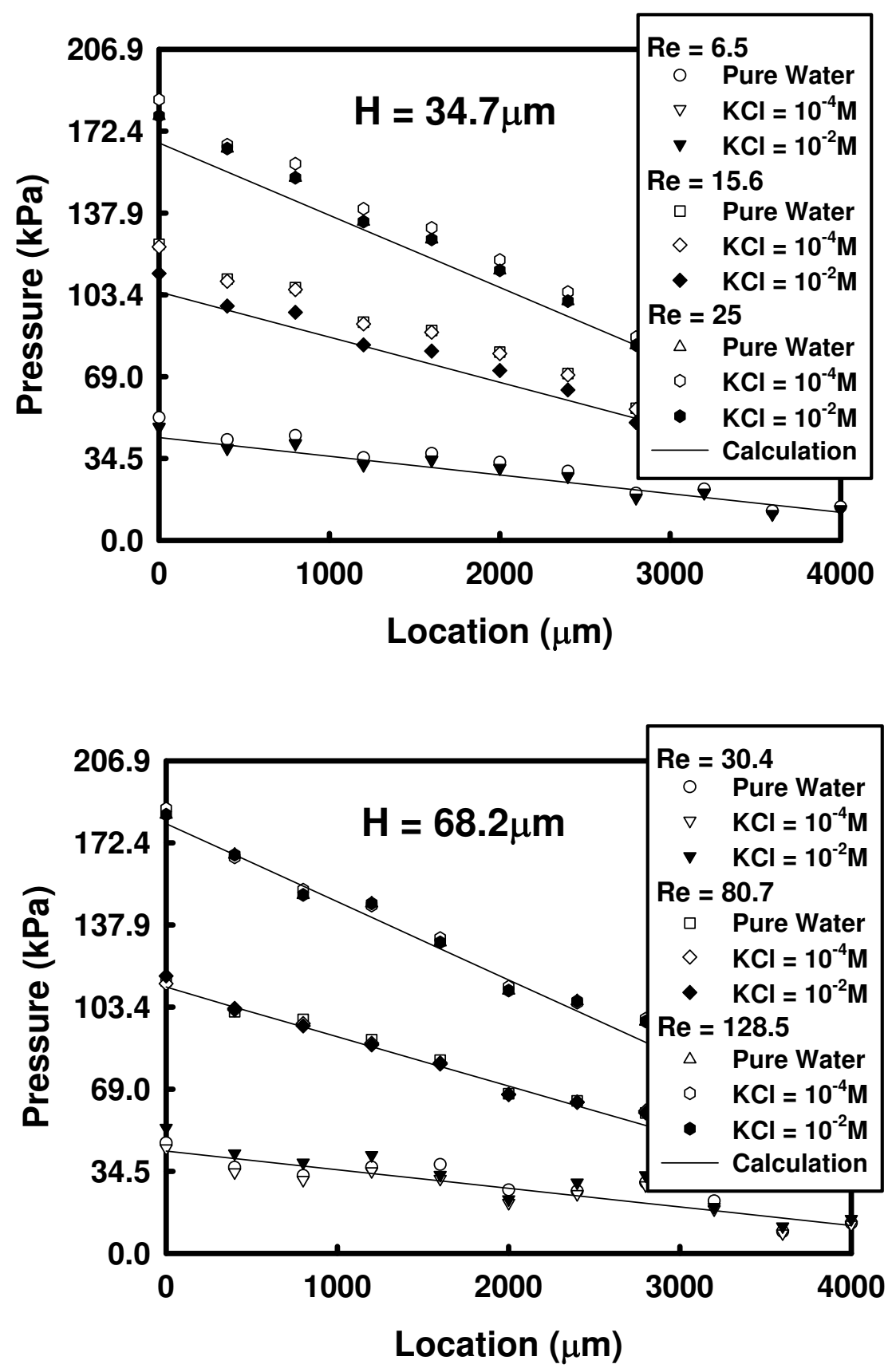

Fig. 31. Local pressure distributions at different Reynolds numbers in a micro-channel with channel height of (a) $34.7 \mu \mathrm{m}$ and (b) $68.2 \mu \mathrm{m}$ (Ko, 2009). 

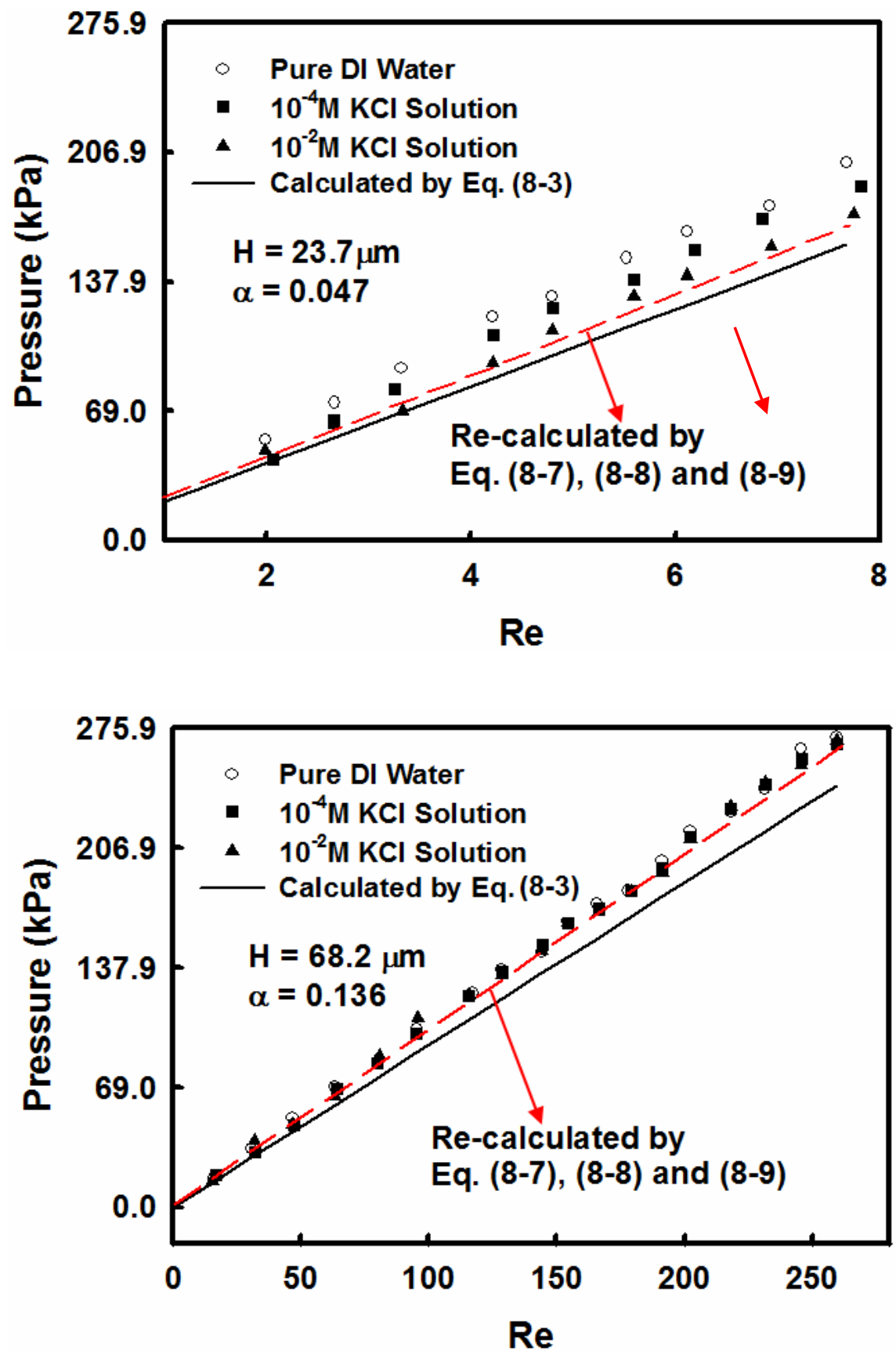

Fig. 32. Pressure drops at different Reynolds numbers in fully developed region a microchannel with (a) channel height of $23.7 \mu \mathrm{m}$ and (b) channel height of $68.2 \mu \mathrm{m}$ (Ko, 2009). 

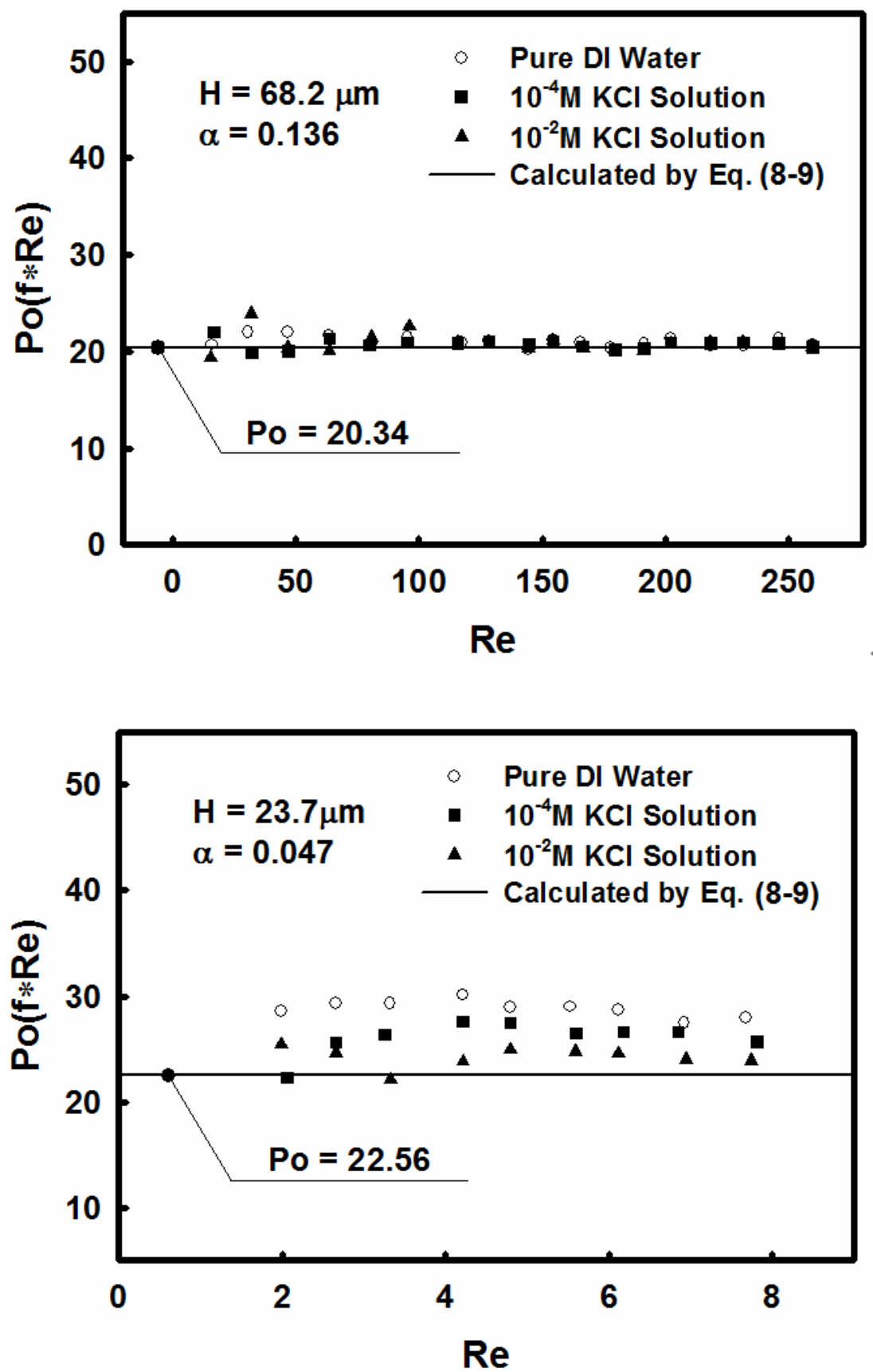

Fig. 33. The Poiseuille numbers at different Reynolds numbers in a micro-channel with (a) channel height of $68.2 \mu \mathrm{m}$ and (b) channel height of $23.7 \mu \mathrm{m}$ (Ko, 2009). 


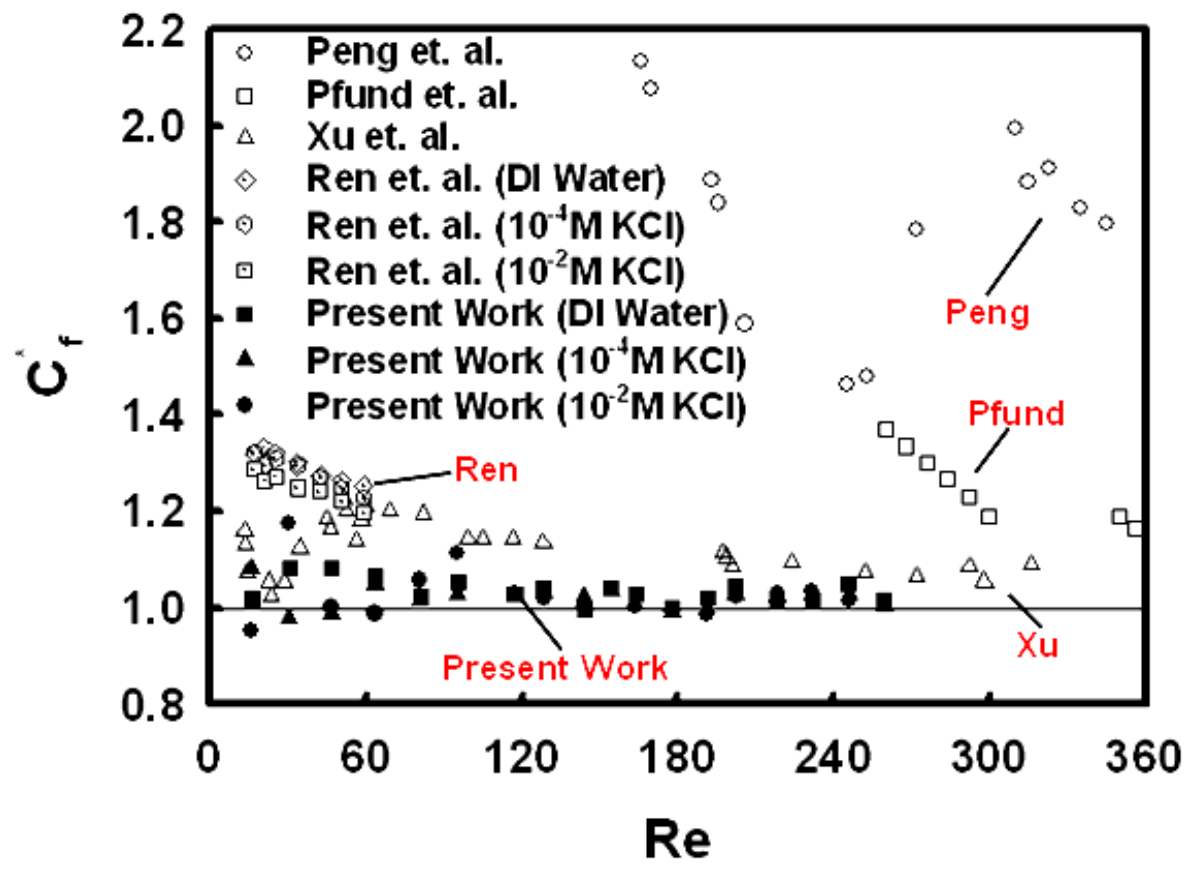

\begin{tabular}{|c|c|c|c|c|c|c|}
\hline References & Channel Material & $\begin{array}{c}\text { Working } \\
\text { Fluid }\end{array}$ & $\begin{array}{c}\text { Height } \\
(\mathrm{m})\end{array}$ & $\begin{array}{c}\text { Width } \\
(\mathrm{m})\end{array}$ & $\begin{array}{c}\text { Aspect } \\
\text { Ratio }\end{array}$ & $\begin{array}{c}\mathrm{D}_{\mathrm{h}} \\
(\mathrm{m})\end{array}$ \\
\hline Peng et al. (1995) & stainless steel & Water & 100 & 200 & 0.5 & 133 \\
\hline Pfund et al.(2000) & $\begin{array}{c}\text { Polycarbonate- } \\
\text { Gasket-Polyimide }\end{array}$ & Water & 263 & 10000 & 0.263 & 416.4 \\
\hline Xu et al. (2000) & Glass-Silicon & Water & 43.7 & 415.3 & 0.106 & 79.08 \\
\hline $\begin{array}{c}\text { Ren et al. (2001) } \\
\text { Present work (Ko, } \\
\text { 2009) }\end{array}$ & Silicon & $\begin{array}{c}\text { Water/K } \\
\mathrm{Cl}\end{array}$ & 40.5 & 5000 & 0.0081 & 80.34 \\
\hline
\end{tabular}




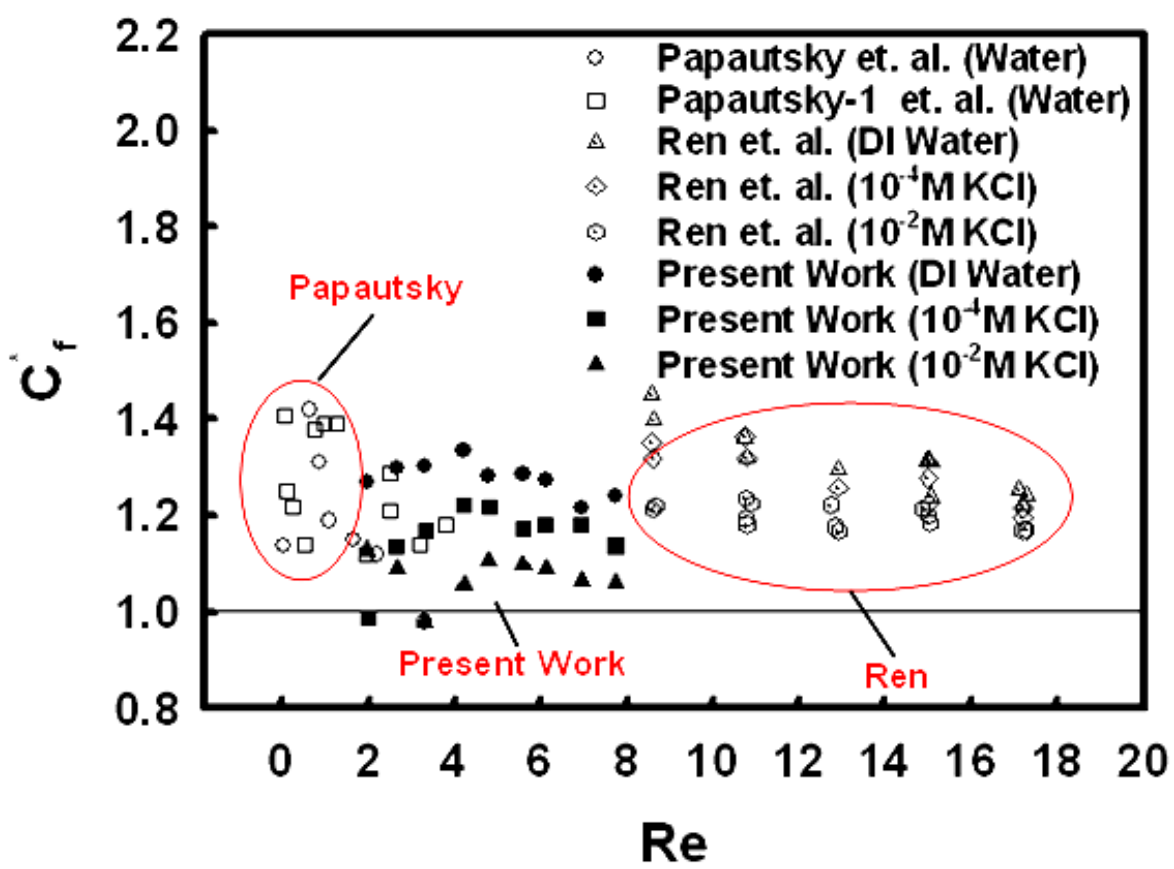

\begin{tabular}{|c|c|c|c|c|c|c|}
\hline Reference & $\begin{array}{c}\text { Channel } \\
\text { Material }\end{array}$ & $\begin{array}{c}\text { Working } \\
\text { Fluid }\end{array}$ & $\begin{array}{c}\text { Height } \\
(\mathrm{m})\end{array}$ & $\begin{array}{c}\text { Width } \\
(\mathrm{m})\end{array}$ & $\begin{array}{c}\text { Aspect } \\
\text { Ratio }\end{array}$ & $\begin{array}{c}\mathrm{D}_{\mathrm{h}} \\
(\mathrm{m})\end{array}$ \\
\hline Papautsky (1999) & Nickel & Water & 24.65 & 600 & 0.0411 & 47.35 \\
\hline Papautsky-1(1999) & Nickel & Water & 26.35 & 150 & 0.1757 & 44.82 \\
\hline Ren et al. (2001) & Silicon & $\begin{array}{c}\text { Water / } \\
\mathrm{KCl}\end{array}$ & 28.2 & 5000 & 0.0056 & 56.08 \\
\hline $\begin{array}{c}\text { Present work } \\
(\text { Ko, 2009) }\end{array}$ & Polymer & $\begin{array}{c}\text { Water / } \\
\mathrm{KCl}\end{array}$ & 23.7 & 500 & 0.0474 & 45.24 \\
\hline
\end{tabular}

Fig. 34. (a) Comparison of the normalized friction constants between the current work and the published results for current channel with (a) $68.2 \mu \mathrm{m}$ in height and (b) $23.7 \mu \mathrm{m}$ in height. 
In addition, data obtained from previous work scatter very much. The scatter in data among different works should not be attributed to the geometry of the channel which has a different aspect ratio since the comparison has already accounted for the aspect ratio effect. The scatter in data among different works is mostly attributed again to the use of the pressures at the inlet and the outlet outside the channel to evaluate the pressure drop inside the channel. This may lead to erroneous result. For example, the data from $\mathrm{Xu}$ et al., as shown in Figure 34(a) appears to be very good and is very close to the theoretical prediction. However, in a much smaller channel height, i.e. $15.4 \mu \mathrm{m}$, where the EDL effect can become significant and is expected to increase the pressure drop, the data from $\mathrm{Xu}$ et al. is identical to the theoretical prediction, as shown in Figure 34(a) of their paper (Xu et al., 2000). Most of the data did not discuss the effect of EDL except the work of Ren et al. (2001). Ren et al. has used a higher concentration of $\mathrm{KCl}$ solution to significantly reduce the thickness of the EDL and its effect on the pressure drop so that the friction constant in a smaller size of channel, as shown in Figure 34(b), with a higher concentration of $\mathrm{KCl}$ solution is smaller than the one with a lower concentration of $\mathrm{KCl}$ solution. However, all the data from Ren et al. are much greater than the theoretical prediction, as show in Figure 34(a) for a greater channel height and Figure 34(b) for a smaller channel height. The higher normalized friction constant obtained is attributed to the erroneous estimation of the entry length, which is used to estimate the pressure drop in the entry region, and the pressure loss at the exit. The normalized friction constant in Ren et al. is estimated from the pressure drop which is measured outside the channel at the inlet and the outlet and subtracted by the pressure drop in the entry region and the pressure loss at the outlet. Despite of this drawback, the data of Ren et al. consistently show that EDL can have a significant effect on the pressure drop when the channel height is small. The EDL effect can become small when a high concentration of $\mathrm{KCl}$ solution or a greater height of channel is used. These findings are also confirmed in our measurements. The agreement of the current pressure drop with the theoretical prediction suggests that much of the conflicting effects of the microchannel size on the pressure drop reported from previous work are clarified. From the comparison, one can further confirm the techniques and the fabrication of the micro-channel used in this study are suitable for precision pressure drop measurement.

\subsection{Flow characteristics for air \\ 8.2.1 Theoretical analysis}

Theoretical analysis of micro flow inside the channel is performed firstly, which is then used to compare with the data of pressure measured and analyze the characteristics of micro flow inside the channel. Since the channel has a large value in its width $(500 \mu \mathrm{m})$ in comparison with its height (from $23 \mu \mathrm{m}$ to $68 \mu \mathrm{m}$ ), the channel flow in the present study can be assumed as laminar flow between two parallel plates at steady state. The configuration with the coordinate system and flow velocity of micro-channel flow are defined in Figure 35. Therefore, the governing equations of the flow in this micro-channel system can be written in the following:

Continuity equation:

$$
\frac{\partial \rho u}{\partial x}+\frac{\partial \rho v}{\partial y}=0
$$


Navier-Stokes Equation:

$$
\begin{gathered}
\rho\left(u \frac{\partial u}{\partial x}+v \frac{\partial u}{\partial y}\right)=-\frac{\partial p}{\partial x}+\mu\left(\frac{\partial^{2} u}{\partial x^{2}}+\frac{\partial^{2} u}{\partial y^{2}}\right) \\
\rho\left(u \frac{\partial v}{\partial x}+v \frac{\partial v}{\partial y}\right)=-\frac{\partial p}{\partial x}+\mu\left(\frac{\partial^{2} v}{\partial x^{2}}+\frac{\partial^{2} v}{\partial y^{2}}\right)
\end{gathered}
$$

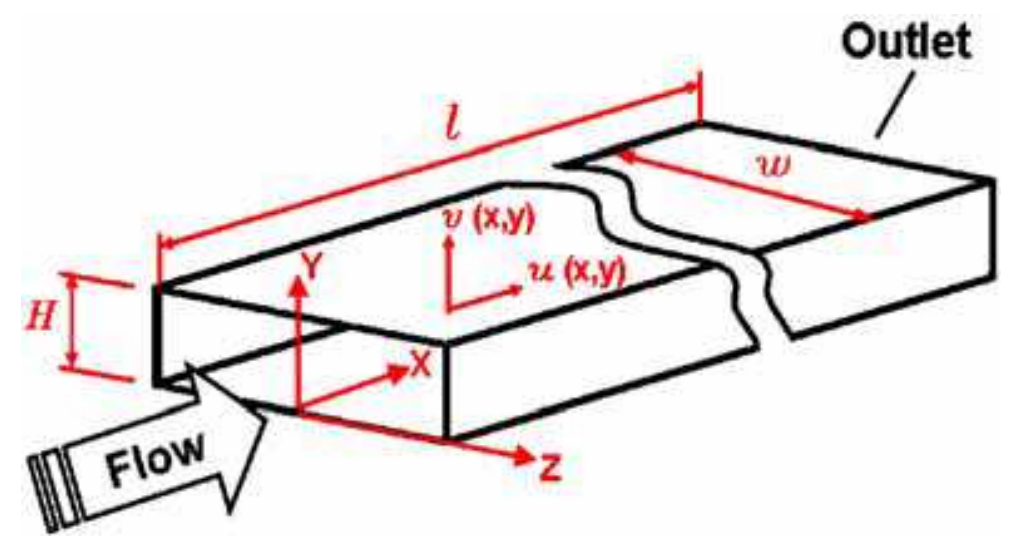

Fig. 35. Schematic diagram and the coordinate system used for the micro-channel flow system.

The micro-channel is actually fabricated by very low thermal conductivity materials which can be considered as well insulated channel. Therefore, the gas flow inside the channel can be assumed to be undergoing isentropic process as follows:

$$
\frac{p}{\rho^{k}}=\text { cons. }
$$

If non-slip boundary condition on the wall is used, then the boundary condition can be written as:

$$
U(y)_{w}=0
$$

In Eq. (8-14), $\mathrm{k}$ is the ratio of specific heat $\mathrm{C}_{\mathrm{p}}$ versus $\mathrm{C}_{\mathrm{v}}$. For micro flow in parallel plate channel, the height is much smaller than either the length or the width of the channel. One can assume that the gradient terms, normal to the surface of channel, in Navier-Stokes Equation are much larger than those along the channel. As a result, one can neglect terms that represent $x$-direction diffusion of momentum (along the channel) relative to those of $y$ direction (normal to the channel surface). That is

$$
u>v, \frac{\partial}{\partial y}>>\frac{\partial}{\partial x} \text { and } \frac{\partial^{2} u}{\partial y^{2}}>>\frac{\partial^{2} u}{\partial x^{2}}
$$


Therefore, the Navier-Stokes Equation for the micro-channel flow can be simplified as

$$
\begin{gathered}
\frac{\partial p}{\partial x}=\mu \frac{\partial^{2} u}{\partial y^{2}} \\
\frac{\partial p}{\partial y}=0
\end{gathered}
$$

Eq. (8-17) and Eq. (8-18) means the pressure varies only in the streamwise direction. Therefore, Eq. (8-17) can be readily solved analytically. This equation is the same as channel flow in the fully developed region. The pressure distribution measurements presented in the later section indicate that the entry length of flow in micro-channel could hardly be observed. It means that the flow in most part of the micro-channel is fully developed except in the very short entry region where $x$ is not large as compared with the width of the channel. The solution of Eq. (8-17) is a parabolic velocity profile as follows:

$$
u(y)=\frac{y^{2}}{2 \mu} \frac{d p}{d x}-\frac{H}{2 \mu} \frac{d p}{d x} y=\frac{1}{2 \mu} \frac{d p}{d x}\left(y^{2}-H y\right)
$$

where $\mathrm{H}$ is the height of the channel. To integrate the above equation along $\mathrm{y}$ direction of the channel, the average velocity can be obtained. Therefore, the mass flow rate $(\mathrm{Qm})$ of in the channel can be shown as follows:

$$
Q_{m}=-\frac{H^{3} w \rho}{12 \mu} \frac{d p}{d x}=-\frac{H^{3} w p^{k}}{\frac{1}{-}} \frac{d p}{12 \mu p_{o}^{k} \rho_{o}^{-1}} d x
$$

where $\mathrm{w}$ is width of the channel and the subscript o refers to the condition at the outlet location of the last pressure sensor in the micro-channel. The above equation can be rearranged as follows:

$$
Q_{m} d x=-\frac{H^{3} w p^{\frac{1}{k}}}{12 \mu p_{o}^{\frac{1}{k}} \rho_{o}^{-1}} d p
$$

One can integrate above equation from the entrance to any location, $x$, in the channel and obtain the pressures distribution inside the channel as follows:

$$
p_{x}=\left[\frac{p_{i}{ }^{k}}{p^{2}}-\frac{12 Q_{m} x\left(\frac{k}{k+1}\right) \mu p_{o}^{k} \rho_{o}^{-1}}{H^{3} w}\right]^{\frac{1}{k+1}}
$$


Where the subscript $\mathrm{i}$ refers to the condition at the inlet location of the first pressure sensor in the micro-channel. To integrate Eq. (8-21) from the entrance to the end of the channel, the mass flow rate can be obtained explicitly as follows:

$$
Q_{m}=\frac{H^{3} w p_{0}{ }^{\frac{k+1}{k}}}{12\left(\frac{k}{k+1}\right) \mu p_{o}^{k} \rho_{o}^{-1} l}\left[\left(\frac{p_{i}}{p_{o}}\right)^{\frac{k+1}{k}}-1\right]
$$

where $l$ is the distance from the first pressure sensor to the last pressure sensor in the microchannel and is equal to $4000 \mu \mathrm{m}$. During the calculation of pressure distribution, the dynamic viscosity $(\mu)$ in the equation is based on the entrance temperature of the channel flow.

For the case when the heat transfer occurs (with a given heat flux boundary condition on the wall), the wall is no longer adiabatic. The above equation can be modified with $\mathrm{k}$ replaced by $\mathrm{n}$ and is written as follows:

$$
p_{x}=\left(p_{i}^{\frac{n+1}{n}}-\frac{12 Q_{m} x\left(\frac{n}{n+1}\right) \mu p_{o}{ }^{n} \rho_{o}^{-1}}{H^{3} w}\right)^{\frac{n}{n+1}}
$$

where $\mathrm{n}$ can be obtained by fitting the above equation to the pressure distribution data. In this way, the pressure variation with either the density or the temperature can be found by a polytropic process as follows:

$$
\frac{p}{\rho^{n}}=\text { const } \text {. }
$$

\subsubsection{Experimental results of the pressure drop for air flow}

The wall roughness has been shown to play very important role on the pressure gradient, which contributed the scattering of friction factor data reported in others (Guo \& Li, 2003; Kleinstreuer \& Koo, 2004), in micro-channel flow. However, the wall information in most of the micro-channels reported in the literature is absent. Therefore, the wall roughness in the current channel is measured and studied. During etching and removing of the silicon substrate, the wall roughness of the channel has been minimized by proper etching process as described previously. The roughness of the current channel wall is measured by the profile meter using a small probe, scanning along axial location of the channel wall. The values of roughness are less than $\pm 5 \mathrm{~nm}$ to $15 \mathrm{~nm}$. The relative roughness is much less than $1 \%$ as compared with the height of the channel (the smallest height of the channel is $23 \mu \mathrm{m}$ ). Therefore, accurate results of pressure drop were obtained based on the small roughness of the wall surface in the micro-channel in this study. Typical results of the pressure distributions, both by theoretical prediction and experiment, for height of channel at $23 \mu \mathrm{m}$ 
are shown with good agreement in Figure 36. Both experimental data and the theoretical prediction indicate that the pressure distribution inside is not linear, due to the compressibility effect of the air flow in the micro-channel, except when the flow speed in the channel is lower than $0.3 \mathrm{Mach}$, which can be assumed as incompressible condition. The agreement between experimental data and theoretical prediction is very good even in the upstream region close to the entrance. Therefore, this means that the pressure distribution in the region close to the entrance has reached a fully developed flow. This clearly indicates that the hydrodynamic entrance length in the micro-channel flow is very short as mentioned previously in the derivation of the pressure distribution equation. Therefore, the assumptions used in the analysis are thus confirmed. In addition, all the pressure data drop smoothly from the entrance to the exit. There is no any sudden change in the pressure gradient where flow may undergo an earlier onset of transition from laminar to turbulent flow as mentioned by others (Peng et al., 1994, 1996), which causes greater friction factor in micro-channel.

The variation of the pressure difference between the inlet and the outlet with the volume flow rate is also measured and compared with theoretical prediction, as shown in Figure 37 for the channel height varied from $23 \mu \mathrm{m}$ to $55 \mu \mathrm{m}$. The agreement is still very good for any of the micro-channels. This result further indicates that there is not any reduction or enhancement in the friction on the wall either might be due to reduction in viscosity or surface roughness effect. There is again no any sudden change in the pressure drop which indicates that the flow may undergo an earlier onset of transition from laminar to turbulent flow as mentioned by others. The Reynolds number defined in Figure 37 is equal to the mean velocity of flow in the hydraulic diameter of the channel and divided by the kinematic viscosity of the air flow.

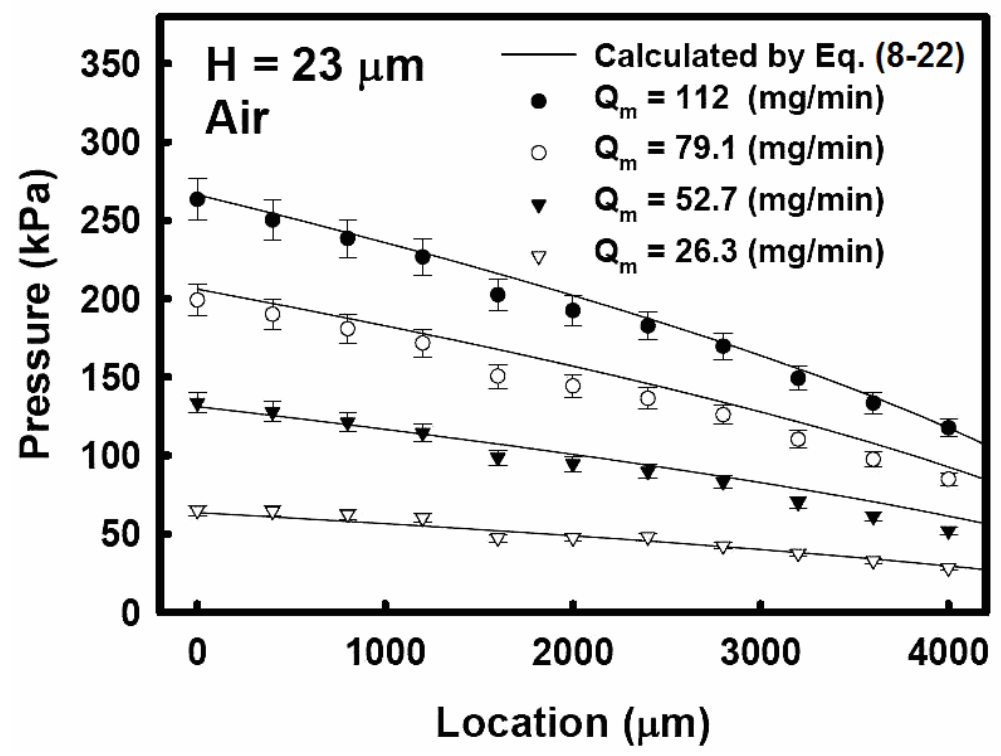

Fig. 36. Comparisons of the pressure distributions between the current data and the analytical results for the airflow along the micro-channel. 
It is noted that the friction factor in micro-channel of air flow is not a constant if one converts the pressure distribution in Figure 36 into the friction factor. This result is contrary to many of other experimental work which obtains a friction factor at a constant value (Takuto et al., 2000; Liu et al., 2004; Kohl et al., 2005; Bayraktar \& Pidugu, 2006). That means that air flow in their micro-channels has been unconsciously assumed as incompressible. To calculate Reynolds number for the amount of mass flow rate in the current channel, the largest Reynolds number is very close to 2000, as shown in Figure 5.4, which is in the laminar regime. In the large scale channel, this is an extremely low Reynolds number flow condition and the flow usually can be assumed as incompressible. However, in the microchannel flow, the flow speed for $\operatorname{Re}=2000$ is $280 \mathrm{~m} / \mathrm{s}$ for channel height of $55 \mu \mathrm{m}$. In this case, the March number for $\operatorname{Re}=2000$ is equal to 0.82 , and the flow is highly compressible and can not be assumed as incompressible. To assume incompressible flow will lead to an erroneous skin friction coefficient. In fact, to assume incompressible flow, the friction factor obtained will be much smaller than in the large scale channel as presented in some of the other works.

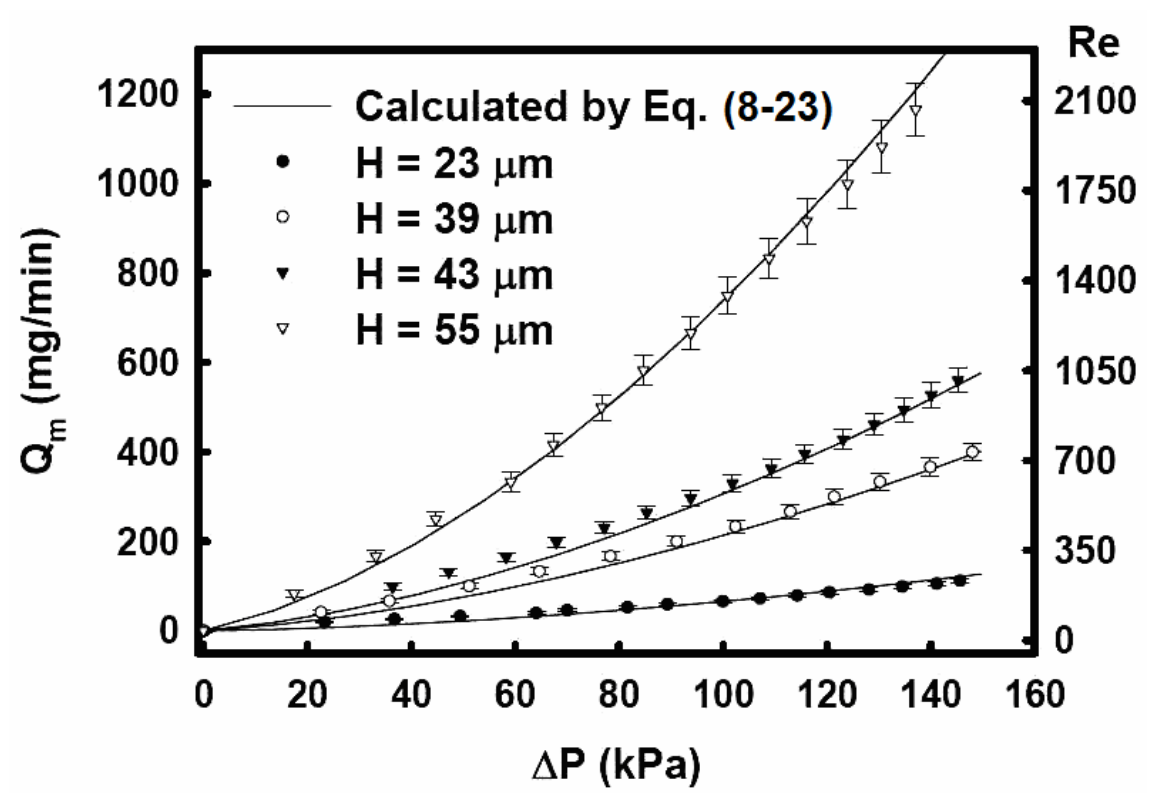

Fig. 37. Variation of the pressure difference between the inlet and the outlet with the mass flow rate or the Reynolds number.

With the constant heat flux imposed on the wall, the pressure distribution is also measured as shown in Figure 38. The pressure variation along the channel is very similar to the case when the channel wall is insulated except that the magnitude of the pressure is higher. Eq. $(8-24)$ is used to fit the pressure distribution data by varying the value of $\mathrm{n}$ in this equation. The value of $\mathrm{n}$ determined from the fit can be used to find the relationship between the pressure and the density in the microchannel under the constant heat flux condition. This pressure versus density relationship is required for determination of the heat transfer coefficient as described in the next section. 


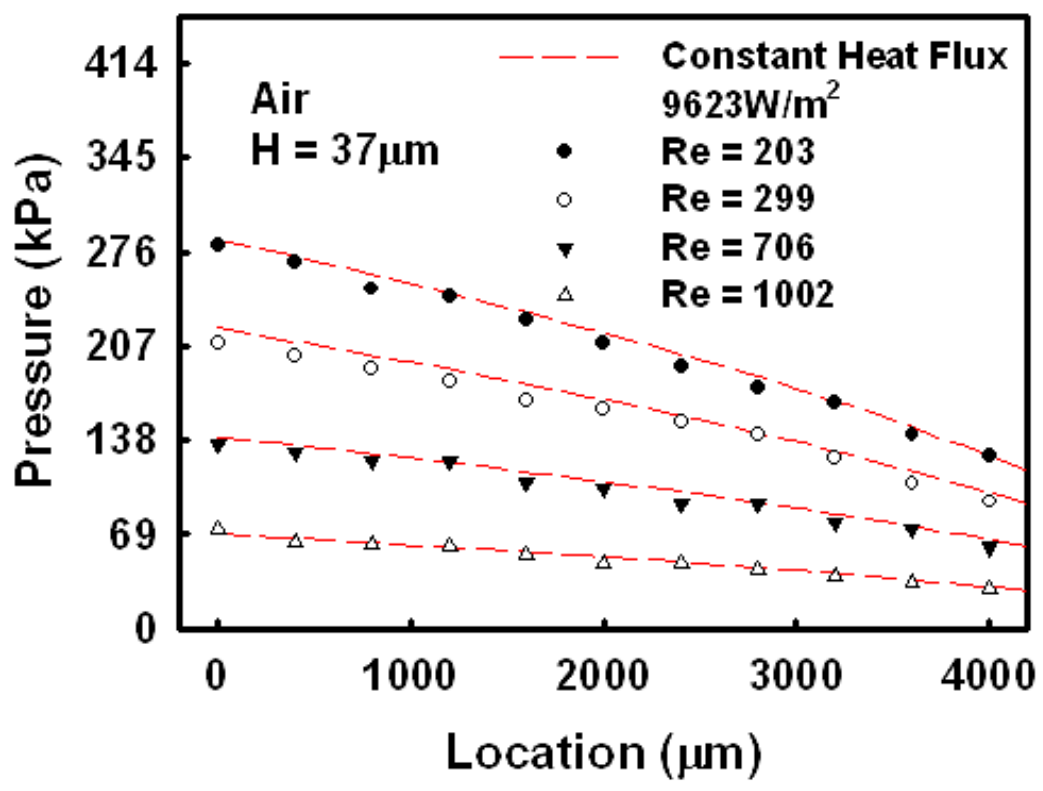

Fig. 38. Comparisons of the pressure distributions between the current data and the analytical results for the airflow along the microchannel for the case under constant wall heat flux, Eq. (8-24) is used to fit the data by varying the value of $n$.

\subsection{Local heat transfer for air flow}

In order to further study the heat transfer characteristics in the micro-channel, the current micro-channel is integrated with array of temperature sensors, pressure sensors and a set of heater. In the current experiment, the heat transfer coefficient, $h_{b}$, is defined by the equation as follows:

$$
h_{b}=\frac{\dot{q}}{\left(T_{w}-T_{b}\right)}
$$

where $\dot{q}$ is the heat flux imposed along the wall by the electric heater and is equal to the product of the voltage and the current passing through the heater divided by the total area of the heater. $\mathrm{T}_{\mathrm{w}}$ is the wall temperatures measured by the temperature sensors along the channel at particular locations $x . T_{b}$ is the bulk temperature of the flow which can be estimated from the amount of heat flux imposed on the wall which heats up the air flow and rises the temperature of the bulk flow. By applying a control volume and conservation of energy for the flow in the channel as discussed by Incropera et al. (2007), one can obtain a conservation equation of energy as follows:

$$
\dot{q} \pi D_{h} d x=\dot{m} c_{p} d T_{b}
$$

where $\dot{m}$ is the mass flow rate of the air in the channel. Rearranging and integrating the above equation from the inlet of the channel, one can obtain: 


$$
\int_{T_{i n}}^{T_{b}} d T_{b} \int_{0}^{x} \frac{\dot{q} \pi D_{h}}{\dot{m} c_{p}} d x
$$

Therefore,

$$
T_{b}=T_{i}+\frac{\dot{q} \pi D_{h}}{\dot{m} c_{p}} x
$$

The local Nusselt number, $\mathrm{Nu}_{\mathrm{b}}$, can be defined as:

$$
N u_{b}=\frac{h_{b} \times D_{h}}{k}
$$

where $k$ is thermal conductivity of the gas flow. Once heat transfer coefficient is obtained, the local Nusselt number can be found from the above equations.

\subsubsection{Direct measurements of the heat transfer for air flow}

The heat transfer experiments have been performed with air flow in a channel with channel height of $37 \mu \mathrm{m}$. The velocity of air flow is controlled by mass flow controller and is assumed in the laminar regime where the Re from 203 to 1006. The thermal conductivity of the air used in the Nusselt number is evaluated at the mean bulk temperature, i.e. an average of the bulk temperature of the flow at the inlet and the outlet of the channel. As shown in Figure 39 (a), the heat flux is varied from 5413 to $21652 \mathrm{~W} / \mathrm{m}^{2}$ and the Reynolds number is kept at 500. The Nusselt numbers in the micro-channel with channel height at 37 $\mu \mathrm{m}$ is significantly higher than that of theoretical prediction by the parallel plates channel (Rohsenow et al., 1985), and become closer as the heat flux on the wall decreases. For the case of heat flux equal or lower than $9623 \mathrm{~W} / \mathrm{m}^{2}$, all the Nusselt number results collapse into a single line, as shown in Figure 39 (b), in the downstream of the channel where flow has become fully developed. The Nusselt number results collapsing into a single curve in the fully developed region agrees with theoretical results for prediction of large scale channel except that the Nusselt number is higher. This indicates that other effects, such as property variation with temperature, compressibility of flow, should be taken into account in order to obtain a good correlation of the heat transfer data.

\subsubsection{Correction for the bulk temperature}

The reason for this deviation may be partially attributed to property variation, such as compressible gas flow and leads to increase in the heat transfer. In order to account for the compressibility of the gas which can expand and reduce the kinetic energy of the flow, and change the bulk temperature of the flow, the theoretical calculation equation for the bulk temperature should be re-derived from concept of energy balance, as follows:

$$
d \dot{q}=\dot{m}\left(e_{2}-e_{1}\right)+\left(\frac{U_{2}^{2}}{2}-\frac{U_{1}^{2}}{2}\right)
$$

where $e$ is enthalpy and the subscript indicates properties at different locations. For a differential control volume, the above equation can be written as: 

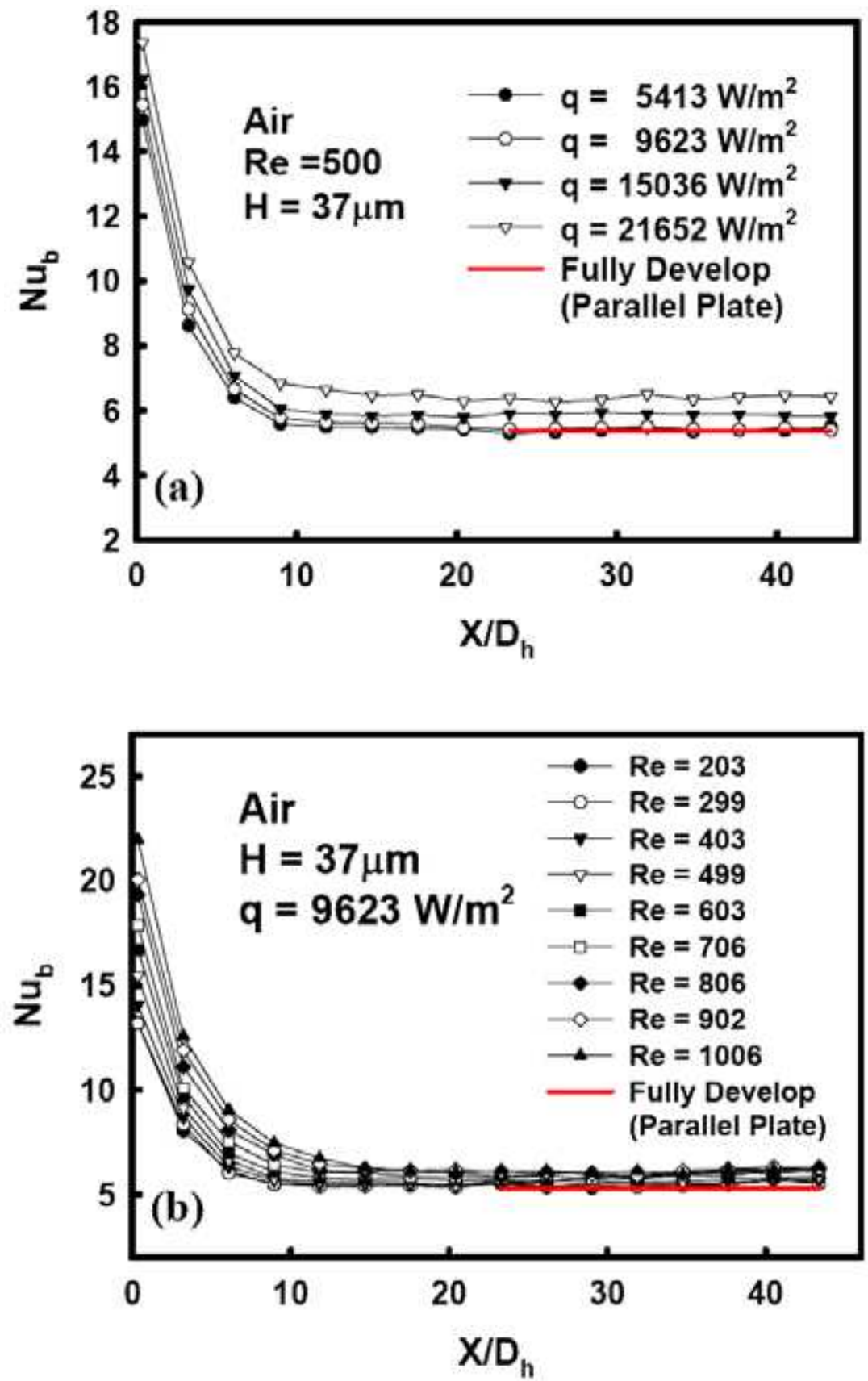

Fig. 39. Experimental results for local Nusselt number distributions under (a) different heating flux conditions and (b) different Reynolds number. 


$$
d \dot{q}=\dot{m} d e+d\left(\frac{U^{2}}{2}\right)
$$

where $d q=\dot{q}_{w} \pi D_{h}$, and $d e=c_{p} d T$, re-arranging the above equation, one obtains

$$
\frac{d T_{b}}{d x}=\frac{\dot{q}_{w} \pi D_{h}}{\dot{m} c_{p}}-\frac{d\left(\frac{U^{2}}{2}\right)}{c_{p} d x}
$$

To integrate above equation from the entrance to the desired location, $x$, in the channel, one can obtain the bulk temperature of the flow as follows:

$$
\mathrm{T}_{b}=\mathrm{T}_{i}+\frac{\dot{q}_{w} \pi D_{h}}{\dot{m} c_{p}} x-\left(\frac{U_{x}^{2}}{2}-\frac{U_{i}^{2}}{2}\right) \frac{1}{c_{p}}
$$

From the continuity equation,

$$
\rho_{1} A_{1} U_{1}=\rho_{2} A_{2} U_{2}
$$

The bulk temperature can be re-arranged as follows:

$$
\left.T_{b}=T_{i}+\frac{\dot{q}_{w} \pi D_{h}}{\dot{m} c_{p}} x-\frac{U_{i}^{2}}{2 c_{p}}\left[\frac{\rho_{i}}{\rho_{x}}\right)^{2}-1\right]
$$

Since the current micro-channel is actually fabricated by very low thermal conductivity materials, the channel wall can be considered as well insulated. Without heat transfer into the channel, the gas flow inside the channel can be assumed to be undergoing isentropic process. For the case when a desired heat flux is imposed on the bottom wall, the gas is assumed under polytropic process and the pressure density relationship can be written as follows:

$$
\frac{p}{\rho^{n}}=\text { cons. }
$$

where $\mathrm{n}$ is a constant and is determined from the heating condition on the wall of the channel. Therefore, the density in Eq. (8-36) can be replaced by the local pressure as follows:

$$
T_{m}=T_{i}+\frac{\dot{q}_{w} \pi D_{h}}{\dot{m} c_{p}} x-\frac{U_{i}^{2}}{2 c_{p}}\left[\left(\frac{p_{i}}{p_{x}}\right)^{\frac{2}{n}}-1\right]
$$

\subsubsection{Heat transfer data}

From the local pressures measured by current pressure sensors along the micro-channel, the bulk temperature can be re-calculated from the above equation. Therefore, the local Nusselt 
numbers along the channel can be obtained and are presented in Figure 40 for different Reynolds number conditions. All the Nusselt number results collapse into a single curve in the fully developed region, as shown in Figure 40 (a) for different heat flux conditions. Again, for the case of heat flux at $9623 \mathrm{~W} / \mathrm{m}^{2}$ the Nusselt numbers at different Reynolds numbers also collapse into a single curve in the fully developed region, as shown in Figure 40 (b), but the curve is slightly lower than the prediction in large scale channel. Theoretical calculation for the heat transfer in large scale rectangular channel at different aspect ratios in the fully developed region has been performed and reported (Incropera et al., 2007). It is found that in large scale channel the Nusselt number is 4.55 for rectangular channel with aspect ratio of 1:10, but is 5.38 for ideal parallel plate channel. In fact, the current microchannel is not an ideal parallel plates channel and is a channel with aspect ratio of 1:13. Therefore, the lower Nusselt numbers of experimental results in the current channel than the prediction for parallel plates channel is expected and is attributed to the effect of aspect ratio.

In order to compare the heat transfer in the entrance region, the flow is assumed to be hydrodynamically fully developed before entering into the channel and the problem becomes a thermal entry length problem because the hydrodynamic entry length is very short as defined as Eq. (8-6). In the thermal entry length region, the heat transfer process can be correlated in terms of the inverse Graetz number, where

$$
G_{z}=\frac{\operatorname{Re} \operatorname{Pr}}{x / D_{h}}
$$

The thermal entry length in the large scale tube can be usually expressed as (Incropera et al., 2007),

$$
G z^{-1} \sim 0.05
$$

This expression or the entry length is found at the point when the Nusselt number results approach a constant value. From our heat transfer data, as shown in Figure 41, the entry length in the current micro-channel can be found and expressed as,

$$
G z^{-1} \sim 0.023
$$

It appears that the current heat transfer data does not have the same trend as in the large scale tube. This is attributed to the fact that the current micro-channel is not an ideal parallel plate channel. The correlation equation for parallel plates channel in the entry region (Naito, 1984) can be expressed as follows:

$$
N u_{x}=0.461043 G z^{1 / 2}\left(1+6.35257 G z^{-1 / 2}-33.4079 G z^{-1}+419.158 G z^{-3 / 2}-1537.84 G z^{-2}\right)
$$

Comparison of the correlation equation for the local Nusselt numbers between the prediction for large scale channel and the experimental data for micro-channel with a channel height of $37 \mu \mathrm{m}$ is made in Figure 41. The agreement in entrance region is very good except in the fully develop region the current data is slightly low due to the aspect ratio effect. 

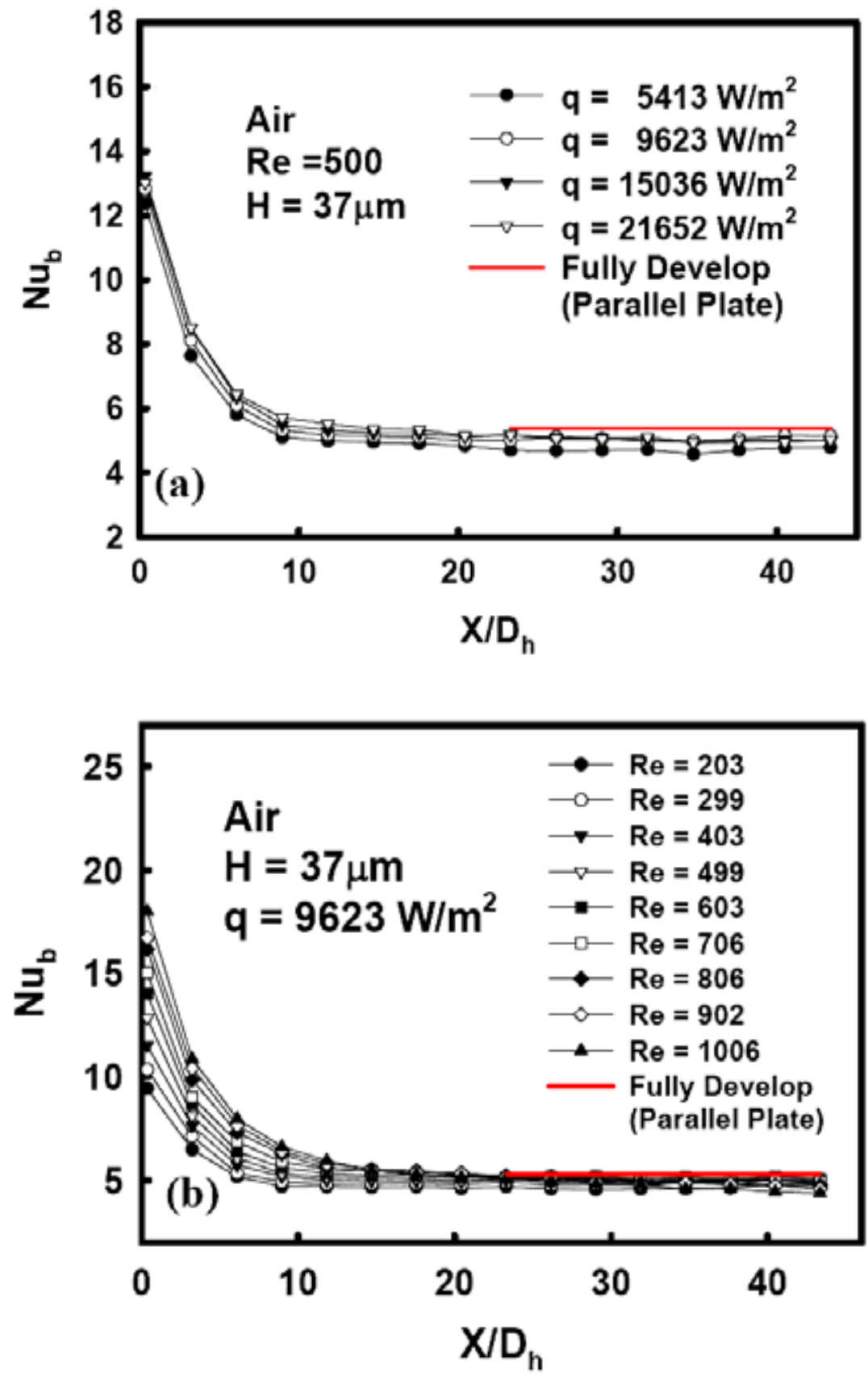

Fig. 40. Re-calculated results for local Nusselt number distributions under (a) different heating flux conditions and (b) different Reynolds number. 


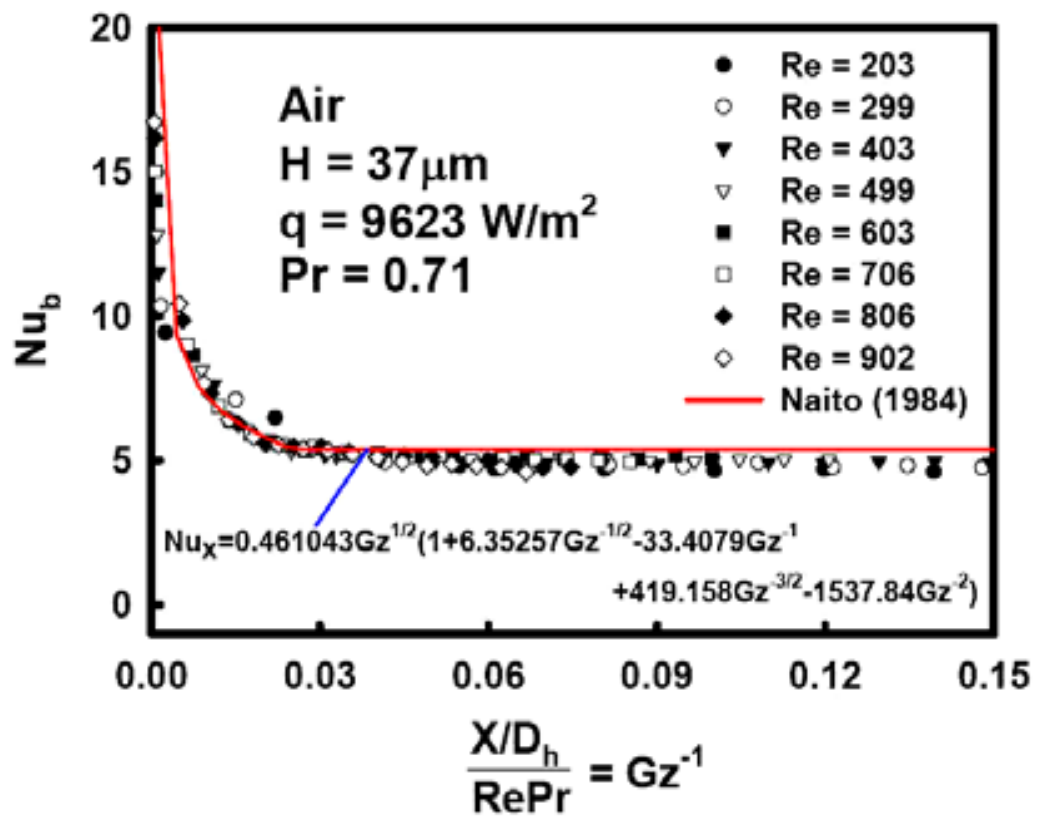

Fig. 41. Comparison of the local Nusselt numbers between the prediction for large scale channel and the experimental data.

Since some of the heat transfer data reported in the literature is the average heat transfer coefficient or the average Nusselt number, comparison with these data can be made when the average Nusselt number is defined as follows:

$$
N u_{\text {ave }}=\frac{1}{x} \int_{0}^{x} N u_{b} d x
$$

The average Nusselt numbers in the current micro-channel are obtained in the range of laminar flow and compared, as shown in Figure 42, with the correlation predicted by Naito for air flow in large scale parallel plates channel. The average Nusselt number is very close, but smaller than the correlation obtained by Naito. This is attributed to the effect of aspect ratio. The result is of interest to compare current heat transfer data with the results of others in micro or large scale channel. To avoid influence of EDL in liquid flow, comparison is limited to air flow in channels. In general, when $\operatorname{Re}>2300$, the flow inside channel becomes turbulent. The average Nusselt number for $\operatorname{Re}>2300$ is much larger than for $\operatorname{Re}<2300$ (Morini, 2004; Incropera et al., 2007). For large scale channel, the Nusselt number in the two parallel plates is, in general, greater than that in circular tube (Incropera et al., 2007). This is indicated in Figure 43 where the average Nusselt number of the numerical results obtained by Naito and experimental results obtained by this study for two parallel plates, and is higher than the correlation obtained by Hausen for circular tube. The heat transfer correlations obtained by Choi (1991) is for air flow in mcirotubes. Their data is much smaller than the correlation of Hausen. The much lower value of Nusselt number and its large 
increase with Reynolds number in Choi's data was attributed to the streamwise conduction of heat along the micro-tube. The micro-tubes used in the past were made of stainless steel which is convenient for electric heating, and is expected to cause large streamwise conduction of heat in the finite thickness of the tube since the thermal conductivity of stainless steel is relatively high and is in the range from 13 to $15 \mathrm{~W} / \mathrm{mK}$ depending upon the types of the steel used. However, the streamwise conduction of heat along the current micro-channel wall has been minimized due to the use of a thick layer of epoxy which has a very low thermal conductivity. In addition, wall roughness in the micro-tubes of Choi is expected large enough which may result the discrepancy. However, the roughness of their micro-tubes is not reported. When one goes into turbulent flow region, the heat transfer data from different work in micro-channel scatters very much, but are all higher than those in large scale channel (Wu \& Little, 1983; Yu et al., 1995; Morini, 2004; Kays et al., 2005). It is noted that data from both the work of Dittus-Boelter and Gnielinski (Rohsenow et al., 1985) is for air flow in large scale tubes. The higher heat transfer data in micro-channel can be attributed to wall roughness effect in the micro-tubes. It has been realized (Kays et al., 2005; Incropera et al., 2007) that wall roughness can significantly enhance turbulent heat transfer in the large scale tube. Thus, wall roughness is expected to significantly enhance turbulent heat transfer in micro-channel. Unfortunately, wall roughness on each of the mcirotube wall was not reported and was expected to be very high in the micro stainless steel tubes if no special treatment on the surface is provided.

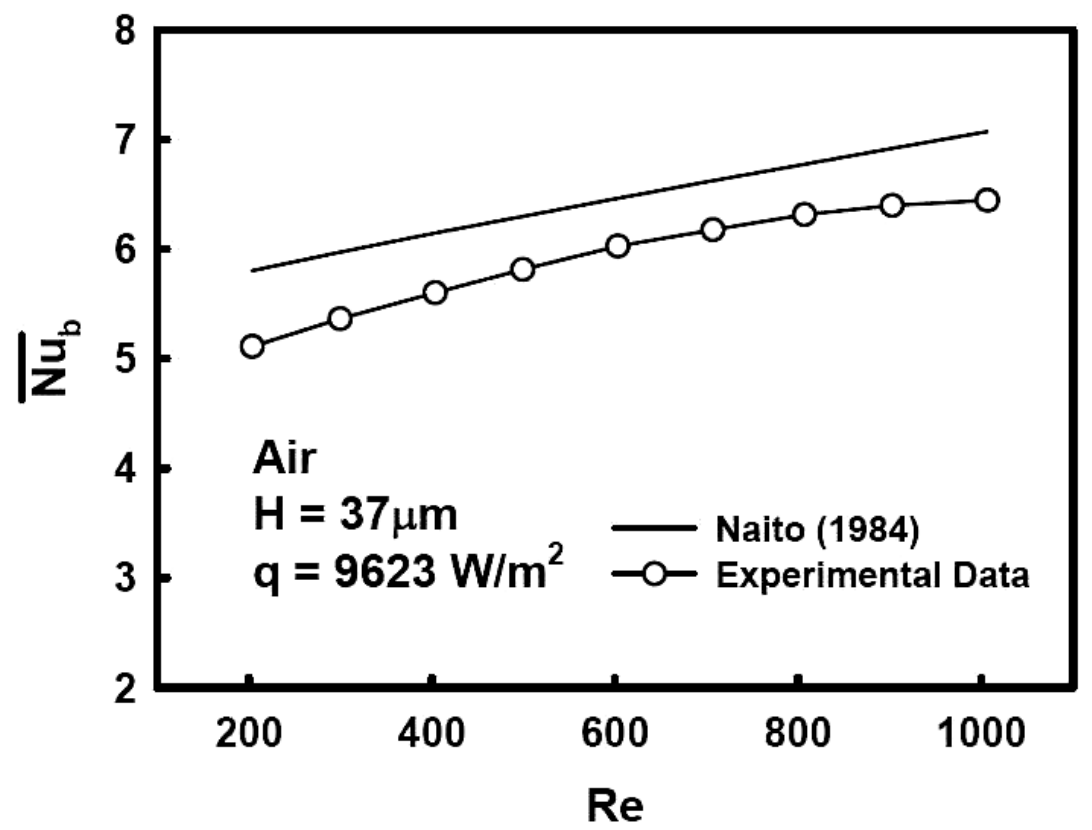

Fig. 42. Comparison of the average Nusselt numbers in the current micro-channel with the correlation predicted by Naito for air flow in large scale parallel plates channel. 


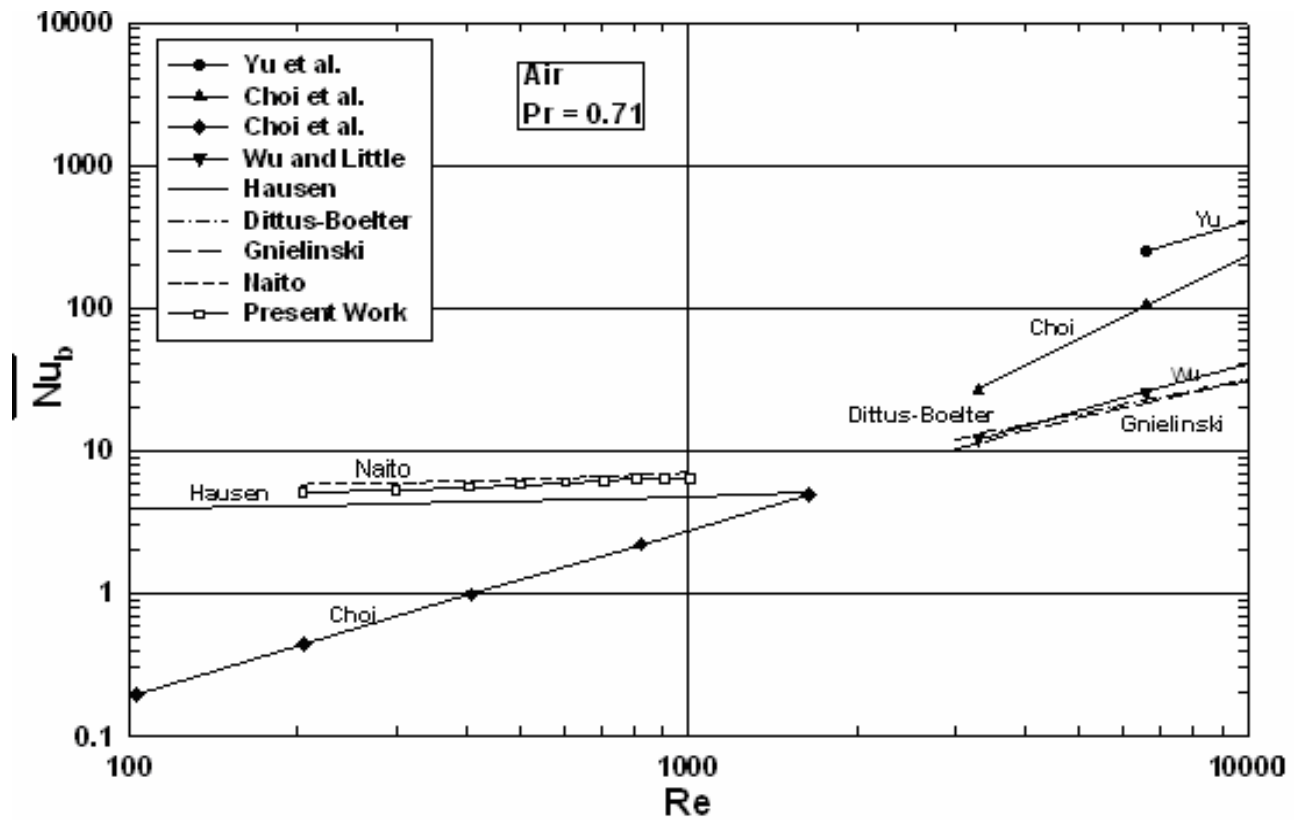

Fig. 43. Comparison of average Nusselt numbers between the current work and published data.

\section{References}

Acosta, R. E., Muller, R.H., and Tobias, W. C. (1985). Transport processes in narrow (Capillary) channels, AIChE Journal, Vol. 31, pp.473-482.

Arkilic, E. B. and Schmidt, M. A. (1997). Gaseous slip flow in long microchannels, Journal of Microelectromechanical System, Vol. 6(2), pp.167-178.

Arshak, K., Morris, D., Arshak, A., Korostysnska, O., Jafer, E., Waldron, D., and Harris, J. (2006). Development of polymer-based sensors for integration into a wireless data aquisition system suitable for monitoring environmental and physiological processes, Biomolecular Engineering, Vol. 23, pp.253-257.

Arulanandam, S., and Li, D. (2000). Liquid transport in rectangular microchannels by electroosmotic pumping, Colloids and Surfaces A: Physicochemical and Engineering Aspects, Vol. 161, pp.89-102.

Bayraktar, T. and Pidugu, S. B. (2006). Review: Characterization of liquid flows in microfluidic systems, Int. J. Heat Mass Transfer, Vol. 49, pp.815-824.

Beskok, A., and Karniadakis, G. E. (1994) Simulation of heat and momentum transfer in complex microgeometries, Journal of Thermophysics and Heat Transfer, Vol. 8, No. 4, pp. 246-259.

Bhatnagar, P. L., Gross, E. P. and Krook, M. (1954) A Model for Collision Processes in Gases. I. Small Amplitude Processes in Charged and Neutral One-Component Systems, Phys. Rev., Vol. 94, pp.511-525.

Bird, G. A. (1976a). Molecular gas dynamics and the direct simulation of gas flows, Clarendon Press, Oxford, pp. 183-207. 
Bird, G. A. (1976b). Molecular gas dynamics, Clarendon Press, Oxford, pp. 110-117.

Brutin, D., Topin, F., and Tadrist, L. (2003) Experimental study of unsteady convective boiling in heated minichannels, International Journal of Heat and Mass Transfer, Vol. 46, pp. 2957-2965.

Chen, H. R. (2001). Design and fabrication of the microchannel system for thermal fluid study, Ph D. Thesis, National Cheng Kung University, Tainan, Taiwan.

Chen, H. R., Gau, C., Dai, B. T. and Tsai, M. S. (2003a). A Novel Planarization Process for Sacrificial Polysilicon Layers in a Micro-Thermal System, Sensors and Actuators A: Physical, Vol. 108/1-3, Nov. pp.86-90.

Chen, H. R., Gau, C., Dai, B. T. and Tsai, M. S. (2003b). A Monolithic Fabrication Process for a Micro-Flow Heat Transfer Channel Suspended over an Air Layer with Arrays of Micro Sensors and Heaters, Sensors and Actuators A: Physical, Vol. 108/1-3, Nov. pp.81-85.

Chen, X. (1996). Gas kinetics and its applications in heat transfer and flow, TsingHua University Press, Beijing.

Cheng, P., Wang, G., and Quan, X. (2009). Recent work on boiling and condensation in microchannels, ASME Journal of Heat Transfer, Vol. 131, pp. 043211-043225.

Choi, S. B., Barron, R. F., and Warrington, R. O. (1991). Fluid flow and heat transfer in microtubes, Micromechanical Sensors, Actuators, and Systems, ASME, DSC, Vol. 32, pp. 123-134.

Choondal, B. S. and Suresh, V. G. (2000). A comparative analysis of studies on heat transfer and fluid flow in microchannels, Proc. of the Micro-Scale Heat Transfer Conf. pp.80-92.

Chu, W. K. H., Hsu, C. T., Wong, M., and Zohar, Y. (1994). Heat transfer in a microchannel flow, Proceedings of the 1994 IEEE Electron Devices Meeting, Hong Kong, pp. 38-43.

Clark, S. K., and Wise, K. D. (1979). Pressure sensitivity in anisotropically etched thindiaphragm pressure sensors, IEEE Trans. Electron Devices, ED-26, pp. 1887-1896.

Core, T. A., Tsang, W. K., and Sherman, S. J. (1993). Fabrication technology for an integrated surface micromachined sensor, Solid State Technolog, pp. 39-47.

Craighead, H. (2006). Future lab-on-chip technologies for interrogating individual molecules, Nature, Vol. 442 (27), pp.387-393.

Eckert, E. R. G., and Drake, R. M. (1972). Analysis of heat and mass transfer, McGraw-Hill, New York, pp.467-495.

Fan, Q., and Xue, H. (1998). Compressible effects in microchannel flows, Proceedings of the IEEE/CPMT Electronics Packaging Technology Conference, pp.224-228.

George, M. (2006). The origins and the future of microfluidics, Nature Vol. 442, pp.368-373.

Giordani. N., Camberlein, L., Gaviot, E., Polet, F., Pelletier, N., and Bêche, B. (2007). Fast psychrometers as new SU-8 based microsystems, IEEE Transactions on Instrumentation and Measurement, Vol. 56, No. 1, pp.102-106, 2007.

Guckel, H. (1991). Surface micromachined pressure transducer, Sens. Actuators A, Vol. 28, pp. 133-146.

Guckel, H. et al. (1990). Microstructure sensors, International Electron Devices Meeting, pp. 613-616.

Guo, Z. and Li, Z. (2003). Size effect on microscale single-phase flow and heat transfer, Int. J. Heat Mass Transfer Vol. 46, pp.149-59.

Harley, J. C., Huang, Y. H., Bau, H., and Zemel, J. N. (1995). Gas flow in micro channels, Journal of Fluid Mechanics, Vol. 284, pp257-274.

Harms, T. M., Kazmierczak, M. J. and Gerner, F. M. (1999). Developing convective heat transfer in deep rectangular microchannels, International Journal of Heat Fluid Flow, Vol. 20, pp. 149-157. 
Harms, T.M., Kazmierczak, M.J., Gerner, F.M., Holke, A., Henderson, H.T., Pilchowski, J. and Baker, K. (1997). Experimental investigation of heat transfer and pressure drop through deep microchannels in a (110) silicon substrate, Proceedings of ASME Heat Transfer Division, ASME HTD, Vol. 351-1, pp. 347-357.

Hetsroni, G., Mosyak, A., Segal, Z., and Ziskind, G. (2002). A uniform temperature heat sink for cooling of electronic devices, International Journal of Heat and Mass Transfer, Vol. 45, pp.3275-3286.

Hetsroni, G., Mosyak, A. and Segal, Z. (2001). Nonuniform temperature distribution in electronic devices cooled by flow in parallel microchannels, IEEE Transactions on components and packaging technologies, Vol. 24, pp.17-23.

Hu, H. Y., Peterson, G. P., Peng, X. F. and Wang, B. X. (1998). Interface fluctuation propagation and superposition model for boiling nucleation, International Journal of Heat and Mass Transfer, Vol. 41, pp.3483-3490.

Incropera F. P., DeWitt D. P., Bergman T. L. and Lavine A. S. (2007). Fundamentals of Heat and Mass Transfer $6^{\text {th }}$ Ed., New York, John Wiley \& Sons Inc.

Jiang, P. X., Fan, M. H., Si, G. S. and Ren, Z. P. (1997). Thermal-hydraulic performance of small scale micro-channel and porous-media heat exchangers, International Journal of Heat and Mass Transfer, Vol. 44, pp.1039-1051.

Jiang, L., Wong, M. and Zohar, Y. (1999). Phase change in microchannel heat sinks with integrated temperature sensors, J. MEMS, Vol., 8, pp.358-365.

Jiang, L., Wong, M., and Zohar, Y. (2001). Forced convection boiling in a microchannel heat sink, Journal of Microelectromechanical System, Vol. 10, pp.80-87.

Jiang, X. N., Zhou, Z. Y., Yao, J., Li, Y. and Ye, X. Y. (1995). Micro-fluid flow in micro channel, Proceedings of the $8^{\text {th }}$ International Conference on Solid-State Sensors and Actuators, and Eurosensors IX (Transducers '95), Stockholm, Sweden, pp.317-320, June 25-29.

Kanda, Y. (1982). A graphical representation of the piezoresistive coefficients in silicon, IEEE Transactions on electron devices, Vol. ED-29, No. 1, pp. 64-70.

Kandlikar, S. G. (2006). Nucleation characteristics and stability considerations during flow boiling in microchannels, Experimental Thermal and Fluid Science, Vol. 30, pp.441-447.

Kays, W. M., Crawford, M. E. and Weigand, B. (2005). Convective Heat and Mass Transfer, $4^{\text {th }}$ ed., McGraw-Hill, New York.

Kennard, E. H. (1938) Kinetic theory of gases-with an introduction to statistical mechanics, McGraw- Hill, Inc., New York, pp.291-337.

Khantuleva, T. A. (1982). Nonlocal hydrodynamical models of gas flows in the transition regime. In: Rarefied gas dynamics 1, Belotserkovskii, O. M., Kogan, M. N., Kutateladze, S. S. and Rebrov, A. K. Ed., Plenum Press, New York, pp.229-235.

Khrustalev, D., and Faghri, A. (1993). Thermal analysis of a micro heat pipe, Heat Pipes and Capillary Pumped Loops, ASME, HTD, Vol. 236, pp.19-30.

Kim, C. J., Kim, J. Y., and Sridharan, B. (1998). Comparative evaluation of drying techniques for surface micromachining, Sens. Actuators A, Vol. 64, pp.17-26.

Kleinstreuer, C. and Koo, J. (2004). Computational Analysis of Wall Roughness Effects for Liquid Flow in Micro-Conduits, J. Fluid Engineering, Vol. 126, pp.1-9.

Knudsen, M. (1934). The kinetic theory of gases, Methuen, London.

Ko, H. S. and Gau, C. (2011). Micro scale thermal fluid transport process in a microchannel integrated with arrays of temperature and pressure sensors, Microfluidics and Nanofluidics, (in press). 
Ko, H. S. and Gau, C. (2009) Bonding of a complicated polymer microchannel system for study of pressurized liquid flow characteristics with electric double layer effect, Journal of Micromechanics and Microengineering, Vol. 19, art no. 115024.

Ko, H. S. (2009). Fabrication and development of micro fluidic system with embedded micro pressure and temperature sensors for study of thermal and fluid flow properties, Ph D. thesis, National Cheng Kung University, Tainan, Taiwan.

Ko, H. S., Liu, C. W., Gau, C. and Jeng, D. Z. (2008). Flow characteristics in a microchannel system integrated with arrays of micro pressure sensors using polymer material, Journal of Micromechanics and Microengineering, Vol. 18, art no. 075016.

Ko, H. S., Liu, C. W., and Gau, C. (2007). Micro pressure sensor fabrication without problem of stiction for a wider range of measurement, Sensors and Actuators A: Physical, Vol. 138, pp.261-267.

Ko, H. S., Liu, C. W., and Gau, C. (2007). A novel fabrication for pressure sensor with polymer material and evaluation of Its performance, Journal of Micromechanics and Microengineering, Vol. 17, pp.1640-1648.

Kohl, M. J., Abdel-Khalik, S. I., Jeter, S. M. And Sadowski, D. L. (2005). An experimental investigation of microchannel flow with internal pressure measurements, International Journal of Heat and Mass Transfer, Vol. 48, pp.1518-1533.

Komvopoulos, K. (1996). Surface engineering and microtribology for microelectromechanical systems, Wear, Vol. 200(1-2), pp.305-327.

Koo, J. and Kleinstreuer, C. (2003). Liquid flow in microchannels: experimental observations and computational analyses of microfluidics effects, J. Micromech. Microeng. Vol. 13 pp.568-579.

Kundt, A. and Warburg, E. (1875). On the friction and thermal conductivity in rerefied gases, Phil. Mag., Vol. 50, pp.53.

Lalonde, P., Colin, S., and Caen, R. (2001). Mesure de debit de gaz dans les microsystemes, Mechanical Industry, Vol. 2, pp.355-362.

Lee, G. B., Lin, C. H. and Chang, G. L. (2003). Micro flow cytometers with buried SU-8/SOG optical waveguides, Sensors and Actuators: Physical A, Vol. 103, pp.165-170.

Lee, M., Wong, Y. Y., Wong, M. and Zohar, Y. (2003). Size and shape effects on two-phase flow patterns in microchannel forced convection boiling, Journal of Micromechanics and Microengineering, Vol. 13, pp.155-164.

Lee, W. Y., Wong, M. and Zohar, Y. (2002). Pressure loss in constriction microchannels, Journal of MicroElectroMechanicalSystem, Vol. 11, No. 3, pp.236-244.

Legtenberg, R., Elders, J. and Elwenspoek, M. (1993). Stiction of surface microstructure after rinsing and drying: model and investigation of adhesion mechanisms, Proc. $7^{\text {th }}$ Int. Conf. Solid-State Sensors and Actuators (Transducer'93), Yogohama, Japan, pp.198-201.

Li, D. (2001). Electro-viscous effects on pressure-driven liquid flow in microchannels, Colloids and Surface A, Vol. 195, pp.35-57.

Li, X., Lee, W. Y., Wong, M. and Zohar, Y. (2000) Gas flow in constriction microdevices, Sensor and Actrators A, Vol. 83, pp.277-283.

Li, Z. X., Du, D. X. and Guo, Z. Y. (2003). Experimental study on flow characteristics of liquid in circular microtubes, Microscale Thermophysicals Engineering, Vol. 7, pp.253-265.

Li, Z. X., Du, D. X. and Guo, Z. Y. (2000). Experimental study on flow characteristics of liquid in circular microtubes, Proceedings of International Conference on Heat Transfer and Transport Phenomena in Microscale, Begell House, New York, USA, pp.162-168. 
Lin, L. and Pisano, A. P. (1991). Bubble forming on a micro line heater, Micromechanical Sensors, Actuators, and Systems, ASME, DSC, Vol. 32, pp.147-164.

Lin, L., Udell, K. S. and Pisano, A. P. (1994). Liquid-vapor phase transition and bubble formation in micro structures, Thermal Science Engineering, Vol. 2, pp.52-59.

Liu, C. W. (2004). Fabrication development for micro channel system by MEMS technology with measurements of the inside thermal transport process, Ph D. thesis, National Cheng Kung University, Tainan, Taiwan.

Liu, C. W., Gau, C. and Dai, B. T. (2004). Design and Fabrication Development of a Micro Flow Heated Channel with Measurements of the inside Micro-Scale Flow and Heat Transfer Process, Biosensors and Bioelectronics, Vol. 20, No. 1, pp.91-101.

Liu, J. and Tai, Y. (1995). MEMS for pressure distribution studies of gaseous flows in microchannels, An Investigation of Micro Structures, Sensors, Actuators, Machines, and Systems, pp. 209-215.

Liu, T. Y., Li, P.L., Liu, C.W., Gau, C. (2011). Boiling flow characteristics in microchannels with very hydrophobic surface to super-hydrophilic surface, International Journal of Heat and Mass Transfer, Vol. 54, pp.126-134.

Madou, M. J. (2002). Fundamentals of microfabrication, 2nd ed., CRC Press, pp.276-277.

Mala, G. M. and Li, D. (1999). Flow characteristics of water in microtubes, International Journal of Heat and Fluid Flow, Vol. 20, pp.142-148.

Mala, G. M., Yang, C. and Li, D. (1998). Electrical double layer potential distribution in a rectangular microchannel, Colloids and Surfaces A: Physicochemical and Engineering Aspects, Vol. 135, pp.109-116.

Mala, G. M., Li, D. and Dale, J. D. (1997). Heat transfer and fluid flow in microchannels, International Journal of Heat and Mass Transfer, Vol. 40, No. 13, pp.3079-3088.

Mala, G. M., Li, D., Werner, C., Jacobasch, H. J. and Ning, Y. B. (1997). Flow characteristics of water through a microchannel between two parallel plates with electrokinetic effects, International Journal of Heat and Fluid Flow, Vol. 18, No. 5, pp.489-496.

Mala, G. M., Li, D. and Dale, J. D. (1996). Heat transfer and fluid flow in microchannels, Microelectromechanical Systems (MEMS), ASME, DSC, Vol. 59, pp.127-136.

Martin, B. W., Hagena, O. F., and Schomburg, W. K. (1998). Strain gauge pressure and volume-flow transducers made by thermoplastic molding and membrane transfer, Proc. MEMS '98, Jan. 25-29, Heidelberg, Germany (1998), pp. 361-366.

Mason, W. P. (1969). Use of solid-state transducers in mechanics and acoustics, J. Aud. Eng. Soc., Vol. 17, pp.506-511.

Maxwell, J. C. (1890). On the condition to be satisfied by a gas at the surface of a solid body, The Scientific Papers of James Clerk Maxwell, Vol. 2, pp.704, Cambridge University Press, London.

Morini, G. L. (2004). Single-phase convective heat transfer in microchannels: a review of experimental results, International Journal of Thermal Science, Vol. 43, pp.631-651.

Monat, C., Domachuk, P., and Eggleton, B. J. (2007). Integrated optofluidics: A new river of light, Nature, Vol. 1, pp. 106-114.

Naito, E. (1984). Laminar heat transfer in the entrance region between parallel plates - the case of uniform heat flux, Heat transfer, Japanese research, Vol. 13(3), pp.92-106.

Obermeier, E. and Kopystynski, P. (1992). Polysilicon as a material for microsensor applications, Sensors and Actuators A, Vol. 30, pp.149-155. 
Obot, N. T. (2002). Toward a better understanding of friction and heat/mass transfer in microchannel - A literatures review, Microscale Thermophysical Engineering, Vol. 6, pp.155-173.

Papautsky, I., Gale, B. K., Mohanty, S., Ameel, T. A. and Frazier, A. B. (1999). Effect of rectangular microchannel aspect ratio on laminar friction constant, SPIE, Vol. 3877, pp.147-158.

Peake, E. R., Zias, A. R. and Egan, J. V. (1969). Solid-state digital pressure transducer, IEEE Trans. on Electron Devices, Vol. 16, pp.870-876.

Pelletier, N., Bêche, B., Tahani, N., Zyss, J., Camberlein, L. and Gaviot, E. (2007). SU-8 waveguiding interferometric micro-sensor for gage pressure measurement, Sensors and Actuators: Physical A, Vol. 135, pp.179-184.

Peng, X. F., Hu, H. Y. and Wang, B. X. (1998a). Boiling nucleation during liquid flow in microchannels, International Journal of Heat and Mass Transfer, Vol. 41, pp.101-106.

Peng, X. F., Hu, H. Y. and Wang, B. X. (1998b), Flow boiling through V-shape microchannels, Experimental Heat Transfer, Vol. 11, pp.87-90.

Peng, X. F., Liu, D., Lee, D. J. and Yan, Y. (2000). Cluster dynamics and fictitious boiling in microchannels, International Journal of Heat and Mass Transfer, Vol. 43, pp.4259-4265.

Peng, X. F., and Peterson, G. P. (1996). Convective heat transfer and flow friction for water flow in microchannel structures, International Journal of Heat and Mass Transfer, Vol. 39, No. 12, pp.2599-2608.

Peng, X. F., Peterson, G. P. and Wang, B. X. (1994). Heat transfer characteristic of water flowing through microchannels, Experimental Heat Transfer, Vol. 7, pp.265-283.

Peng, X. F., Peterson, G. P. and Wang, B. X. (1996). Flow boiling of binary mixtures in microchanneled plates, International Journal of Heat and Mass Transfer, Vol. 39, No. 6, pp.1257-1264.

Peng, X. F., Tien, Y. and Lee, D. J. (2001). Bubble nucleation in microchannels: statistical mechanics approach, International Journal of Heat and Mass Transfer, Vol. 44, pp. 2957-2964.

Peng, X. F. and Wang, B. X. (1993). Forced convection and flow boiling heat transfer for liquid flowing through micro channel, International Journal of Heat and Mass Transfer, Vol. 36, No. 14, pp.3421-3427.

Peng, X. F. and Wang, B. X. (1994). Evaporation space and fictitious boiling for internal evaporation of liquid, Science Foundation in China, Vol. 2, pp.55-5.

Peng, X. F. and Wang, B. X. (1998a), Forced-convection and boiling characteristics in microchannels, Proceedings of the 11 th International Heat Transfer, Vol. 1, pp.371-390.

Peng, X. F. and Wang, B. X. (1998b). Boiling characteristics in microchannels/micro structures, The 11th Int. Symposium on Transport Phenomena, ISTP-11, Hsinchu, Taiwan, pp 485-491.

Peng, X. F., Wang, B. X., Peterson, G. P. and Ma, H. B. (1995). Experimental investigation of heat transfer in flat plates with rectangular microchannels, International Journal of Heat and Mass Transfer, Vol. 38, No. 1, pp.127-137.

Pong, K. C., Ho, C. M., Liu, J. and Tai, Y. C. (1994). Nonlinear pressure distribution in uniform microchannel, Application of Microfabrication to Fluid Mechanics, ASME FED, Vol. 197, pp.51-56.

Pfahler, J., Harley, J. and Bau, H. (1991). Gas and liquid flow in small channels, Micromechanical Sensors Actuators, and Systems, ASME, DSC, Vol. 32, pp.49-59. 
Pfahler, J., Harley, J., Bau, H. and Zemel, J. (1990a). Liquid transport in micron and submicron channels, Sensors and Actuators A, Vol. 21/23, pp.431-434.

Pfahler, J., Harley, J., Bau, H. and Zemel, J. (1990b). Liquid and gas transport in small channels, Microstructures, Sensors, and Actuators, ASME, DSC, Vol. 19, pp.149-157.

Pfund, D., Rector, D., Shekarriz, A., Popescu, A. and Welty, J. (2000). Pressure drop measurements in a microchannel, Fluid Mechanics and Transport Phenomena, Vol. 46, pp.1496-1507.

Pfund, D. A., Shekarriz, A., Popescu, A. and Welty J. R. (1998). Pressure drops measurements in microchannels, Proceedings of MEMS, ASME DSC, Vol. 66, pp.193198.

Phan, H. T., Caney, N., Marty, P., Colasson, S. and Gavillet, J. (2009). Surface wettability control by nanocoating: The effects on pool boiling heat transfer and nucleation mechanism, International Journal of Heat and Mass Transfer, Vol. 52, pp.5459-5471.

Qu, W., Mala, G. M. and Li, D. (2000a). Pressure-driven water flows in trapezoidal silicon microchannels, International Journal of Heat and Mass Transfer, Vol. 43, pp.353-364.

Qu, W., Mala, G. M. and Li, D. (2000b). Heat transfer for water flow in trapezoidal silicon microchannels, International Journal of Heat and Mass Transfer, Vol. 43, pp.3925-3936.

$\mathrm{Qu}, \mathrm{W}$. and Mudawar, I. (2002). Experimental and numerical study of pressure drop and heat transfer in a single-phase micro-channel heat sink, International Journal of Heat and Mass Transfer, Vol. 45, pp.2549-2565.

Qu, W. and Mudawar, I. (2003a). Flow boiling heat transfer in two-phase micro-channel heat sinks-I. Experimental investigation and assessment of correlation methods, International Journal of Heat and Mass Transfer, Vol. 46, pp.2755-2771.

$\mathrm{Qu}, \mathrm{W}$. L. and Mudarwar, I. (2003b). Measurement and prediction of pressure drop in twophase micro-channel heat sinks, International Journal of Heat and Mass Transfer, Vol. 46, pp. 2737-2753.

Ren, L. and Li, D. (2001). Electroosmotic flow in heterogeneous microchannels, Journal of Colloid and Interface Science, Vol. 243, pp.255-261.

Ren, L., Li, D. and Qu, W. (2001a). Electro-viscous effects on liquid flow in microchannels, Journal of Colloid and Interface Science, Vol. 233, pp.12-22.

Ren, L., Qu, W. and Li, D. (2001b). Interfacial electrokinetic effects on liquid flow in microchannels, International Journal of Heat and Mass Transfer, Vol. 44, pp.3125-3134.

Ribeiro, J. C., Minas, G., Turmezei, P., Wolffenbuttel, R. F. and Correia, J. H. (2005). A SU-8 fluidic microsystem for biological fluids analysis, Sensors and Actuators: Physical A, Vol. 123-124, pp.77-81.

Rohsenow, W. M., Hartnett, J. P. and Ganic, E. N. (1985). Handbook of Heat Transfer Fundamentals 2nd ed., McGraw-Hill, New York, pp.7-49.

Rostami, A. A., Mujumdar, A. S. and Saniei, N. (2002). Flow and heat transfer for gas flowing in microchannel: a review, Heat and Mass Transfer, Vol. 38, pp.359-367.

Sharp, K. V., Adrian, R. J. and Beebe, D. J. (2000). Anomalous transition to turbulence in microtubes, Proceedings of International Mechanical Engineering Cong. Expo., 5th Micro-Fluidic Symp., Orlando, FL, pp. 150-158.

Shen, C. H. and Gau, C. (2004). Thermal chip fabrication with arrays of sensors and heaters for micro-scale impingement cooling heat transfer analysis and measurements, Biosensors and Bioelectronics, Vol. 20, No. 1, pp.103-114. 
Shen, C. H. (2003). Thermal chip fabrication with arrays of sensors and heaters with analysis and measurements of micro scale impingement cooling flow and heat transfer, Ph D. Thesis, National Cheng Kung University, Tainan, Taiwan.

Shih, J. C., Ho, C. M., Liu, J. and Tai, Y. C. (1996). Monatomic and polyatomic gas flow through uniform microchannels, ASME DSC, Vol.59, pp.197-203.

Shirinov, A. V. and Schomburg, W. K. (1996). Polymer pressure sensor from PVDF, Proc. Eurosensor, Göteborg, Schweden Sep. 17th-20th, pp.84-85.

Smoluchowski, M. Von (1910). Uber den temperaturesprung bei warmeleitung in gasen, Anz. Wiss. Krakau ser. A, Vol. 5, pp.129.

Sugiyama, S., Shimaoka, K. and Tabata, O. (1991). Surface micromachined micro-diaphragm pressure sensors, Proc. $6^{\text {th }}$ Int. Conf. Solid-State Sensors and Actuators (Transducer'91), pp.188-191.

Sze, M. (1994). Semiconductor Sensors, John Wiley and Sons, Inc., New York, pp.17-80.

Sze, M. (2002). Semiconductor Devices, Physics and Tecnology, 2nd ed., John Wiley and Sons, Inc., New York, pp.171-200.

Takuto, A., Soo, K. M., Hiroshi, I. and Kenjiro, S. (2000). An experimental investigation of gaseous flow characteristics in microchannels, Proceedings of the International Conference on Heat Transfer and Transport Phenomena in Microscale, Banff, Canada, pp.155-161.

Takao, K. (1961). Rarefied gas flow between two parallel plates, in: Rarefied gas dynamics, Talbot, L., Ed., Academic Press, New York, Section 1, pp.465-473.

Tao, C. P. and Mahulikar, S. P. (1998). Laminar convection behavior in microchannels in conventional thermal entry length and beyond, Proceedings of the IEEE/CPMT Electronics Packaging Technology Conference, pp.126-132.

Touloukina, Y. S. (1970-1979). Thermophysical properties of matter: the TPRC data series; a compressive compilation of data, IFI/Plenum, New-York.

Trung, N., Nguyen, N. and Wu, Z. (2005). Micromixer-a review, J. Micromech. Microeng., Vol. 15, pp.R1-R16.

Tsien, H. S. (1948). Superaerodynamics, the mechanics of rarefied gases, Journal of Aeronautic Society, Vol. 13, pp.653-664.

Tufte, O. N., Chapman, P. W. and Long, D. (1962). Silicon diffused-element piezoresistive diaphragms, Journal of Applied Physics, Vol. 33, pp.3322-3327.

Turner, S. E., Sun, H., Faghri, M. and Gregory, O. J. (2001). Compressible gas flow through smooth and rough microchannels, Proceedings of IMECE, New York, USA, HTD24145.

Vilkner, T., Janasek, D. and Manz, A. (2004). Micro total analysis systems: recent developments, Anal. Chem., Vol. 76, pp.3373-3386.

Wadsworth, D. C., Erwin, D. A. and Muntz, E. P. (1993). Transient motion of a confined rarefied gas due to wall heating or cooling, Journal of Fluid Mechanics, Vol. 248, pp.219-235.

Wang, G. D., Cheng, P. and Bergles, A. E. (2008). Effects of inlet/outlet configurations on flow boiling instability in parallel microchannels, International Journal of Heat and Mass Transfer, Vol. 51, pp.2267-2281.

Wang, G. D., Cheng, P. and Wu, H. Y. (2007). Unstable and stable flow boiling in parallel microchannels and in a single microchannel, International Journal of Heat and Mass Transfer, Vol. 50, pp.4297-4310. 
Webb, R. L. and Zhang, M. (1998). Heat transfer and friction in small diameters channels, Microscale Thermo physics Engineering, Vol. 2, pp. 189-202.

White, F. M. (1991). Viscous fluid flow, McGraw-Hill, New York.

Wu, H. Y. and Cheng, P. (2003a). Friction factors in smooth trapezoidal silicon microchannels with different aspect ratios, International Journal of Heat and Mass Transfer, Vol. 46, pp. 2519-2525.

Wu, H. Y. and Cheng, P. (2003b). Visualization and measurements of periodic boiling in silicon microchannels, International Journal of Heat and Mass Transfer, Vol. 46, pp.2603-2614.

Wu, H. Y. and Cheng, P. (2003c). Liquid/two-phase/vapor alternating flow during boiling in microchannels at high heat flux, International Communications in Heat and Mass Transfer, Vol. 30, pp.295-302.

Wu, H. Y. and Cheng, P. (2004). Boiling instability in parallel silicon microchannels at different heat flux, International Journal of Heat and Mass Transfer, Vol. 47, pp.36313641.

Wu, P. and Little, W. H. (1983). Measurement of friction factor for the flow of gases in very fine channels used for micro-miniature Joule-Thompson refrigerators, Cryogenics, pp 272-277.

Xu, B., Ooi, K. T., Wong, N. T. and Choi, W. K. (2000). Experimental investigation of flow friction of liquid flow in microchannels, Int Comm. Heat Mass Transfer, Vol. 27, pp.1165-1176.

Xu, B., Ooi, K. T., Wong, N. T., Liu, C. Y. and Choi, W. K. (1999). Liquid flow in microchannels, Proceedings of the 5th ASME/JSME Joint Thermal Engineering Conference, San Diego, CA, pp.150-158.

Yang, C. and Li, D. (1997). Electrokinetic effects on pressure-driven liquid flows in rectangular microchannels, Journal of Colloid and Interface Science, Vol. 194, pp.95107.

Yang, C., and Li, D. (1998). Analysis of electrokinetic effects on the liquid flow in rectangular microchannels, Colloids and Surface A: Physicochemical and Engineering Aspects, Vol. 143, pp.339-353.

Yang, C., Li, D. and Masliyah, J. H. (1998). Modeling forced liquid convection in rectangular microchannels with electrokinetic effects, International Journal of Heat and Mass Transfer, Vol. 41, pp.4229-4249.

Yen, S. M. (1971). Monte carlo solutions of nonlinear Boltzmann equation for problems of heat transfer in rarefied gases, International Journal of Heat and Mass Transfer, Vol. 14, pp. 1865-1869.

Yu, D., Warrington, R.O., Barron, R. and Ameel, T. (1995). An experimental and theoretical investigation of fluid flow and heat transfer in microtubes, Proceedings of ASME/JSME Thermal Engineering Joint Conference, Maui, pp.523-530.

Ziering, S. (1961). Plane Poiseuille Flow, in: Rarefied gas dynamics," Talbot, L., Ed., Academic Press, New York, Section 1, pp.451-463.

Zohar, Y., Lee, Y. K., Lee, W. Y., Jiang, L. and Tong, P. (2002). Subsonic gas flow in a straight and uniform microchannel, J. Fluid Mech. Vol. 472, pp.125-151. 


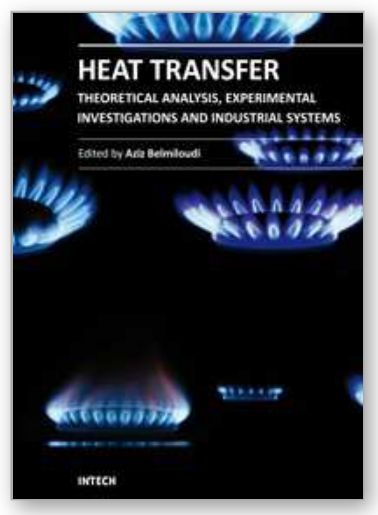

\author{
Heat Transfer - Theoretical Analysis, Experimental Investigations \\ and Industrial Systems \\ Edited by Prof. Aziz Belmiloudi
}

ISBN 978-953-307-226-5

Hard cover, 654 pages

Publisher InTech

Published online 28, January, 2011

Published in print edition January, 2011

Over the past few decades there has been a prolific increase in research and development in area of heat transfer, heat exchangers and their associated technologies. This book is a collection of current research in the above mentioned areas and discusses experimental, theoretical and calculation approaches and industrial utilizations with modern ideas and methods to study heat transfer for single and multiphase systems. The topics considered include various basic concepts of heat transfer, the fundamental modes of heat transfer (namely conduction, convection and radiation), thermophysical properties, condensation, boiling, freezing, innovative experiments, measurement analysis, theoretical models and simulations, with many real-world problems and important modern applications. The book is divided in four sections : "Heat Transfer in Micro Systems", "Boiling, Freezing and Condensation Heat Transfer", "Heat Transfer and its Assessment", "Heat Transfer Calculations", and each section discusses a wide variety of techniques, methods and applications in accordance with the subjects. The combination of theoretical and experimental investigations with many important practical applications of current interest will make this book of interest to researchers, scientists, engineers and graduate students, who make use of experimental and theoretical investigations, assessment and enhancement techniques in this multidisciplinary field as well as to researchers in mathematical modelling, computer simulations and information sciences, who make use of experimental and theoretical investigations as a means of critical assessment of models and results derived from advanced numerical simulations and improvement of the developed models and numerical methods.

\title{
How to reference
}

In order to correctly reference this scholarly work, feel free to copy and paste the following:

C. W. Liu, H. S. Ko and Chie Gau (2011). Microchannel Heat Transfer, Heat Transfer - Theoretical Analysis, Experimental Investigations and Industrial Systems, Prof. Aziz Belmiloudi (Ed.), ISBN: 978-953-307-226-5, InTech, Available from: http://www.intechopen.com/books/heat-transfer-theoretical-analysis-experimentalinvestigations-and-industrial-systems/microchannel-heat-transfer

\section{INTECH}

open science | open minds

\section{InTech Europe}

University Campus STeP Ri

Slavka Krautzeka 83/A

51000 Rijeka, Croatia

\section{InTech China}

Unit 405, Office Block, Hotel Equatorial Shanghai

No.65, Yan An Road (West), Shanghai, 200040, China

中国上海市延安西路65号上海国际贵都大饭店办公楼405单元 
Phone: +385 (51) 770447

Fax: +385 (51) 686166

www.intechopen.com
Phone: +86-21-62489820

Fax: +86-21-62489821 
(C) 2011 The Author(s). Licensee IntechOpen. This chapter is distributed under the terms of the Creative Commons Attribution-NonCommercialShareAlike-3.0 License, which permits use, distribution and reproduction for non-commercial purposes, provided the original is properly cited and derivative works building on this content are distributed under the same license. 